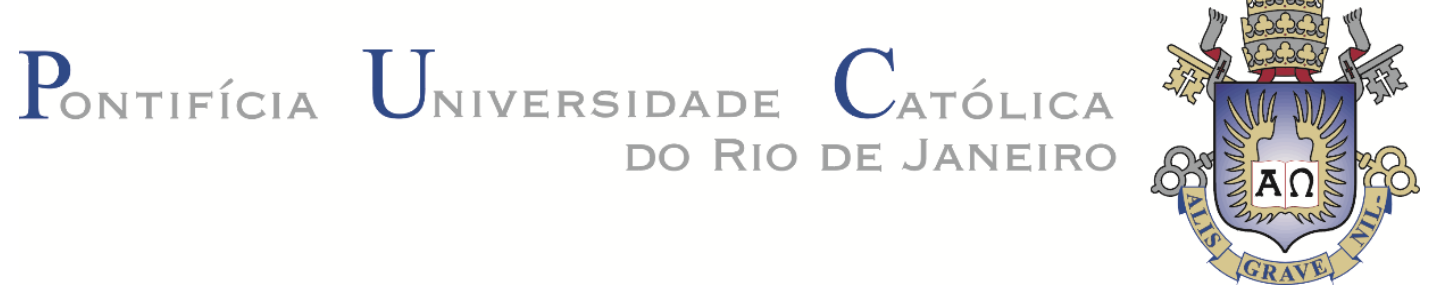

Fabrício Valente

\title{
Análise Numérica dos Processos \\ de Queda de Blocos na \\ Região Sudeste do Brasil
}

Dissertação de Mestrado

Dissertação apresentada ao Programa de Pós-graduação em Engenharia Civil da Pontifícia Universidade Católica do Rio de Janeiro como requisito parcial para obtenção do grau de Mestre em Engenharia Civil.

Orientador: Prof. Eurípedes do Amaral Vargas Júnior

Co-orientadora: Prof. Raquel Quadros Velloso 


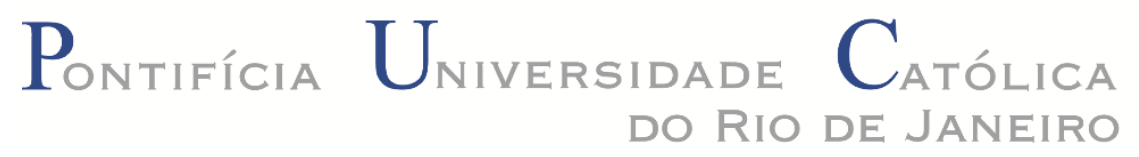

Fabrício Valente

\section{Análise Numérica dos Processos de Queda de Blocos na Região Sudeste do Brasil}

Dissertação apresentada ao Programa de Pós-graduação em Engenharia Civil da Pontifícia Universidade Católica do Rio de Janeiro como requisito parcial para obtenção do grau de Mestre em Engenharia Civil.

Prof. Eurípedes do Amaral Vargas Júnior Orientador

Departamento de Engenharia Civil e Ambiental - PUC-Rio

Profa. Raquel Quadros Velloso

Co-Orientadora

Departamento de Engenharia Civil e Ambiental - PUC-Rio

Prof. Emilio Velloso Barroso Universidade Federal do Rio de Janeiro

Dr. Felipe Gobbi Silveira Universidade do Vale do Rio dos Sinos - UNISINOS

Prof. Marcio da Silveira Carvalho

Coordenador Setorial do

Centro Técnico Científico - PUC-Rio

Rio de Janeiro, 07 de Março de 2017 
Todos os direitos reservados. É proibida a reprodução total ou parcial do trabalho sem autorização do autor, da orientadora e da universidade.

Fabrício Valente

Graduou-se em Engenharia Civil pela Universidade Federal de Ouro Preto em 2014. Ingressou no mestrado na Pontifícia Universidade Católica do Rio de Janeiro em março de 2015, desenvolvendo dissertação na linha de pesquisa de Mecânica das Rochas.

Ficha Catalográfica

Valente, Fabrício

Análise Numérica dos Processos de Queda de Blocos na Região Sudeste do Brasil / Fabrício Valente; orientador: Eurípedes do Amaral Vargas Júnior. - 2017.

113 f. : il. color. ; $30 \mathrm{~cm}$

Dissertação (mestrado) - Pontifícia Universidade Católica do Rio de Janeiro, Departamento de Engenharia Civil, 2017.

Inclui bibliografia

1. Engenharia civil - Teses. 2. Queda de Blocos. 3. Análise Numérica. 4. Mecânica de Contato. 5. Casos Tridimensionais. I. Vargas Jr., Eurípedes do Amaral. II. Pontifícia Universidade Católica do Rio de Janeiro. Departamento de Engenharia Civil. III. Título. 


\section{Agradecimentos}

Aos meus familiares. Aos meus orientadores, Vargas e Raquel. Aos amigos, em especial aos que estiveram comigo durante a construção dessa dissertação: Thai, Bel e Phil. A Geobrugg e o Felipe, pela ajuda no desenvolvimento da dissertação. A PUC-Rio e a Faperj pelo auxílio. 


\section{Resumo}

Valente, Fabrício; Vargas Jr., Eurípedes do Amaral (Orientador). Análise Numérica dos Processos de Queda de Blocos na Região Sudeste Do Brasil. Rio de Janeiro, 2017. 113 p. Dissertação de Mestrado. Departamento de Engenharia Civil, Pontifícia Universidade Católica do Rio de Janeiro.

Este trabalho tem como finalidade comparar e analisar diferentes modelos numéricos na análise do processo de queda de blocos com diferentes geometrias, para que seja possível determinar os riscos à infraestrutura e à população local que este evento pode causar. Foram utilizados o software RAMMS e o programa de modelagem PFC3D para simulação de queda de blocos. O primeiro foi desenvolvido pelo instituto suíço WSL, o software utiliza a dinâmica não suave (nonsmooth), não havendo penetração dos blocos com a superfície, e as leis de contato são feitas por restrições. O segundo utiliza o método dos elementos discretos através de dinâmica de contato suave. Na primeira parte do trabalho foram realizadas simulações de casos simples de queda de blocos para ambos os modelos, a fim de analisar o principal parâmetro do contato rocha-solo de cada programa com $\mathrm{o}$ alcance das rochas. $\mathrm{O}$ modelo de contato no programa PFC3D utilizado foi o método linear, e depois foi adicionada uma força de resistência ao rolamento para que o modelo conseguisse reproduzir o comportamento de solos mais macios. Os modelos foram simulados para casos reais, primeiro foram aplicados para uma encosta na BR116, onde um evento de deslizamento já tinha ocorrido. Foram realizadas simulações com os dois modelos na região, comparando-os e analisando com os vestígios deixados pelo evento. Outro caso estudado foi o de blocos susceptíveis ao deslizamento no bairro Glória, no município de Petrópolis. E por último, foram criados modelos para analisar o comportamento da vegetação em ambos os modelos. Com os resultados obtidos, conclui-se que o PFC3D consegue simular o processo de queda com melhor precisão através do auxílio da força de resistência ao rolamento. Para ambas simulações, o caso da BR116 e o do bairro Glória, os modelos apresentarem uma mesma tendência quanto a trajetória do bloco, mas melhorias na calibração do modelo linear com resistência ao rolamento 
precisam ser realizadas para que melhores resultados sejam obtidos. A presença de vegetação se mostrou como um mecanismo muito eficiente para perdas de energia no sistema, diminuindo significativamente a velocidade dos blocos.

\section{Palavras-chave}

Mecânica das rochas; queda de blocos; mecânica de contato; método dos elementos discretos. 


\section{Abstract}

Valente, Fabício; Vargas Jr., Euripedes do Amaral (Advisor). Numerical Analysis of the Rockfall Process in the Southeast Region of Brazil. Rio de Janeiro, 2017. 113 p. Dissertação de Mestrado. Departamento de Engenharia Civil, Pontifícia Universidade Católica do Rio de Janeiro.

The aim of this work is to compare and analyze different numerical models on the rockfall process with different geometries, to determine the risks to the local infrastructure and population. It was used the software RAMMS and the modeling program PFC3D to simulate rockfall events. The first software was developed by the Swiss institute WSL, it uses the nonsmooth dynamics system, it is a dynamic behavior where there is no penetration between the rock and the surface and the contact laws are created by restrictions laws. And the second one uses the discrete element method applying the smooth dynamics system to simulate the event. On the first part of the work, numerical models were created on both models to simulate simple cases of rockfall events, to compare the main soil-rock parameter of both modeling program with the distance reached of the rocks. The contact model used on the PFC3D program was the linear method, and after the first simulations was added a rolling resistance force to the model reproduce soft. Both models were applied to real cases, the BR116 was the first case modeled, where some natural hazards have already happened. The results of the numerical simulations were compared and analyzed. It was also created a model to simulate the rockfall event of the Gloria neighborhood, in Petropolis; rocks that could fall were determined and simulations for those blocks were performed, the deposition area and the blocks trajectory of each model were examined. And finally, it was studied the vegetation effect of each model and its particularities. Through the results, it is possible to conclude that the PFC3D can simulate the rockfall process with better accuracy using the rolling resistance method. For both simulation, the BR116 and the Gloria neighborhood, the models showed the same tendency of the blocks' trajectory, but it is necessary to improve the calibration of the rolling resistance coefficient. The 
existence of the vegetation revealed as a very effect lose energy mechanism on the system, decreasing significantly the velocity of the blocks.

\section{Keywords}

Rock mechanics; rockfall; contact mechanics; discrete elemente method 


\section{Sumário}

1 Introdução 19

1.1 Relevância e Justificativa da Pesquisa 19

1.2 Estrutura do trabalho 20

2 Revisão Bibliográfica 22

2.1 Visão Geral das Principais Aproximações de Modelagem de Queda de Blocos 22

2.2 Análise da Trajetória $\quad 25$

2.3 O Método dos Elementos Discretos 27

2.3.1 Modelos de Contato $\quad 29$

2.3.1.1 Modelo Linear e o Amortecimento Viscoso 29

2.3.1.2 Modelo Linear com a adição da Resistência ao Rolamento 33

2.4 O Software RAMMS $\quad 35$

2.4.1 Modelagem dos Blocos $\quad 37$

2.4.2 Movimemto de Queda Livre e Forças Giroscópicas 38

$\begin{array}{lll}2.4 .3 & \text { Forças de Contato } & 39\end{array}$

2.4.4 Forças Impulsivas $\quad 40$

2.4.5 Forças de Arraste e Derrapagem 41

3 Programa Das Simulações Numéricas 45

3.1 Comparação entre os modelos de RAMMS x PFC3D 45

3.1.1 Simulação no RAMMS $\quad 47$

3.1.2 Simulação no PFC3D $\quad 50$

3.2 Análise de Queda de Blocos na BR116

3.2.1 Simulação no RAMMS $\quad 56$

3.2.2 Simulação no PFC3D 57

3.3 Análise dos Blocos Susceptíveis a Queda no Município de Petrópolis 57

3.3.1 Simulação no RAMMS $\quad 60$

3.3.2 Simulação no PFC3D 62

3.4 Os Efeitos da Árvores em Queda de Blocos $\quad 63$

3.4.1 Simulação de Árvores como Blocos Rígidos no PFC3D 64

3.4.2 Efeitos da Vegetação para Casos Reais no Estado do Rio de Janeiro
através do Software RAMMS

$4 \quad$ Resultados e Discussões $\quad 68$

4.1 Considerações Iniciais $\quad 68$

4.2 Análises Comparativas entre o RAMMS e o PFC3D 68

4.2.1 Modelo Linear $\quad 68$

2.3.2.1 Plano inclinado em $37^{\circ} \quad 68$

2.3.2.1 Plano inclinado em $50^{\circ}$

4.2.2 Modelo Linear com Resistência ao Rolamento 78

$\begin{array}{ll}\text { 2.3.2.1 Plano inclinado em } 37^{\circ} & 78\end{array}$

2.3.2.1 Plano inclinado em $50^{\circ} \quad 82$

4.2.3 Observações $\quad 86$

4.2.1.1 Inclinação da Superfície 86

4.2.3.2 Geometria dos Blocos $\quad 87$

4.2.3.3 Modelos Dinâmicos $\quad 87$

$\begin{array}{lll}4.3 & \text { Análise de Queda de Blocos na BR116 } & 88\end{array}$ 
4.4 Análise dos Blocos Susceptíveis a Queda no Município de Petrópolis

4.5 Efeitos da Vegetação na Queda de Blocos

4.5.1 Simulação de Árvores como Blocos Rígidos no PFC3D

101

4.5.2 Efeitos da Vegetação para Casos Reais no Estado do Rio de Janeiro através do software RAMMS

5 Conclusão

5.1 Conclusão

106

5.2 Sugestões para Futuros Trabalhos 108

6 Referências bibliográficas 


\section{Lista de Figuras}

Figura 2.1 - O elemento Voigt-Kelvin consiste em uma mola e um amortecedor conectados em paralelo.

Figura 2.2 - Comportamento e componentes reológicos do modelo linear.

Figura 2.3 - Atualização da força linear de cisalhamento e deslizamento tangencial relativo durante o deslizamento de modelos lineares.

Figura 2.4 - Representação esquemática de (a) uma posição estável

(b) uma posição potencialmente não estável.

Figura 2.5 - Escaneamento de rochas em campo através de laser (RAMMS::ROCKFALL User Manual).

Figura 2.6 - Geração da geometria da rocha e suas propriedades de inércia (Leine et al, 2013).

Figura 2.7 - Forças de atrito de Coulomb. 40

Figura 2.8 - O fenômeno de derrapagem (Leine et al, 2013).

Figura 2.9 - Modelo de atrito dependente da derrapagem (Leine et al, 2013).

Figura 2.10 - Força de arraste da floresta agindo no centro de gravidade do bloco (RAMMS::ROCKFALL User Manual).

Figura 3.1 - Superfície de $37^{\circ}$ e posição de lançamento dos blocos. $\quad 47$

Figura 3.2 - Superfície de $50^{\circ}$ e posição de lançamento dos blocos. $\quad 47$

Figura 3.3 - Modelagem do terreno no Arcgis. 48

Figura 3.4 - Terreno inserido no software RAMMS. 48

Figura 3.5 - Rocha equant, rocha long e rocha platy. 49

Figura 3.6 - Procedimentos para a realização das simulações de queda de blocos no software RAMMS. 50

Figura 3.7 - Parede criada no programa PFC3D. 51

Figura 3.8 - Blocos criados por bubblepack. 51 
Figura 3.9 - Procedimentos para a realização das simulações de queda de blocos no modelo de elementos discretos.

Figura 3.10 - Região susceptível a desastres naturais (Google Maps). 54

Figura 3.11 - Cicatriz deixada pelo deslizamento, antes (2009) e depois (2011) (Google Maps).

Figura 3.12 - Curvas de Nível BR 116.

Figura 3.13 - Topografia da BR116 no software RAMMS. 56

Figura 3.14 - Topografia tridimensional da BR116 no PFC3D. 57

Figura 3.15 - Conversão das curvas de nível da topografia para o modelo tridimensional. 58

Figura 3.16 - Localização dos Blocos Susceptíveis a Queda. $\quad 59$

Figura 3.17 - Região de depósito de tálus definida no RAMMS. 61

Figura 3.18 - Terreno no RAMMS. 61

Figura 3.19 - Pontos inseridos na topografia. 62

Figura 3.20 - Superfície formada por triângulos. 63

Figura 3.21 - Efeito de árvores em queda de blocos. 64

Figura 3.22 - Deslizamento no munícipio de Petrópolis. 65

Figura 3.23 - Topografia com a presença de vegetação densa. $\quad 66$

Figura 3.24 - Topografia sem a presença da vegetação. 66

Figura 4.1 - Rochas Equant lançadas em um plano inclinado de $37^{\circ}$. 69

Figura 4.2 - Rochas Long lançadas em um plano inclinado de $37^{\circ}$. $\quad 70$

Figura 4.3 - Rochas Flat lançadas em um plano inclinado de $37^{\circ}$. 71

Figura 4.4 - Alcance das rochas de diferentes geometrias em um plano inclinado de $37^{\circ}$ no modelo de simulação RAMMS.

Figura 4.5 - Alcance das rochas de diferentes geometrias em um plano inclinado de $37^{\circ}$ no modelo de simulação PFC.

Figura 4.6 - Rochas Equant lançadas em um plano inclinado de $50^{\circ} . \quad 74$

Figura 4.7 - Rochas Long lançadas em um plano inclinado de $50^{\circ} . \quad 75$

Figura 4.8 - Rochas Flat lançadas em um plano inclinado de $50^{\circ}$. 76

Figura 4.9 - Distância percorrida pelos blocos em um plano inclinado em $50^{\circ}$ no software RAMMS.

Figura 4.10 - Distância percorrida pelos blocos em um plano inclinado em $50^{\circ}$ no software PFC3D. 
Figura 4.11 - Relação do coeficiente de arraste e de resistência de rolamento para rochas equant em superfície inclinada de $37^{\circ}$.

Figura 4.12 - Relação do coeficiente de arraste e de resistência de rolamento para rochas long em superfície inclinada de $37^{\circ}$.

Figura 4.13 - Relação do coeficiente de arraste e de resistência de rolamento para rochas flat em superfície inclinada de $37^{\circ}$.

Figura 4.14 - Relação entre a distância e o coeficiente de resistência ao rolamento para rochas de diferentes geometrias em uma superfície inclinada de $37^{\circ}$ lançados através do software PFC.

Figura 4.15 - Relação do coeficiente de arraste e de resistência de rolamento para rochas equant em superfície inclinada de $50^{\circ}$.

Figura 4.16 - Relação do coeficiente de arraste e de resistência de rolamento para rochas long em superfície inclinada de $50^{\circ}$.

Figura 4.17 - Relação do coeficiente de arraste e de resistência de rolamento para rochas flat em superfície inclinada de $50^{\circ}$.

Figura 4.18 - Relação entre a distância e o coeficiente de resistência ao rolamento para rochas de diferentes geometrias em uma superfície inclinada de $50^{\circ}$ lançados através do software PFC.

Figura 4.19 - Trajetória de queda de blocos equant na BR116 através do RAMMS (Google Maps).

Figura 4.20 - O valor do coeficiente de resistência ao rolamento para diferentes solos.

Figura 4.21 - Trajetória de queda de blocos equant na BR116 através do PFC3D (Google Maps).

Figura 4.22 - Trajetória de queda de blocos long na BR116 através do RAMMS (Google Maps).

Figura 4.23 - Trajetória de queda de blocos long na BR116 através do PFC3D (Google Maps).

Figura 4.24 - Mapa de isoenergias considerando camada de solo em toda a superfície (Villela 2011).

Figura 4.25 - Trajetória do bloco 1 no software RAMMS e no programa PFC3D com modelo linear.

Figura 4.26 - Simulação de queda de bloco no PFC3D usando o modelo linear, bloco 3 e 4. 
Figura 4.27 - Trajetória do bloco 3 no software RAMMS (a esquerda)

e no programa PFC (a direita) com resistência ao rolamento.

Figura 4.28 - Trajetória do bloco 10 no software RAMMS

(à esquerda) e no programa PFC3D (à direita) com resistência ao rolamento.

Figura 4.29 - Trajetória do bloco 11 no software RAMMS (à esquerda) e no programa PFC3D (à direita) com resistência ao rolamento.

Figura 4.30 - Trajetória do bloco 1 no software RAMMS (à esquerda)

e no programa PFC3D (à direita) com resistência ao rolamento

ajustado por tentativas.

Figura 4.31 - Trajetória do bloco 1 no programa PFC3D com resistência ao rolamento.

Figura 4.32 - Trajetória do bloco 2 no software RAMMS (à esquerda)

e no programa PFC3D (à direita) com resistência ao rolamento ajustado por tentativas.

Figura 4.33 - Trajetória do bloco 4 no software RAMMS (à esquerda) e no programa PFC3D (à direita) com resistência ao rolamento ajustado por tentativas.

Figura 4.34 - Simulação de queda de blocos com árvores no percurso usando o PFC3D.

Figura 4.35 - Modelos de queda de blocos sem árvores e com árvores.

Figura 4.36 - Trajetória e Zona de Deposição dos Blocos para o caso 1 - com vegetação.

Figura 4.37 - Trajetória e Zona de Deposição dos Blocos para o caso 2 - sem vegetação. 


\section{Lista de Tabelas}

Tabela 3.1 - Valores dos parâmetros de contato. 52

Tabela 3.2 - Dimensões das rochas. 56

Tabela 3.3 - Coordenadas dos blocos (Ribeiro, 2013). 59

Tabela 3.4 - Dimensões dos blocos (Ribeiro, 2013). 60

Tabela 4.1 - Coeficientes de resistência ao rolamento equivalente para diferentes blocos e solos. 90 


\section{Lista de Abreviações}

CERJ Companhia de Eletricidade do Rio de Janeiro

CRT Concessionária Rio Teresópolis

DEM Discrete Element Method

DGPS Differential Global Positioning System

DRM Departamento de Recursos Minerais

ESRI Environmental Systems Research Institute

FEM Finite Element Method

IBGE Instituto Brasileiro de Geografia e Estatística

PFC3D Particle Flow Code Tridimensional

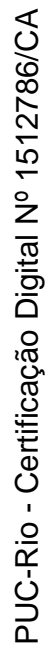

RAMMS Rapid Mass Movement

SLF

Institut für Schnee und Lawinenforschung

UTM

Universal Transverse Mercator

WSL

Wald, Schnee und Landschaft 


\section{Lista de Símbolos}

\begin{tabular}{|c|c|c|}
\hline & $C$ & Constante de amortecimento \\
\hline & $C^{\text {crit }}$ & Constante de amortecimento crítico \\
\hline & $C_{v}$ & Coeficiente de arraste viscolplástico \\
\hline & $D$ & Forças de arraste \\
\hline & $e_{n}$ & Coeficiente de Restituição Normal \\
\hline & $e_{t}$ & Coeficiente de Restituição Tangencial \\
\hline & $F^{d}$ & Força de amortecimento viscoso \\
\hline & $F_{g}$ & Força gravitacional \\
\hline \begin{tabular}{l} 
仓 \\
\hdashline
\end{tabular} & $F_{d f}$ & Força de arraste da vegetação \\
\hline$\frac{N}{N}$ & $F_{n}^{l}$ & Força de acréscimo normal linear \\
\hline$\frac{\text { 을 }}{\underline{\pi}}$ & $F_{S}^{\mu}$ & Força cisalhante \\
\hline : & $F_{S}^{*}$ & Força cisalhante experimental \\
\hline 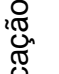 & $F_{v}$ & Força de arraste viscoplástica \\
\hline 焉 & $G$ & Forças giroscópicas \\
\hline$\frac{1}{\tilde{n}}$ & $g$ & Aceleração da Gravidade \\
\hline ذِ & $g_{s}$ & Diferença entre as partículas em contato \\
\hline & $h$ & Termos de força \\
\hline & $k$ & Rigidez de contato tangente \\
\hline & $k_{n}$ & Rigidez normal \\
\hline & $k_{r}$ & Rigidez de resistência ao rolamento \\
\hline & $m$ & Massa do sistema \\
\hline & $M$ & Matriz de massa constante e diagonal \\
\hline & $M^{r}$ & Magnitude da atualização do momento de resistência \\
\hline & $M^{*}$ & Torque limite \\
\hline & $q$ & Função posição \\
\hline & $R$ & Raio equivalente \\
\hline & $S$ & Derrapagem \\
\hline
\end{tabular}




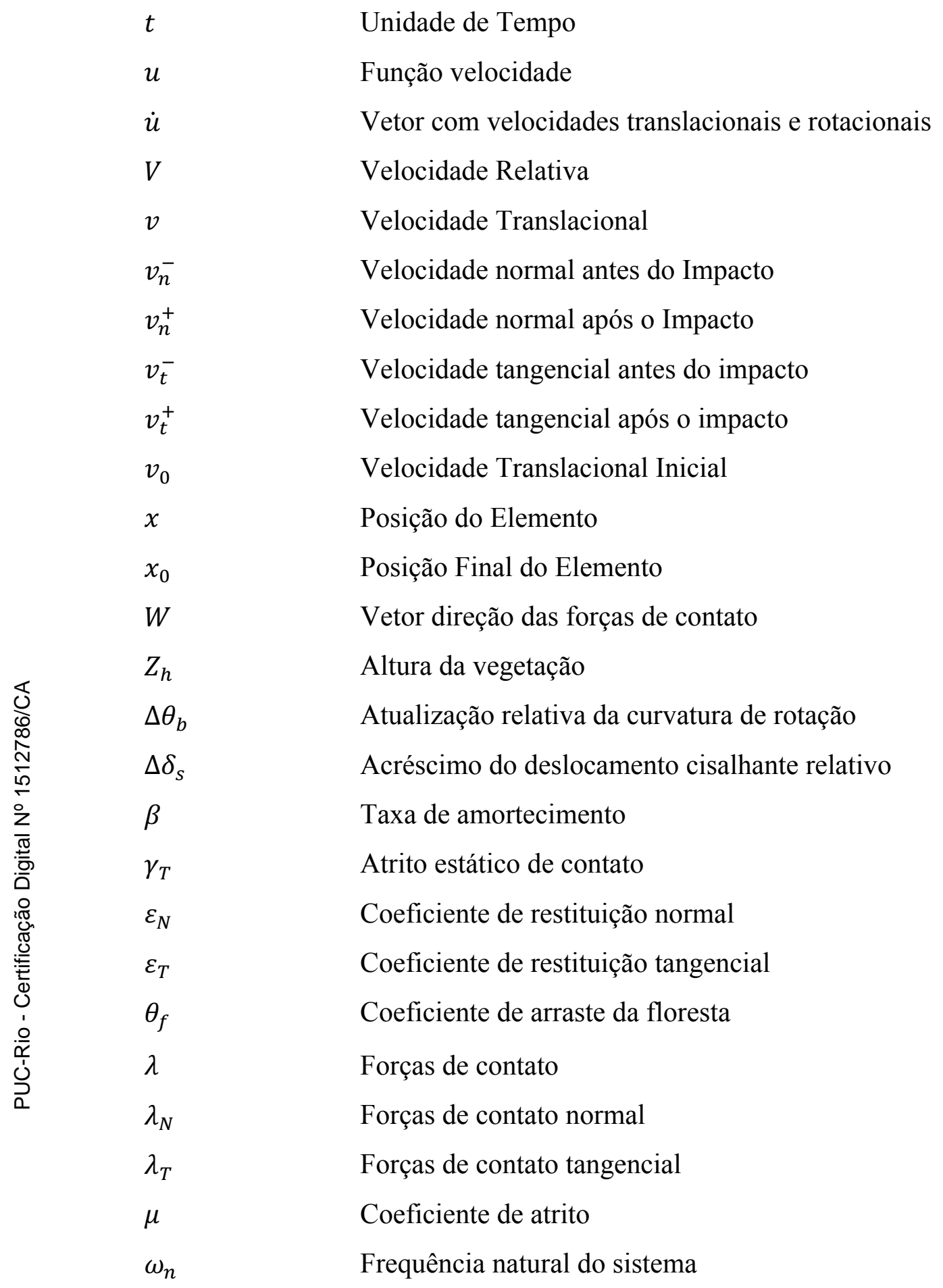




\section{1 Introdução}

\section{1 \\ Relevância e Justificativa da Pesquisa}

No estado do Rio de Janeiro 96,71\% da população fluminense vive nas cidades, de acordo com o censo do Instituto Brasileiro de Geografia e Estatística (IBGE), referente a 2010. A maioria da urbanização ocorre de uma forma não planejada no estado, deixando muitas vezes a população em regiões propícias a movimentos de massa. Estes eventos vêm ocorrendo frequentemente colocando em risco a vida dessas pessoas.

A queda de blocos é um tipo de movimento gravitacional muito comum nas regiões serranas do estado do Rio de Janeiro. Este tipo de movimento define-se como uma ação de queda livre a partir de uma elevação, onde a superfície não se movimenta. Em penhascos ou taludes íngremes, blocos rochosos deslocados pelo intemperismo, caem pela ação da gravidade. As causas das quedas podem ser diversas: variação térmica do maciço rochoso, perda de sustentação dos blocos por ação erosiva da água, alívio de tensões de origem tectônica, vibrações e outras.

Métodos para prever a trajetória de queda de blocos em terrenos complexos tridimensionais possuem grande valor prático, já que eles podem ser usados para determinar as zonas de perigo, áreas por onde os blocos percorrem e se depositam; sendo possível assim, evitar fatalidades, como danos a infraestruturas e também perdas humanas. Prever estes eventos é uma tarefa difícil, mas a instalação de barreiras de proteção é comum e é uma maneira efetiva de controlar tais eventos. No entanto, a simulação da queda é muito desafiadora já que quando o bloco está se deslocando através de vários modos de movimento, sendo eles: queda livre, deslizamento, rolamento e salteamento. A distância percorrida, dispersão lateral e altura dos saltos são fortemente influenciados pelo formato da rocha e pela interação com o terreno e outros obstáculos, como árvores. 
Para uso prático é necessário estabelecer um modelo computacional confiável que utilize parâmetros constitutivos que consigam caracterizar as propriedades da superfície do terreno, tal como a rigidez, o conteúdo dos grãos, a cobertura do solo e da vegetação, e que sejam independentes do tamanho e formato das rochas. Isto colocaria o modelo de queda de blocos em uma fundação física sólida e permitiria uma aplicação generalizada dos modelos de trajetória para avaliação de riscos e projetos de medidas mitigatórias.

Este trabalho tem como principal objetivo analisar o comportamento de queda de blocos utilizando dois diferentes programas de modelagem numérica, o primeiro é o RAMMS (Leine et al 2013), um programa de queda de blocos desenvolvido por um grupo de pesquisa suíço que utiliza dinâmica não suave (nonsmooth) e o segundo é o método dos elementos de discretos através do PFC3D, que utiliza dinâmica suave. As análises são focadas nos seguintes pontos:

- Fazer uma correlação entre os dois modelos através de seus parâmetros de perda de energia;

- Analisar a influência da geometria na trajetória do bloco para diferentes inclinações de encostas;

- Determinar um modelo de contato para o método de elementos discretos que possa representar o fenômeno de queda de blocos;

- Aplicar os modelos para casos reais;

- Analisar o efeito da presença de árvores na trajetória de blocos.

\section{2}

\section{Estrutura do trabalho}

Este trabalho é dividido em cinco capítulos, sendo este primeiro (Capítulo 1) contendo a introdução, mostrando as devidas justificativas e objetivos. O Capítulo 2 apresenta a revisão bibliográfica, descrevendo os principais métodos usados para prever a trajetória da queda de blocos e detalha os fundamentos necessários para desenvolver os dois diferentes tipos de modelagem numérica, que são estudados nesta dissertação.

O Capítulo 3 descreve os modelos desenvolvidos em análises numéricas, desde a criação do terreno e do bloco, aos parâmetros utilizados na simulação. Apresenta também uma breve descrição de como os parâmetros foram determinados. 
No Capítulo 4 se encontram os resultados. Todas as simulações desenvolvidas estão presentes neste capítulo, assim como a análise dos resultados.

A conclusão e as recomendações futuras se encontram no Capítulo 5. Por fim, as referências bibliográficas estão detalhadas no Capítulo 6. 


\section{2 \\ Revisão Bibliográfica}

\section{1 \\ Visão Geral das Principais Aproximações de Modelagem de Queda de Blocos}

É possível diferenciar quatro tipos de códigos de simulação de queda de blocos, sendo eles: aproximação horizontal 2D, aproximação vertical 2D, aproximação 2.5D (sendo uma concatenação das duas citadas) e aproximações 3D. O objetivo de todos estes métodos é computar a curva espacial $(x(t), y(t), z(t))$ do centro de massa, isto é, a trajetória do bloco. A aproximação horizontal 2D mais simples computa a velocidade de $(x(t), y(t))$ assumindo que a rocha é um bloco deslizante no terreno, onde a coordenada é definida pela altura do terreno. Uma aproximação vertical 2D simula a trajetória de $(s(t), z(t))$ através de fases de saltos e voos em uma encosta ao longo de um caminho $(x(s), y(s))$ no mapa com um parâmetro de trajetória $s$. A concatenação desses dois últimos modelos leva a aproximação $2.5 \mathrm{D}$, que primeiro computa o movimento $(x, y)$ usando uma aproximação horizontal $2 \mathrm{D}$, definindo assim o caminho do perfil da encosta, e subsequentemente realiza uma simulação vertical 2D do perfil da encosta calculado anteriormente (Leine et al, 2014). Finalmente, aproximações 3D simulam diretamente a velocidade espacial translacional $(x(t), y(t), z(t))$ mas não necessariamente a velocidade rotacional do bloco. Embora as técnicas de simulações 2D e 2.5D terem sido predominantemente usadas no passado, mudanças graduais podem ser observadas quanto a simulações 3D. Uma extensiva visão geral de simulações para queda de blocos é dada por (Volkwein A. et al, 2011). As simulações de queda de blocos tridimensionais podem ser classificadas de acordo com a geometria de modelagem do bloco, sendo elas:

- Modelos de ponto de massa: Uma rocha é considerada como sendo um ponto de massa, isto é, uma partícula. A única propriedade cinética da rocha é sua massa. O movimento do bloco é descrito por um vetor de posição tridimensional e um vetor de velocidade translacional. O ponto de massa 
pode também possuir uma geometria, na qual é usada unicamente para calcular o contato com o terreno ou com obstáculos (principalmente árvores).

- Modelos esféricos: A esfera é considerada como uma esfera rígida homogênea com um determinado raio. As propriedades cinéticas da rocha são sua massa e o seu momento de inércia, o qual não depende do seu eixo de rotação. O movimento da rocha é descrito por uma posição do vetor, onde a orientação do bloco é irrelevante. A velocidade generalizada é descrita por um vetor de velocidade translacional e um vetor de velocidade angular.

- Modelos de formatos rígidos complexos: O bloco é dotado de uma geometria, a qual é parametrizada por um número de parâmetros geométricos. Por exemplo, um bloco pode ser um bloco retangular com três parâmetros (altura, comprimento, profundidade) ou um poliedro arbitrário. A velocidade generalizada é descrita por um vetor de velocidade translacional e um vetor de velocidade angular.

- Modelos de formatos complexos de elementos discretos: Uma rocha é considerada como sendo uma coleção de esferas ou partículas de pontos ligados a elementos elásticos interconectados ou não. Assim, a deformação do bloco pode também ser levada em consideração.

Modelos de pontos de massa não levam em consideração a geometria da rocha e nem a distribuição de energia entre os graus de liberdade angulares e translacionais. A modelagem de blocos com esferas leva a um excessivo caminho percorrido já que a esfera continuará rolando em uma superfície inclinada e pode parar somente em um local plano. Além de que, as forças giroscópicas estão ausentes em modelos esféricos, devido a sua geometria simétrica. Modelos com formatos complexos são influenciados por essas forças giroscópicas, por isso precisam de muito mais esforço computacional e especificações detalhadas do formato do bloco. A simulação completa tridimensional de queda de blocos com modelos de formatos complexos permitem estudar a influência da geometria da rocha na trajetória percorrida e a cicatriz da trajetória. Pesquisas sobre queda de blocos tem sido dominada por simples pontos de massa e modelos $2 \mathrm{D}$ devido a eficiência computacional. Com a melhoria da eficiência computacional, 
modelagem de simulações complexas 3D de queda de blocos está se tornando mais competitiva.

Existem diversos tipos de modelagem através de aproximações para simulações de corpos mecânicos, das quais as mais importantes são o método dos elementos finitos (FEM), o método dos elementos discretos (DEM) e aproximações do corpo rígido. Aproximações por FEM permitem prever tensões e deformações. O método dos elementos discretos considera o corpo como sendo uma coleção de partículas conectadas através de elementos viscoelásticos. A aproximação de corpo rígido negligencia deformações dos corpos e assume que as deformações, que ocorrem devido as forças aplicadas e de contato, são muito menores que o movimento macroscópico dos corpos. Assim, se somente a velocidade macroscópica dos objetos em contato é de interesse, como é o caso na simulação de queda de rochas, então este tipo de simulação é numericamente mais eficiente. A maioria das simulações de queda de blocos usa a aproximação de corpos rígidos. Finalmente, códigos de simulação para corpos rígidos em contato podem ser classificados de acordo com a modelagem da interação de contato rocha-superfície, dividindo-se assim entre os seguintes tópicos:

- Modelos de impacto de repiques: Modelos de pontos de massa são sempre combinados com um modelo de repique empírico com fatores de repiques normal e tangencial. Aproximações estatísticas têm sido propostas para considerar a variabilidade dos repiques;

- Aproximação Penalty e técnicas de regularização: o raciocínio por trás destas técnicas é que todas as forças são descritas por leis de forças de valores únicos, que são descritas em função das posições e velocidades generalizadas;

- Leis de contato rígido/Método dinâmico de contato não suave (nonsmooth): Leis de contato rígido usam um conjunto de leis de força para descrever a interação entre os corpos em contato. A impenetrabilidade dos corpos em contato (rocha e terreno) é, portanto, descrito exatamente usando um complemento de desigualdade (Lei de Signorini). Além de que, a lei de Coulomb de atrito é empregada na sua forma não regularizada. Podendo assim, descrever o travamento da rocha com o terreno. Além das leis de força de contato, as leis de impacto precisam também ser descritas. 


\section{2}

\section{Análise da trajetória}

Basicamente, a estratégia principal é conduzir uma análise da trajetória através de abordagens realizada com modelagens de blocos (Descoeudres et al, 1987). A análise da trajetória consiste em gerar um alto número de trajetórias variando as condições iniciais e introduzindo variáveis aleatórias controláveis nas colisões com o terreno. Atualmente, esta condição de variar as aleatórias para prever a trajetória é usada em vários modelos (Crosta et al, 2004; Dorren et al, 2004, Bourrier et al, 2009a, Christen et al, 2007). Dessa forma, é possível fazer uma previsão de onde os blocos irão parar, seus prováveis caminhos, suas alturas máximas em uma determinada posição e assim em diante.

Assim, trajetórias dos blocos são dadas através das fases de queda livre e de colisão com o terreno. $\mathrm{O}$ atrito do ar é geralmente negligenciado durante a queda livre, então a trajetória, dada por $v(t)$ e $x(t)$, de um ponto material saindo de $x_{0}$ com velocidade $v_{0}$ é:

$$
\begin{gathered}
v(t)=g z t+v_{0} \\
x(t)=\frac{g z}{2} t^{2}+v_{0} t+x_{0}
\end{gathered}
$$

onde $g=-9.81 \mathrm{~ms}^{-2}$ é a aceleração da gravidade e $\mathrm{z}$ é uma unidade de vetor para cima.

Cada colisão dissipa energia segundo uma função do ângulo de impacto, da inclinação da encosta e da velocidade do bloco. Considerando as velocidades de colisão ao longo da direção normal e tangencial da encosta, $v_{n} \mathrm{e} v_{t}$, respectivamente, dois parâmetros são geralmente usados para diferenciar a dissipação nessas direções em termos da taxa de velocidades depois e antes da colisão, sobescrita por (+) e (-). As expressões mais comuns destes coeficientes de restituição são: 


$$
\begin{aligned}
& e_{n}=-\frac{v_{n}^{+}}{v_{n}^{-}} \\
& e_{t}=-\frac{v_{t}^{+}}{v_{t}^{-}}
\end{aligned}
$$

Quando a colisão é identificada, as velocidades normal e tangencial, $v_{n}^{-} \mathrm{e}$ $v_{t}^{-}$, antes do impacto são usadas para computar as velocidades depois da colisão.

$$
\begin{aligned}
& v_{n}^{+}=-e_{n} v_{n}^{-} \\
& v_{t}^{+}=-e_{n} v_{t}^{-}
\end{aligned}
$$

A posição onde ocorreu a colisão e a velocidade após o impacto são usadas como condições iniciais para a próxima fase de queda livre. Com isso, a duração da colisão é igual a zero.

Além disso, a definição do coeficiente de restituição é o núcleo do modelo, sendo assim, há diferentes definições utilizadas na bibliografia. As definições podem ser mais sofisticadas e utilizar considerações estatísticas, geométricas e energéticas. Também, pode ser considerado como um efeito acoplado das velocidades normal e tangencial, então as velocidades depois da colisão são expressas como:

$$
\left(\begin{array}{c}
v_{n}^{+} \\
v_{t}^{+}
\end{array}\right)=\left[\begin{array}{ll}
e_{n n} & e_{n t} \\
e_{n t} & e_{n t}
\end{array}\right] \cdot\left(\begin{array}{c}
v_{n}^{-} \\
v_{t}^{-}
\end{array}\right)
$$

Em simulações tridimensionais, a velocidade tangencial é um vetor $v_{t}$ e alguma estatística pode ser introduzida, em particular o ângulo de impacto entre o bloco e superfície (Bourrier et al 2009).

No final, os modelos de análises de trajetória focam no comportamento da colisão. Cada modelo tem sua própria fórmula, uns mais sofisticados que outros, 
mas a colisão ocorre entre as partículas (às vezes corpos modelados rígidos) e o terreno.

\section{3 \\ O Método dos Elementos Discretos}

De acordo com Donze (2009), muitos geomateriais, como rochas, não se caracterizam como materiais granulares, no entanto, modelos discretos são frequentemente aplicados para investigar seu comportamento mecânico, assumindo que o material pode ser aproximado como um conjunto de elementos discretos colados. Assim o comportamento mecânico geral pode ser estimado através destas partículas sob processos de descarregamento e carregamento, causando movimento, deslocamento, deslizamento e rotação entre as partículas.

Cundall e Strack (1979) foram pioneiros quanto ao método dos elementos discretos (MED, ou DEM em inglês), foi a primeira proposta de aproximação na literatura. Basicamente, o algoritmo envolve dois estágios. No primeiro, forças de interação são computadas, quando elementos levemente penetram uns nos outros; esta formulação de força-deslocamento é referida como método do contato suave ou também como método de força-deslocamento. No segundo estágio, a segunda lei de Newton é utilizada para determinar, para cada partícula, a aceleração resultante, que é então integrada no tempo para achar a velocidade e a posição do elemento. Este processo é repetido até o fim simulação. Esta solução numérica simultânea do sistema de partículas é também conhecida como Dinâmica Molecular.

O algoritmo fundamental do DEM é baseado em equações diferenciais de movimento de corpos em contato. Em cada intervalo de tempo, após detectar a colisão das partículas, calcula-se a rigidez de contato, as forças coesivas e as forças resultantes de cada elemento, e então, a segunda lei de Newton (lei de movimento) é utilizada para que se possa obter a velocidade, aceleração e posição atualizadas de cada partícula. A Figura 2.1 demonstra o modelo Voigt-Kelvin (sistema massamola-amortecedor com um grau de liberdade), o qual é utilizado no DEM para modelar contato entre dois objetos. Forças de contato são calculadas de acordo com a relação força-deslocamento (Lei de Hoek) que pode ser linear ou não-linear. 


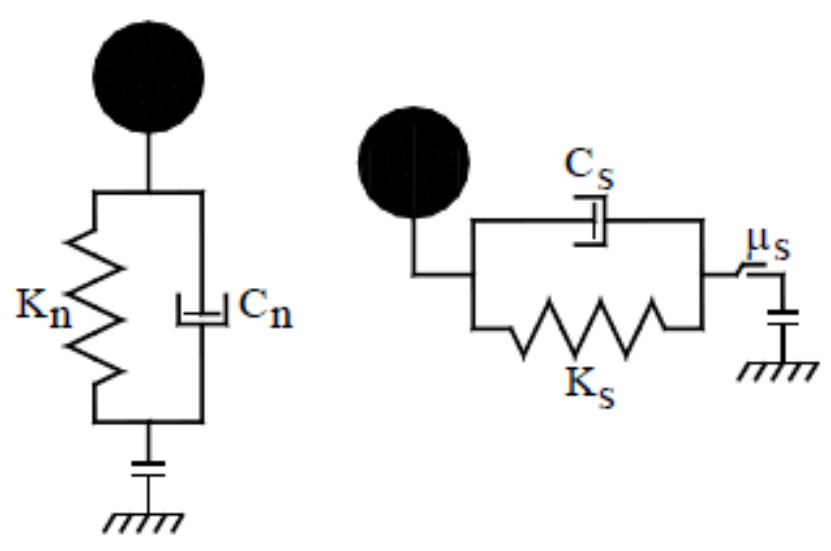

Figura 2.1 - O elemento Voigt-Kelvin consiste em uma mola e um amortecedor conectados em paralelo.

O uso do DEM para analisar as propriedades mecânicas dos materiais está se tornando cada vez mais popular na engenharia. A natureza descontinua e heterogênea das rochas leva a um comportamento mecânico complexo, o que acaba dificultando o uso de métodos numéricos convencionais. O código numérico usado neste trabalho, o DEM, pode representar o material como um conjunto de partículas que interagem umas com as outras. Alguns estudos do DEM aplicados à geotecnia foram realizados por Donze et al (2009). Jin (2007) e O'Sullivan (2011), onde foram feitos estudos sobre a particularidades do modelo quanto ao comportamento de blocos rochosos.

As partículas são as entidades geométricas fundamentais na simulação do modelo. Elas podem ser coladas umas nas outras a fim de obter diferentes geometrias, isto depende do problema proposto. As partículas podem ser usadas tanto para representar o solo quanto blocos rochosos.

Neste trabalho, para a modelagem do DEM foi utilizado o programa PFC3D (Itasca, 1999). No programa define-se também as paredes, que são usadas para obter o plano desejado, para interação com as partículas. As paredes são criadas através de polígonos com origem e limites definidos.

Thoeni et al (2013) realizaram alguns experimentos de queda de blocos utilizando o método dos elementos discretos. Tendo como proposta calibrar o modelo e validá-lo, os autores compararam as simulações numéricas com resultados experimentais e mostraram que o modelo pode precisamente prever a trajetória dos blocos e sua velocidade para análise de queda de rochas. Jincai et al 
(2009) também realizaram experimentos usando o método dos elementos discretos para parametrização das variáveis. Foi desenvolvida uma metodologia onde os parâmetros do método de elementos discretos são determinados através de retroanálises de uma trajetória de blocos observada em um campo experimental ou traçada em um local de investigação de eventos de queda de rochas. Lisjak et al (2010) adotaram uma aproximação baseada na combinação entre os elementos finitos e discretos para simular a queda de blocos. Foram realizados testes em escala real de queda de rochas, onde estes testes foram utilizados para calibrar o modelo numérico, demonstrando como trajetórias experimentais podem ser precisamente reproduzidas.

Richefeu et al (2015) realizaram experimentos utilizando método de elementos discretos para analisar o comportamento de avalanche de queda de blocos, avaliando a trajetória e toda sua zona de deposição. Um estudo numérico foi realizado, baseado em experimentos de laboratório, a fim de obter melhor uma parametrização das variáveis numéricas. E depois foi aplicado o modelo em avalanches de rochas. Os autores mostraram que as simulações numéricas são capazes de prever o comportamento desses eventos no campo.

\subsection{1 \\ Modelos de Contato}

Vários modelos de contato para aplicação da simulação DEM são utilizados. Modelos de contato determinam o procedimento de cálculo da rigidez e forças de contato no modelo. Geralmente, forças de contato são calculadas de acordo com a relação força-deformação; deformações podem ser determinadas pela geometria dos corpos em contato, e a magnitude da rigidez de contato é definida por cada modelo de contato. Uma vez que as forças de contato têm efeito significativo no comportamento geral do modelo de queda de blocos, é necessário apresentar cada modelo de contato usado neste trabalho.

\subsubsection{1}

\section{Modelo Linear e o Amortecedor Viscoso}

O modelo fornece um comportamento de uma interface infinitesimal que não resiste a rotação relativa. A força de contato é resolvida através de uma componente linear e do amortecimento $\left(F_{c}=F^{l}+F^{d}\right)$. A componente linear 
fornece um comportamento de atrito linear elástico, enquanto o amortecedor fornece um comportamento viscoso (Figura 2.2). A força linear é produzida por molas lineares com rigidezes normais e tangenciais constantes, $k_{n} e k_{s}$. A força do amortecimento é produzida por amortecedores viscosos dados em termos das taxas de amortecimentos críticos normal e cisalhante, $\beta_{n} e \beta_{s}$. As molas lineares agem em paralelo com os amortecedores. O contato é ativado se, e somente se, a distância entre as superfícies, $g_{s}$, for menor ou igual a zero.

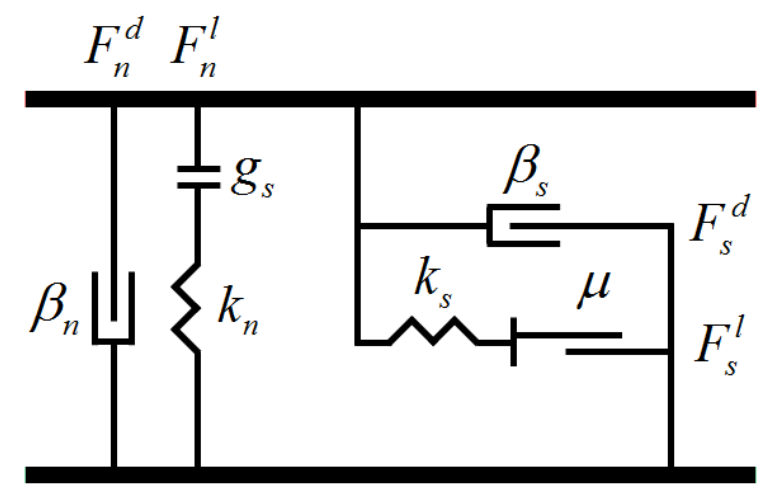

Figura 2.2 - Comportamento e componentes reológicos do modelo linear.

A lei de força deslocamento para o modelo linear consiste na seguinte forma. Primeiro ocorre a atualização da força linear normal baseada na força normal:

$$
F_{n}^{l}=k_{n} g_{s} \text { para } g_{s}<0
$$

O acréscimo da força cisalhante é calculado da seguinte maneira. Calcula-se uma força cisalhante:

$$
F_{S}^{*}=\left(F_{s}^{l}\right)_{0}-k_{S} \Delta \delta_{S}
$$

onde $\left(F_{S}^{l}\right)_{0}$ é a força linear cisalhante no início do passo de tempo, e $\Delta \delta_{s}$ é o acréscimo do deslocamento cisalhante relativo. E computada a força cisalhante máxima:

$$
F_{S}^{\mu}=-\mu F_{n}^{l}
$$


Atualiza-se a força linear de cisalhamento através das seguintes equações:

$$
F_{S}^{l}=\left\{\begin{array}{cl}
F_{S}^{*}, & \text { se }\left\|F_{S}^{l}\right\|=F_{S}^{\mu} \\
F_{S}^{\mu}\left(\frac{F_{S}^{*}}{\left\|F_{S}^{*}\right\|}\right), & \text { caso contrário }
\end{array}\right.
$$

O corpo irá deslizar se $\left\|F_{S}^{l}\right\|=F_{S}^{\mu}$. A figura 2.3 demonstra o estado de deslizamento ou não do corpo.

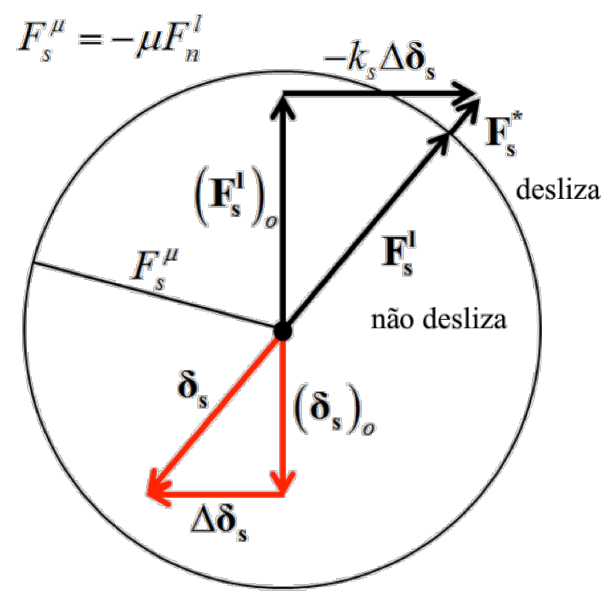

Figura 2.3 - Atualização da força linear de cisalhamento e deslizamento tangencial relativo durante o deslizamento de modelos lineares.

O amortecimento viscoso é ativado quando ocorre o contato entre os elementos. Este tipo de amortecimento é formado por amortecedores normal e cisalhante, que atuam paralelamente com o modelo constitutivo de contato existente, como o modelo linear já descrito.

De acordo com An e Tannant (2007), o amortecimento representa a energia perdida em simulações com o DEM, o valor escolhido para o amortecedor é obtido através de experiência e conhecimentos do usuário quanto ao problema. A força de amortecimento viscoso é calculada pelas seguintes equações:

$$
F^{d}=C|V|
$$




$$
C=\beta C^{\text {crit }}
$$

Onde:

$F^{d}$ é a força de amortecimento viscoso

$|V|$ é a velocidade relativa entre os elementos em contato

$C$ é a constante de amortecimento

$\beta$ é a taxa de amortecimento

$C^{\text {crit }}$ é a constante de amortecimento crítico

Sendo:

$$
C_{i}^{c r i t}=2 m \omega_{n}=2 \sqrt{m k}
$$

Onde:

$\omega_{n}$ é a frequência natural do sistema

$k$ é a rigidez (tangente) de contato

$m$ é a massa média de duas esfera quando o contato for esfera-esfera e a massa da esfera quando o contato for esfera-parede

$\mathrm{O}$ amortecimento crítico, $\beta$, é o que determina o comportamento do amortecedor no modelo. Quando $\beta$ for igual a 0 , toda energia do sistema é preservada durante o impacto. $\mathrm{O}$ sistema se encontra subamortecido quando $\beta$ possuir um valor entre 0 e 1 , a esfera perde energia aos poucos, até ficar estacionária, quando toda energia estiver dissipada. Quando $\beta$ for igual a 1 , o sistema se encontra em amortecimento crítico, toda energia é perdida logo no primeiro impacto.

De acordo com Hu et al. (2011), a relação entre o amortecimento crítico $(\beta)$ e o coeficiente de restituição $(e)$ é dada pela seguinte equação:

$$
\beta=\frac{\ln (e)}{\sqrt{\ln ^{2}(e)+\pi^{2}}}
$$




\subsubsection{2 Modelo Linear com a adição da Resistência ao Rolamento}

As superfícies e áreas de deposição de blocos rochosos são muitas vezes muito íngremes. Em muitos casos não é possível parar o bloco na encosta. A figura 2.4 mostra duas situações nas quais para uma dada inclinação $\alpha$ da encosta, onde o bloco consegue ou não parar. Intuitivamente, entende-se que um bloco liso pode parar devido a sua longa face, mesmo se o talude for íngreme, enquanto um bloco cúbico não.

Para que o bloco pare em uma encosta inclinada, uma condição necessária para que isto ocorra, é que a posição do centro de massa não exceda a passagem vertical pelo ponto de contato. $\mathrm{O}$ formato do bloco pode ser caracterizado por um ângulo $\beta$, definido como um ângulo máximo entre a normal da face e o vetor que conecta o centro de massa aos vértices dessa face (Figura 2.4(a)). A condição necessária para a desestabilização pode então, ser formalmente expressada como:

$$
\alpha-\beta<0
$$

Em outras palavras, se esta condição não é satisfeita, o bloco não irá parar, a não ser que um momento no ponto de contato resista a ação de alavanca do peso

Para o equilíbrio do bloco na situação da figura 2.4 (b), é necessário que o momento devido ao peso relativo do bloco no ponto de contato, $\operatorname{lsen}(\alpha-\beta) \mathrm{mg}$, seja superado pelo valor limite do momento de resistência, $\mu_{r} l f_{n}=\mu_{r} l m g \cos (\alpha)$. Isto resulta em valor mínimo da magnitude do coeficiente de resistência, $\mu_{r}^{\min }$, ao rolamento para a possível estabilização:

$$
\mu_{r}^{\min }=\frac{\sin (\alpha-\beta)}{\cos (\alpha)}
$$




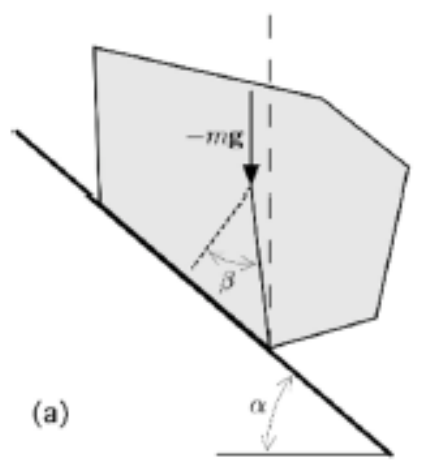

(b)

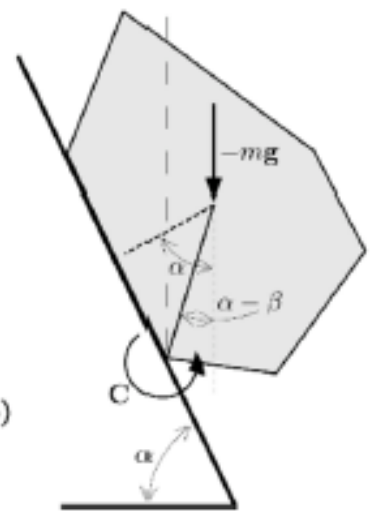

Figura 2.4- Representação esquemática de (a) uma posição estável (b) uma posição potencialmente não estável.

Richefeu (2012) realizou algumas simulações de queda de blocos usando o DEM, ele se viu na necessidade de usar essa força de resistência ao rolamento devido à maciez de alguns solos. E quando a simulação consistia em blocos mais alongados, o autor não adotou a resistência ao rolamento. Ele conseguiu aproximações através de tentativas, mudando o coeficiente de resistência ao rolamento, para aproximações de quedas de blocos experimentais.

Devido a este problema é inserido o modelo de contato de resistência ao rolamento. É um modelo simples, baseado no modelo linear, que incorpora um torque que age nas partículas em contato contrário à velocidade de rolamento. Este modelo é baseado no trabalho de Ai et al (2000) e também no trabalho desenvolvido por Wensrich et al (2012).

Primeiro, o momento de resistência ao rolamento é atualizado através da seguinte equação:

$$
M^{r}=M^{r}-k_{r} \Delta \theta_{b}
$$

onde $\Delta \theta_{b}$ é o incremento relativo da curvatura de rotação.

A rigidez de resistência ao rolamento $k_{r}$ é definida como sendo:

$$
k_{r}=k_{s} R^{2}
$$


A magnitude da atualização do momento de resistência ao rolamento é então checada com o limite definido:

$$
M^{r}=\left\{\begin{array}{c}
M^{r},\left\|M^{r}\right\| \leq M^{*} \\
M^{*}\left(\frac{M^{r}}{\left\|M^{r}\right\|}\right), \text { caso contrário }
\end{array}\right.
$$

O torque limite é definido como:

$$
M^{*}=\mu_{r} R F_{n}^{l}
$$

Ou seja, ocorrerá o deslizamento se $\left\|M^{r}\right\|=M^{*}$.

\section{4}

\section{O Software RAMMS}

O método de mecânica não suave (nonsmooth) (Acary et al, 2008; Frémond 1995; Glocker, 2001; Jean, 1999; Leine et al, 2008) utiliza leis de contato rígido. Devido a não penetração dos contatos na aproximação do modelo é necessário um conjunto de leis de força (lei de Signorini e lei de atrito de Coulomb) e leis de impacto instantâneo (do tipo Newton ou Poisson), que faz com que em um determinado tempo de colisão ocorra uma mudança instantânea na velocidade dos corpos em contato. A formulação de comportamento de contato unilateral e de atrito requer leis de contato constitutivas, que são um conjunto pré-determinado. As equações de movimento são, portanto, descritas por otimizações diferenciais, e não por equações ordinárias diferenciais. Métodos numéricos de integração no tempo para resolver otimizações diferenciais estão sendo desenvolvidos e melhorados.

Este método de simulação possui as seguintes características:

1. Simulação totalmente tridimensional baseada no método de dinâmica de contato não suave com leis de contato rígidas;

2. Forma complexa que consiste de um poliedro arbitrário convexo e, portanto, sem restrição para blocos;

3. Terreno baseado em um modelo de elevação digital de alta resolução;

4. Uma lei de atrito especializada para queda de blocos, a qual permite a descrição de um comportamento de cicatrização (rochas tendem a deslizar sob o terreno antes de saltarem); 
5. Uma força de arraste para interação de florestas;

6. Uma técnica de integração no tempo energeticamente consistente, o qual garante que não haja aumento da perda de energia durante as fases de voo.

Este método de simulação foi implementado no software RAMMS (Rapid Mass Movement), uma ferramenta para prever desastres naturais, desenvolvido pelo WSL Insitute for Snow and Avalanche Research SLF (Christen et al, 2010; Christen et al, 2012)

Este método considera a rocha como sendo um corpo perfeitamente rígido, tridimensional e inquebrável no formato de um poliedro convexo, que pode entrar em contato com uma superfície impenetrável.

No software RAMMS a interação rocha-solo é parametrizada por operadores de atrito que agem na superfície do bloco rochoso. Comparado com modelos de repiques (que aplicam coeficientes de restituição para modelar toda a interação rocha-solo), no contato rígido, a abordagem do corpo rígido aplica forças de contato nas bordas e nos pontos de contato do bloco. Isto facilita uma modelagem natural dos quatros modos primários de movimento (rolamento, salteamento, deslizamento e sobressaltos) sem o uso de métodos estatísticos que definam os parâmetros de ressaltos. Todos os quatro modos são representados no RAMMS. Trajetórias longas e dispersas dos blocos geralmente estão associadas ao modo de ressalto, no entanto, é necessária uma transição do ressalto para o módulo de rolamento/deslizamento para que o bloco pare. A variação dos ressaltos é definida automaticamente pelo formato e orientação da rocha no impacto. A propagação estatística da trajetória e dispersão do bloco na queda é gerada mudando somente as condições inicias. Os parâmetros do solo não são aleatórios, eles são determinados de acordo com a natureza do material.

As formas dos blocos são criadas através de uma nuvem de pontos (points cloud), que definem a superfície da geometria da rocha. O formato pode ser de uma geometria simples ou mais complexas, tais como equant, platy ou long. Uma característica única do RAMMS é que geometrias reais de blocos obtidas através de escaneamento a laser durante investigações de campo podem ser usadas em um aplicativo de modelagem. Com o tempo, o usuário pode construir e gerir uma livraria contendo os modelos das rochas que representam diferentes configurações 
geológicas. No presente, as rochas são consideradas indestrutíveis, isto é, não fragmentam ou mudam de forma durante as análises.

Outra característica do RAMMS é a inclusão de rotações do bloco tanto quando ele encontra na superfície como no ar. O modelo do software inclui forças giroscópicas induzidas por rotações do bloco. Estas forças são necessárias para simular os movimentos de salto e de rolamento, similares aos de rodas, que ocorrem em blocos, sendo frequentemente responsáveis por longas trajetórias.

Para modelar a interação com o terreno, considerando rochas com geometrias arbitrárias e velocidades rotacionais, é necessário um método que localize precisamente a orientação relativa do bloco no terreno. RAMMS emprega álgebra quaternária para este problema. Este método localiza sequências rotacionais mesmo quando forças de contato não lineares mudam as direções translacionais e rotacionais do bloco. Modelando o contato rocha-solo desta forma é possível que toda mecânica de impacto seja simulada deterministicamente. Os braços de momento e torques, responsáveis por como a geometria do bloco converte movimento translacional em momento angular, influenciando a altura do repique, são computados, e assim permitem modelar os quatros diferentes tipos de movimento.

\subsection{1}

\section{Modelando o Bloco Rochoso}

A geometria do bloco é considerada como sendo um poliedro convexo tridimensional, sendo assim, pode ser definida como uma envoltória convexa de um conjunto de pontos finitos em um espaço tridimensional. O Instituto Suíço de Pesquisa de Neve e Avalanche (WSL) escaneia através de laser rochas reais encontradas em campo. Desta forma, uma nuvem de pontos é gerada (tipicamente consistida de uma centena de pontos), que é consequentemente convertida em um poliedro convexo, e usada no modelo (figura 2.5). A geração da geometria da rocha é representada na figura 2.6. A geometria do bloco é especificada por um ponto na nuvem em um corpo fixo com o eixo de coordenada B de origem em C (figura 2.6a). A envoltória convexa do ponto na nuvem é construída depois que o centro de massa $\mathrm{S}$ e o tensor de inércia da rocha são determinados, sob a suposição de uma distribuição de massa homogênea (Figura 2.6b e 2.6c). 

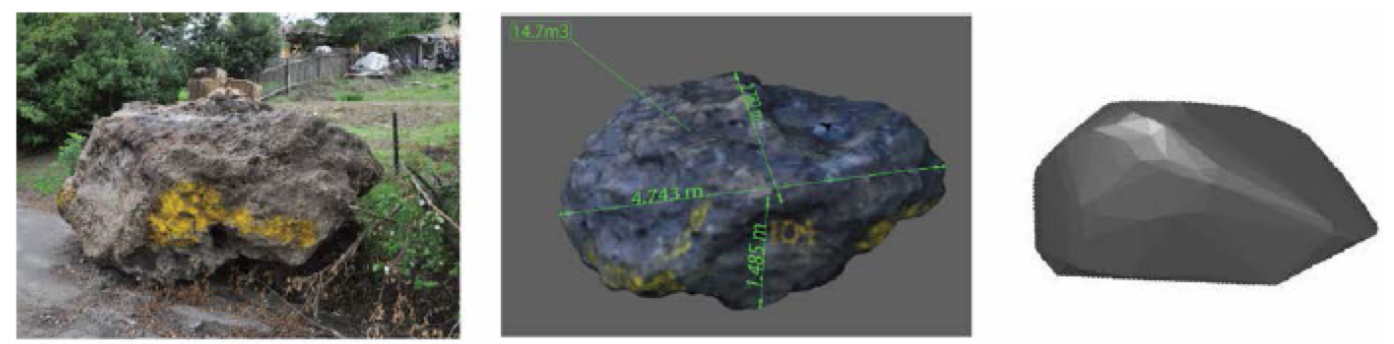

Figura 2.5- Escaneamento de rochas em campo através de laser (RAMMS::ROCKFALL User Manual).
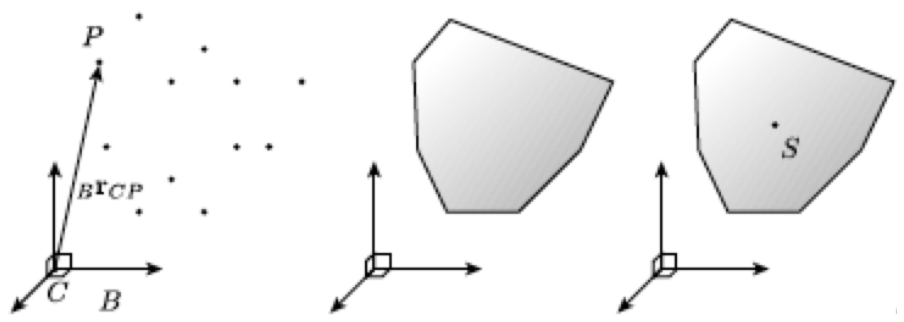

Figura 2.6 - Geração da geometria da rocha e suas propriedades de inércia (Leine et al, 2013).

\subsection{2 \\ Movimento de Queda Livre com Gravidade e Forças Giroscópicas}

Em queda livre o movimento é governado pela seguinte equação (Leine et al. 2013):

$$
M \dot{u}-h(q, u)=0
$$

onde $\mathrm{M}$ é a matriz de massa constante e diagonal (contendo a massa e os três momentos de inércia I). $\mathrm{O}$ vetor $u$ contém as três velocidades rotacionais e as três velocidades translacionais. Essas forças que governam o movimento do bloco determinarão a trajetória do bloco.

A força gravitacional $\left(F_{g}\right)$ age globalmente no bloco. A força de arraste $(D)$ é implementada para representar os efeitos de árvores, vegetação e deformação do solo. Ao lado das forças giroscópicas $(G)$, essas forças determinarão a rotação do bloco quanto ele estiver no ar e na superfície. Todos os termos de força $(h)$ são em função da posição $(q)$ e velocidade $(u)$ da rocha, formando o vetor força: 


$$
h(q, u)=\left[\begin{array}{c}
F_{g}+D \\
G
\end{array}\right]
$$

\subsection{3}

\section{Forças de Contato}

Quando o contato é detectado entre a rocha e o terreno, forças de contato $(\lambda) \mathrm{e}$ forças de contato de atrito $\left(F_{c}\right)$ agem no ponto de contato. Estas forças podem ser consideradas como forças externas que mudam a direção dos blocos em queda. Para representar as forças de contato usa-se a letra grega $(\lambda)$, que são multiplicadores Lagrangeanos, que impõem a restrição de não penetração no contato.

Forças de contato são modeladas como restrições rígidas laterais com coeficiente de Coulomb, usando aproximações de dinâmica de contato não suave. Para o caso de contato, as equações governantes de movimento são representadas por:

$$
M \dot{u}-h(q, u)=\lambda W(q)
$$

onde a direção das forças de contato é dada por $W(q)$. A combinação dessas forças determinará a complexidade das rotações e desvios da trajetória, que são inerentes para simular queda de blocos.

A vantagem de utilizar este método de restrições nos contatos para blocos rígidos é que as forças de contato são aplicadas diretamente nestes pontos de contato, respeitando a configuração (orientação e velocidade) do impacto.

$\mathrm{O}$ ponto de contato $\mathrm{C}$ tem uma componente de força de contato normal $\left(\lambda_{N}\right)$ e duas componentes tangenciais $\left(\lambda_{T 1}\right),\left(\lambda_{T 2}\right)$. A força de contato $\left(\lambda_{N}\right)$ garante a unilateridade do contato, isto é, a restrição de não penetração. As componentes de força tangenciais ocorrem devido ao atrito de Coulomb e são governadas por leis de contato.

A componente da força normal $\left(\lambda_{N}\right)$ é resolvida através de otimizações cônicas diferenciais, no qual o vetor de força normal transiente sob o período de contato finito pode ser computado.

A componente de força tangencial $\left(\lambda_{T}\right)$ obedece a lei espacial de atrito de Coulomb (figura 2.7). $\mathrm{O}$ atrito estático do contato $\left(\gamma_{T}=0\right)$ ocorre contanto que a 
magnitude da força tangencial $\left\|k \lambda_{T}\right\|$ é menor que $\mu \lambda_{N}$, no qual $\lambda_{N}$ é a força normal aplica e $(\mu)$ o coeficiente de atrito. A direção é também resolvida com inclusões cônicas normal projetando um disco de atrito na superfície (figura 2.7). A formulação cobre casos de travamento e deslizamento.

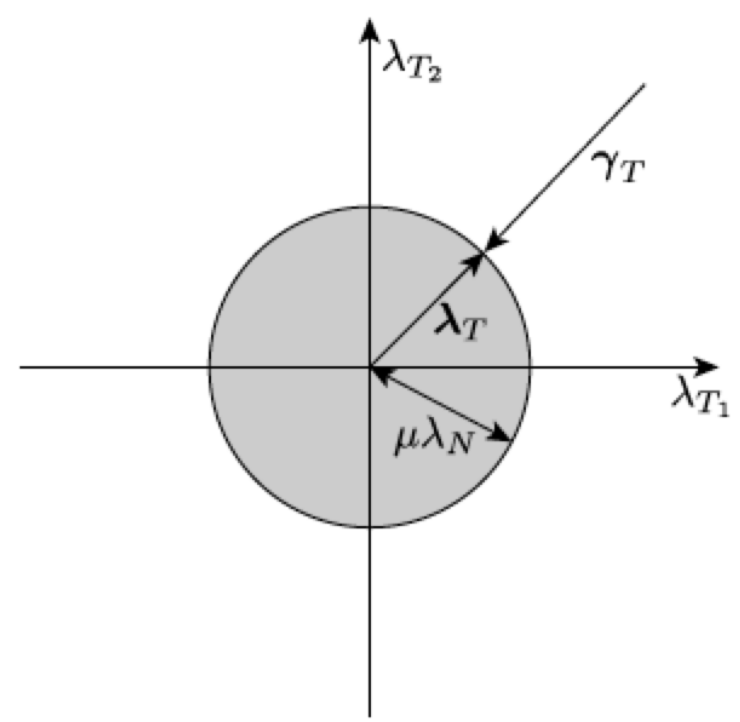

Figura 2.7 - Forças de atrito de Coulomb.

\subsection{4}

\section{Forças Impulsivas}

Esta lei de impacto é baseada na lei de impacto Newtoniana (Glocker, 2013; Leine et al, 2008; Moreau, 2008), no qual as velocidades relativas normais dos pares de contato antes e depois do contato são governadas pelo coeficiente de restituição $\left(\varepsilon_{N}\right)$. Onde, $\varepsilon_{N}=1$, corresponde a completa restituição da velocidade normal, assim, quanto menor $\varepsilon_{N}$, maior será a dissipação de energia do sistema. Geralmente o valor é definido como muito baixo. A lei de ação e reação é totalmente cumprida.

$$
\gamma_{N}^{+}+\varepsilon \gamma_{n}^{-}=0
$$

Forças normais impulsivas podem também induzir forças tangenciais. No modelo de queda de blocos, $\varepsilon_{T}$ é definido como sendo igual a zero, já que seus efeitos são inexistentes (Glocker, 2013). 
Para determinar a direção da força resultante que age no bloco a configuração do impacto precisa ser computada. Para isso é necessário determinar a velocidade relativa entre os pontos de contato do bloco e do terreno.

\subsection{5}

\section{Forças de Arraste e Derrapagem}

Duas forças fisicamente diferentes se opõem ao movimento de queda de blocos: o atrito de deslizamento e a força de arraste. Atrito de deslizamento age nos pontos de contato da rocha com a superfície, é o atrito do tipo Coulomb associado com a distância do deslizamento da rocha no terreno. No entanto, devido ao atrito que age nos pontos extremo da rocha, isso irá gerar torques que iniciarão movimentos rotacionais. A parametrização da força de atrito é de grande importância já que ela controla quando o bloco desliza, rola ou salta. Já o arraste, age no centro de massa da rocha, o que acaba não criando momentos rotacionais adicionais. Há duas forças de arraste no modelo RAMMS. A primeira leva em consideração a vegetação, e a segunda leva em consideração o arraste viscoplástico, devido a deformação do terreno durante o contato com o solo.

Através de observações em campo notou-se um fenômeno de derrapagem em queda de blocos. Quando ocorre o impacto, a rocha penetra na cobertura do terreno, formando uma cicatriz enquanto desliza, e por fim, o bloco acaba se desprendendo do terreno. Um traço no terreno com uma cicatriz de comprimento finito pode ser observado. A figura 2.8 mostra o fenômeno de derrapagem, enquanto a rocha desliza ela vai acumulando terra na sua frente, o que acaba aumentando a resistência ao deslizamento. Este aumento do atrito no contato entre a rocha e o terreno faz com que o bloco tombe e se desprenda do terreno. A modelagem deste fenômeno é de muita importância já que influencia a altura e distância do salto dos blocos.

Para simular tal fenômeno um modelo de derrapagem dependente do atrito foi criado, ampliando o modelo de atrito de Coulomb com um coeficiente de atrito dependente da derrapagem $(\mu(s))$, onde a derrapagem (s) é um estado interno do modelo de atrito. A derrapagem é definida como sendo a distância do centro de massa que o bloco percorre durante a fase de contato (figura 2.8). O coeficiente de atrito dependente é definido como sendo: 


$$
\mu(s)=\mu_{\min }+\frac{2}{\pi}\left(\mu_{\max }-\mu_{\min }\right) \arctan (k s)
$$

onde $\mu_{\text {min }}, \mu_{\max }$, e $k$ são parâmetros do modelo de atrito. $\mathrm{O}$ coeficiente de atrito $\mu$ é igual a $\mu_{\min }$ para $s=0$ e tende a $\mu_{\max }$ para altos valores de $s$ (Figura 2.9). Assim, a resistência de atrito aumenta com o aumento da derrapagem, mas satura para altos valores.

A distância da derrapagem $(s)$ é uma variável de estado transitório, tendo uma evolução no tempo que é descrito por uma equação simples diferencial:

$$
\dot{s}= \begin{cases}\left\|v_{s}\right\| & \text { se } g_{n} \leq 0 \\ -\beta \text { s } & \text { se } g_{n}>0\end{cases}
$$

O parâmetro $\beta$ controla o quão rápido o atrito é liberado assim que o bloco deixa a cicatriz da superfície. Se $\beta$ é alto, o atrito imediatamente é removido assim que a rocha deixa a superfície. Por outro lado, quando $\beta$ é baixo, o atrito de deslizamento age, mesmo quando o bloco não se encontra mais em contato com a superfície. $\mathrm{O}$ parâmetro $\beta$ está ligado a profundidade da penetração do bloco no solo. Alta penetração (solos mais macios) estão associados com menores valores de $\beta$.
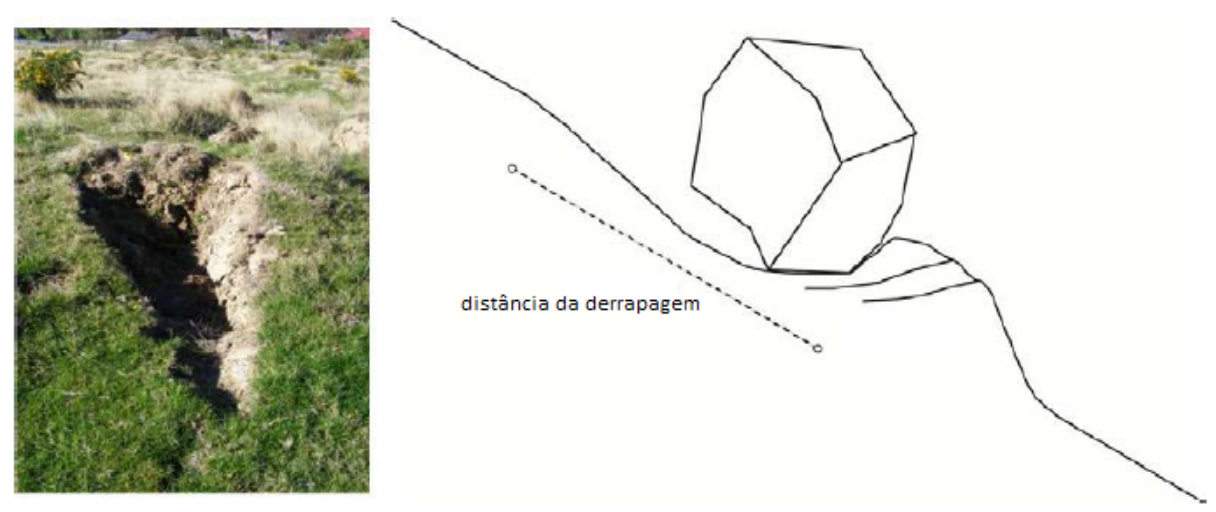

Figura 2.8 - O fenômeno de derrapagem (Leine et al, 2013). 


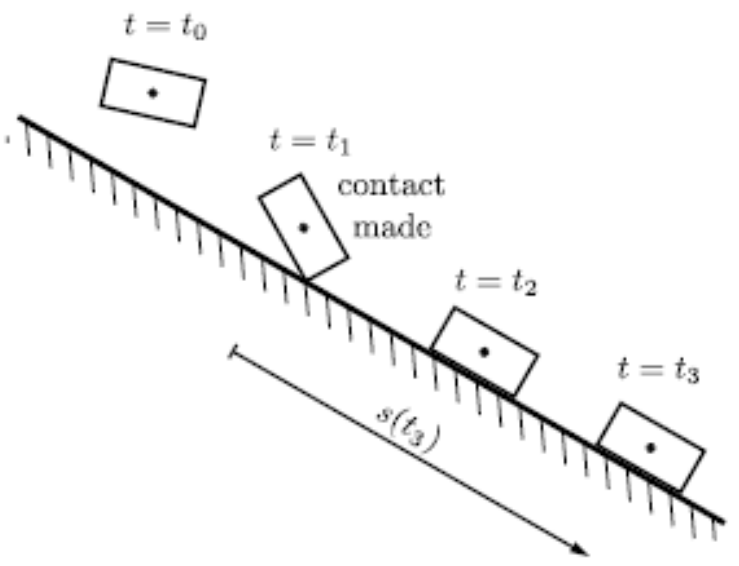

(a)

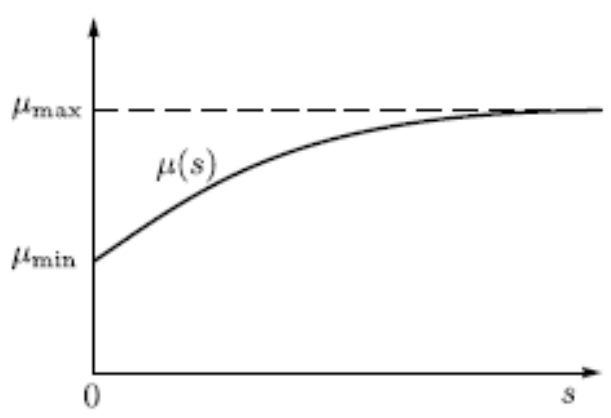

(b)

Figura 2.9 - Modelo de atrito dependente da derrapagem (Leine et al, 2013).

Glover (2015) realizou alguns estudos de como estes parâmetros afetam o comportamento dos blocos durante a queda. Foi descoberto que para baixo valores de $\mu_{\max }$ resulta em longos deslizamentos e alcance, com o aumento do valor do parâmetro. Glover (2015) analisou também a influência do parâmetro $k$, que controla a taxa de mudança de $\mu_{\min }$ para $\mu_{\max }$ mantendo o valor de $k$ baixo, o bloco desliza por mais tempo, enquanto altos valores de $k$ o bloco vai se desprender da superfície com mais facilidade, levando a altos valores de sobressaltos e de velocidade dos blocos.

De acordo com Glover (2015) quando o parâmetro $\beta$ é mantido baixo, altos valores atrito são mantidos por mais tempo, promovendo assim maiores sobressaltos e velocidades angulares das rochas. E quando vai aumentado o seu valor, o efeito do atrito no contato vai se desfazendo rapidamente, resultando em sobressaltos e velocidades angulares reduzidas.

Uma força adicional dependente do deslizamento é introduzida levando em conta a deformação viscoplástico que ocorre em solos macios sob impacto da rocha. Altas deformações viscoplásticos são também encontradas em materiais de substrato mais rígidos como cascalhos, onde o contato entre os grãos acaba por dissipar energia. A força de arraste viscoplástica é determinada como:

$$
F_{v}=-\frac{m}{2} C_{v} v_{s}^{2}
$$


$\mathrm{O}$ arraste do solo age quando a rocha está em contato com o solo assim como quando ele está deslizando na superfície do terreno. Percebe-se que a força é proporcional a energia cinética total do bloco. O coeficiente de arraste $\left(C_{v}\right)$ varia entre $0.0 \mathrm{~m}^{-1}$ (rígido) e $1.0 \mathrm{~m}^{-1}$ (macio).

O arraste da floresta (figura 2.10) é dado pela seguinte relação:

$$
F_{d f}=-C_{f} v_{s}
$$

onde,

$$
C_{f}= \begin{cases}\theta_{f} & \text { se } Z \leq Z_{h} \\ 0 & \text { se } Z>Z_{h}\end{cases}
$$

A força age no centro de massa da rocha quando ela está localizada abaixo da camada de altura $\left(Z_{h}\right)$. Valores típicos de $Z_{h}$ estão entre $5 \mathrm{~m}$ e $30 \mathrm{~m}$ (valor padrão igual a $30 \mathrm{~m}$ ); valores típicos de $\theta_{f}$ ficam entre $100 \mathrm{~kg} / \mathrm{s}$ e $1000 \mathrm{~kg} / \mathrm{s}$.

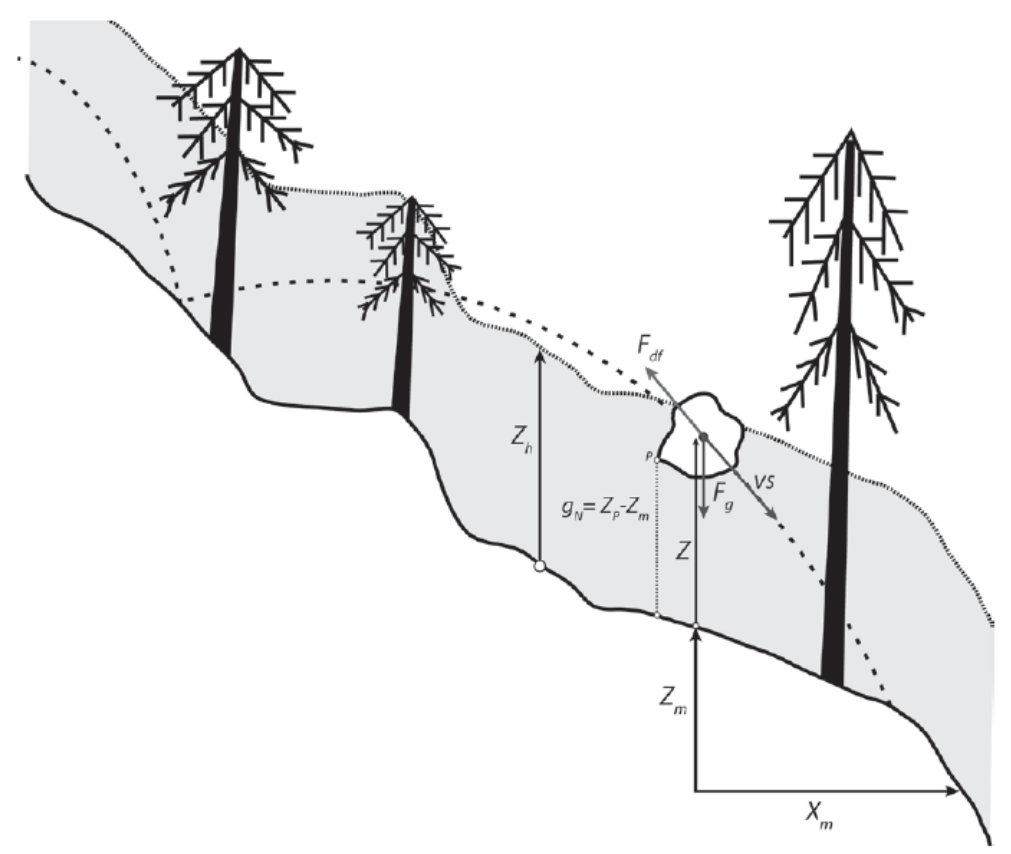

Figura 2.10 - Força de arraste da floresta agindo no centro de gravidade do bloco.

(RAMMS::ROCKFALL User Manual). 


\section{3 \\ Programa das Simulações Numéricas}

A primeira parte do programa de simulações numéricas consistiu em uma comparação entre os dois modelos a fim de obter uma correlação entre os parâmetros que causam perda de energia no sistema. Analisou-se a distância percorrida pelos blocos rochosos em uma superfície inclinada, obtendo uma relação entre os parâmetros utilizados no programa PFC3D e no software RAMMS. Nas primeiras simulações com o método dos elementos discretos foi utilizado o modelo de contato linear e depois foi inserida a força de resistência ao rolamento.

Experimentos reais foram realizados na segunda parte do trabalho. Foi usado um evento de queda de bloco já ocorrido, na BR 116, para análise das modelagens; foram realizadas simulações com dados do local em ambos os modelos de simulação, a fim de compará-los, também analisando os efeitos do impacto de queda de blocos na rodovia local. Um estudo dos impactos da queda de blocos em uma área rochosa no município de Petrópolis, no bairro da Glória, também foi feito, utilizando ambos os modelos.

Por fim, foram realizadas simulação para analisar o efeito da presença de árvores nos desvios de trajetória e na perda de energia cinética dos blocos de rocha.

\section{1}

\section{Comparações entre os modelos de RAMMS x PFC3D}

$\mathrm{Na}$ primeira parte do trabalho foram feitas análises comparativas através de simulações simples entre os dois modelos. Foram criadas superfícies com inclinações de 37 e 50 graus e blocos de diferentes geometrias foram lançados de uma determinada altura (Figuras 3.1 e 3.2).

Em ambos os modelos, parâmetros foram variados para que fosse possível comparar a distância percorrida pelos blocos. No software RAMMS, o tipo de terreno foi sendo alterado e enquanto no PFC3D, o coeficiente de restituição normal foi alterado. 
Quando o terreno é alterado no software RAMMS, dois parâmetros mudam no modelo de contato, o coeficiente de atrito e o coeficiente de arraste, que determina a força de arraste do solo no bloco devido a suas propriedades viscoplásticas. A fim de comparar os modelos e obter uma relação entre seus parâmetros, foi utilizado o coeficiente de arraste, sendo um parâmetro de mais simples manejo e também por afetar diretamente a perda de energia do sistema.

No programa PFC3D, nos primeiros experimentos o modelo linear foi adotado para a comparação com o software RAMMS. As análises foram realizadas variando o coeficiente de restituição normal. No simulador PFC3D, altera-se a taxa do amortecedor crítico normal $\beta_{n}$, para que o coeficiente de restituição seja alterado, a relação foi dada pela equação (2.15).

Após as simulações usando o modelo linear, observou-se a necessidade de inserir um mecanismo de perda de energia, além do amortecimento normal e tangencial, para que o bloco conseguisse perder parte da sua energia cinética enquanto estivesse rolando. Foi então utilizado o modelo linear com uma resistência ao rolamento. Nestas simulações, o coeficiente de restituição, tanto normal quanto tangencial foram mantidos iguais a 0 , ou seja, toda a energia foi perdida durante $o$ impacto. Variou-se o coeficiente de resistência ao rolamento, o qual afeta o acréscimo da resistência ao rolamento durante o rolamento do bloco.

Após todas as simulações foram relizadas análises dos resultados através de gráficos de dois eixos, para que fosse feita uma análise dos parâmetros dos dois modelos com o alcance dos blocos. No modelo linear, plotou-se o coeficiente de arraste versus o alcance do bloco para as simulações do software RAMMS e coeficiente de restituição versus alcance para o programa PFC3D. E no modelo linear com resistência ao rolamento foi plotado para o software RAMMS o coeficiente arraste versus distancia, e para o modelo do PFC3D o coeficiente de resistência ao rolamento versus o alcance. 


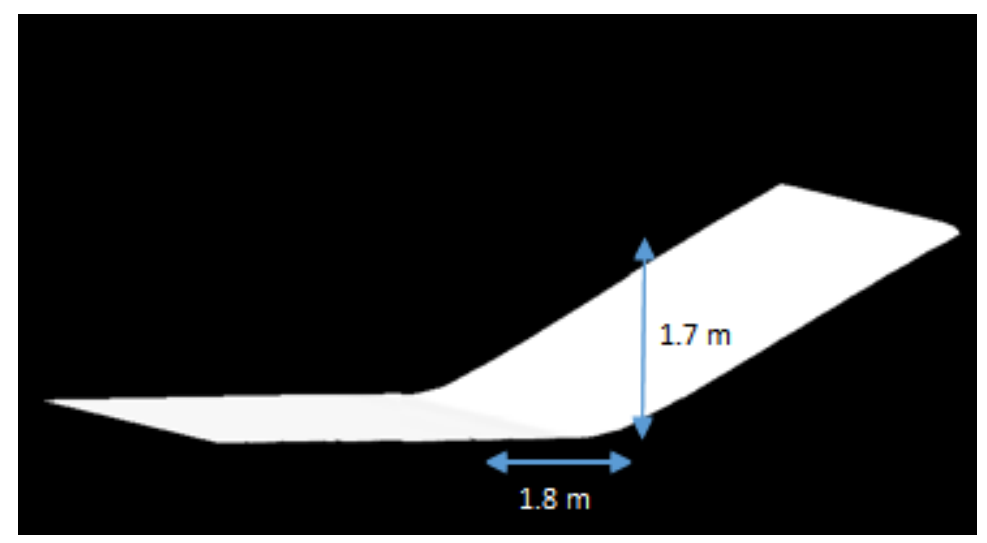

Figura 3.1 - Superfície de $37^{\circ}$ e posição de lançamento dos blocos.

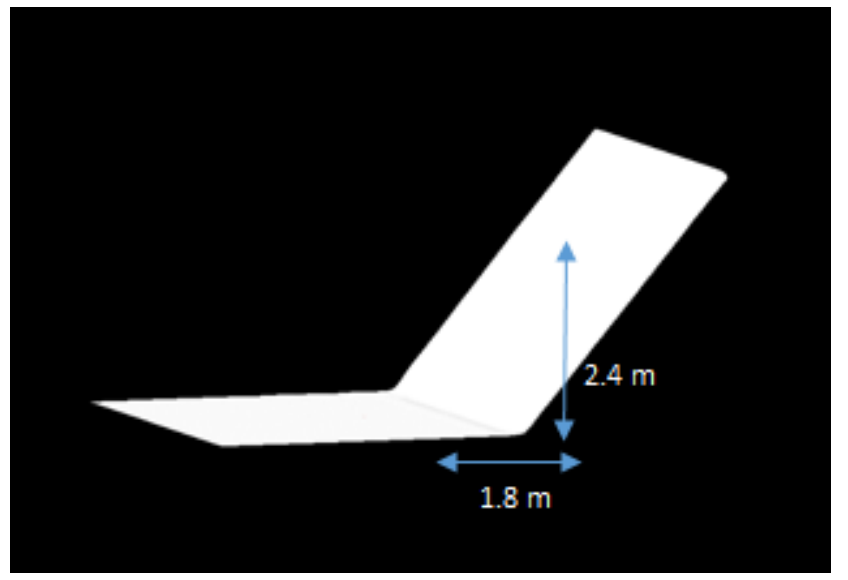

Figura 3.2 - Superfície de $50^{\circ}$ e posição de lançamento dos blocos.

\subsection{1}

\section{Simulação no RAMMS}

Para a simulação no software RAMMS foi necessária a obtenção dos seguintes dados de entrada. Primeiro a topografia do terreno, onde foi preciso obter as coordenadas e as altitudes do terreno a fim de obter a topografia tridimensional, e depois convertê-la para o formato ESRI, formato aceito pelo software. O software possui um banco de dados com pontos nas nuvens para a criação de blocos rochosos.

O terreno foi criado com a ajuda do software Arcgis. A geometria foi dada a partir de polilinhas e polígonos, para determinar os limites e altitude da superfície (Figura 3.3). O raster foi criado através de uma ferramenta de conversão dentro do próprio software. Raster consiste em uma matriz de pontos, usado muito em computação gráfica, que representa uma grade retangular de pixel ou pontos de cor. 
E assim, o raster foi transformado em ESRI dentro do próprio programa (figura $3.4)$.
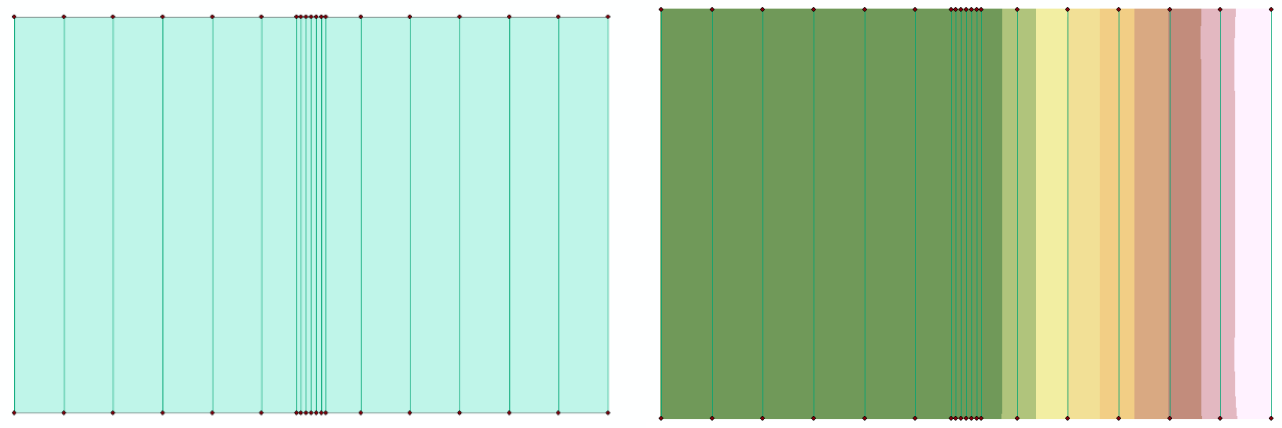

Figura 3.3 - Modelagem do terreno no Arcgis.

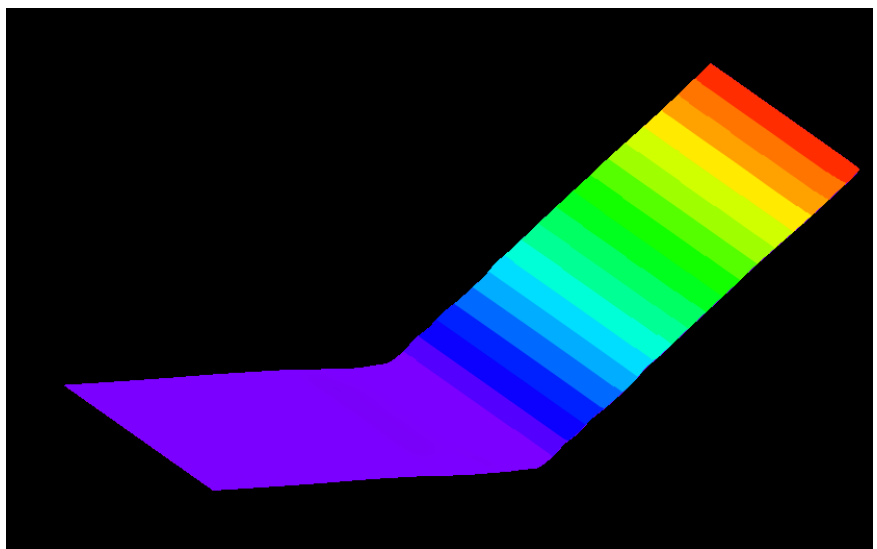

Figura 3.4 - Terreno inserido no software RAMMS.

Foram utilizados três tipos de blocos, diferenciando-se pela geometria, sendo uma com dimensões mais regulares (equant), outra mais alongada (long) e uma última mais achatada (platy) (Figura 3.5). Os formatos das rochas já estavam disponíveis no banco de dados do programa.

Para testes de barreiras para proteção de queda de blocos, é comum usar uma rocha de formato padrão, ignorando os diferentes formatos (Gerber, 2001); esta é uma aproximação aceita na prática como meio de proteção a queda de blocos, o que acaba negligenciando a possibilidade de a geometria dos blocos terem uma forte influência no impacto nessas barreiras e na trajetória.

Vários estudos, quanto a classificação das geometrias dos blocos, foram realizados (Krumbein, 1941; Wentworth, 1922; Krumbein, 1941; Sneed and Folk, 1958; Blott e Pye, 2008). Sneed e Folk (1958) argumentaram que a medida dos três principais eixos é a melhor forma de representar os blocos. Surgindo as geometrias que são usadas na simulação. 

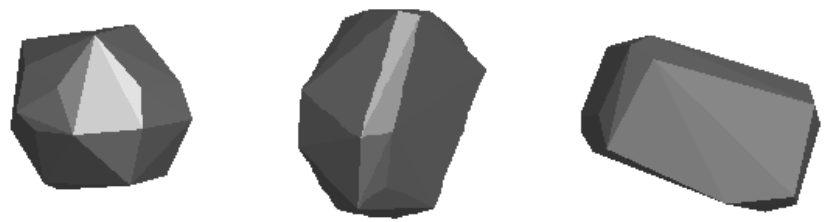

Figura 3.5 - Rocha equant, rocha long e rocha platy.

Assim as simulações foram feitas da seguinte forma. Primeiro foi determinado o terreno no qual o experimento ocorreria. Por exemplo, primeiro foi escolhido o terreno inclinado em $37^{\circ}$. Depois foi escolhida a geometria do bloco, o primeiro testado foi o bloco de geometria equant. Selecionando em seguida o tipo de solo, sendo o primeiro tipo o extra soft. O bloco era lançado de 50 diferentes posições iniciais, com seu eixo de simetria girado de forma aleatória.

Estes passos foram repetidos várias vezes, até completar as duas inclinações, os três diferentes tipos de geometria e todos os tipos de solos. Resultando em um total de 2100 trajetórias. Após todas as simulações foram gerados arquivos em formato de texto para cada bloco, contendo a posição em todas as coordenadas de cada bloco.

A figura 3.6 ilustra todos os procedimentos realizados para a realização das simulações no software RAMMS. 


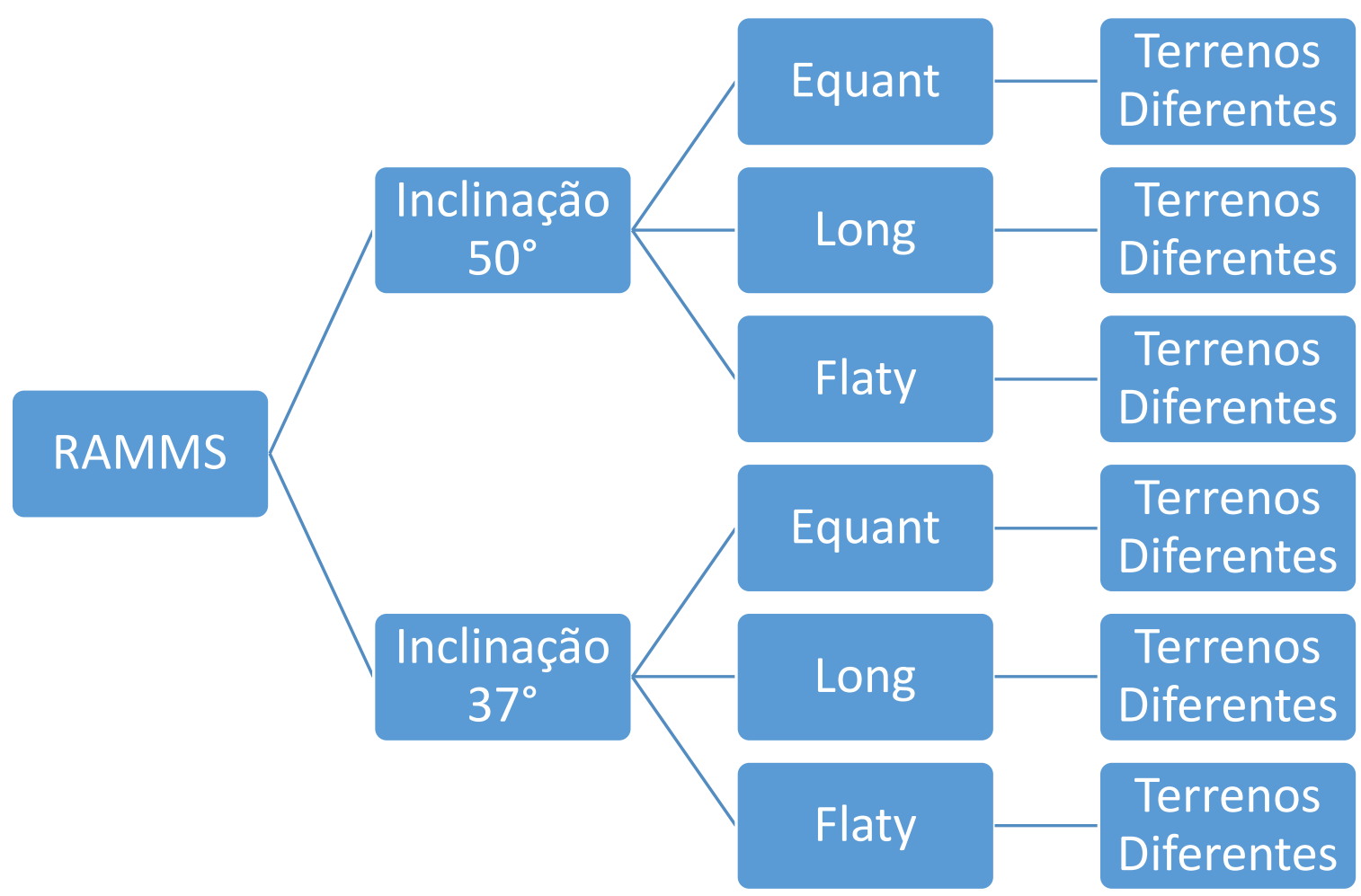

Figura 3.6 - Procedimentos para a realização das simulações de queda de blocos no software RAMMS.

\subsection{2 \\ Simulação no PFC3D}

No método dos elementos discretos foi utilizado o software PFC3D para a simulação. Primeiro determinou-se as paredes através das coordenadas e altitudes dos seus vértices. Depois, os blocos foram construídos a partir das diferentes geometrias definidas. Para a simulação foi desenvolvido um código no programa de simulação PFC3D, onde foram definidos os parâmetros e o modelo de contato.

A superfície inclinada (Figura 3.7) foi criada através de um comando onde era necessário inserir as coordenadas dos vertícies das superfícies. Com os vértices definidos, foram criadas faces triangulares, gerando assim paredes do formato desejado, no caso, superfícies inclinadas de $37^{\circ}$ e $50^{\circ}$. 


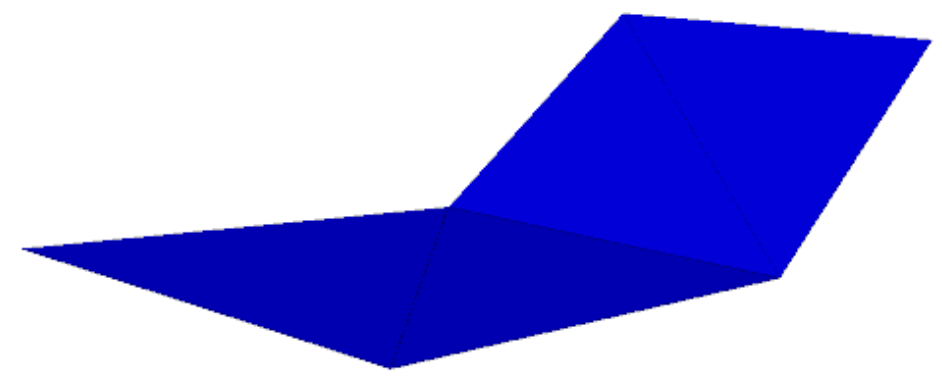

Figura 3.7 - Parede criada no programa PFC3D

Os blocos utilizados no programa possuem praticamente as mesmas características que o do simulador RAMMS. Com pequenas alterações devido a diferença de criação entre os dois modelos.

A partir dos pontos nas nuvens dos blocos já definidos pelo software RAMMS, foram criados os blocos no PFC3D. Com os pontos já determinados foram construídas as arestas exteriores da rocha usando um algoritmo de casca convexo. Através desse algoritmo foram criadas as paredes do bloco, formando a geometria da rocha. Por final, um conjunto de partículas foi inserido dentro das paredes que delimitam a geometria do bloco (Figura 3.8) através de uma ferramenta disponível no PFC3D, chamada de bubblepack. Consiste em um algoritmo desenvolvido por Taghavi (2011), onde as partículas são geradas dentro de paredes definidas no programa de uma maneira ótima, gerando uma aproximação do eixo médio.
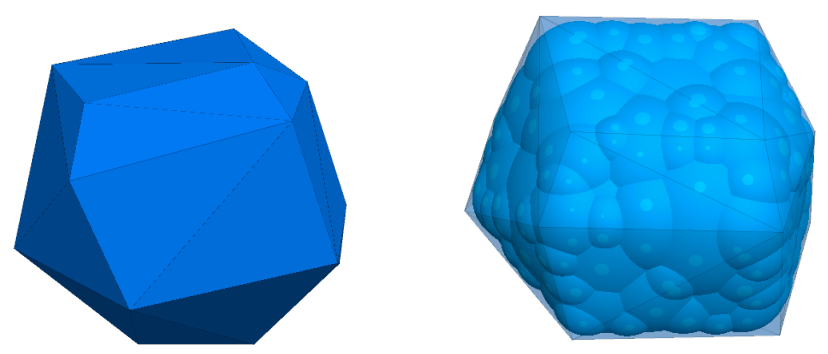

Figura 3.8 - Blocos criados por bubblepack.

A tabela 3.1 mostra os valores atribuídos aos parâmetros do modelo linear para que a simulação ocorresse, os valores das rigidezes normal e tangencial foram adotados segundo Rechefeu (2016), já que apresentou uma certa estabilidade na simulação, sendo que esses parâmetros não pareceram influenciar 
significativamente o funcionamento do processo de queda de blocos. Outro fator que foi modificado nas simulações foi a orientação inicial do bloco. Para cada lançamento foram realizadas dez simulações, cada uma com uma orientação diferente, definida de forma aleatória, girando o bloco em torno do seu eixo principal.

Tabela 3.1 - Valores dos parâmetros de contato.

\begin{tabular}{|l|c|}
\hline \multicolumn{2}{|l|}{ Valores adotados no Modelo Linear } \\
\hline Rigidez Normal: & $10^{8}$ \\
\hline Rigidez Tangencial: & $10^{8}$ \\
\hline Coeficiente de atrito: & 0.577 \\
\hline Amortecedor tangencial: & 1 \\
\hline
\end{tabular}

Na primeira parte das simulações a parametrização foi feita usando o modelo Linear. Primeiro determinou-se a inclinação da topografia. Em seguida, foi escolhida a geometria do bloco e o coeficiente de restituição. Este experimento foi realizado para dez diferentes orientações iniciais do bloco, que era girado de forma aleatória.

Este procedimento foi, então, realizado para todas inclinações do terreno, todas as geometrias definidas e para diferentes valores de coeficiente de restituição. Gerando um total de 420 simulações.

Por final, este mesmo procedimento foi realizado para o método linear com resistência ao rolamento, mas variou-se o coeficiente de resistência ao rolamento. Resultando em mais 420 simulações, totalizando 840 trajetórias no final. Todas as trajetórias foram exportadas em arquivos de texto para que fossem determinados seu alcance a fim de comparação.

A figura 3.9 ilustra os procedimentos para a simulação da queda de blocos realizados nesta primeira fase através do PFC3D. 


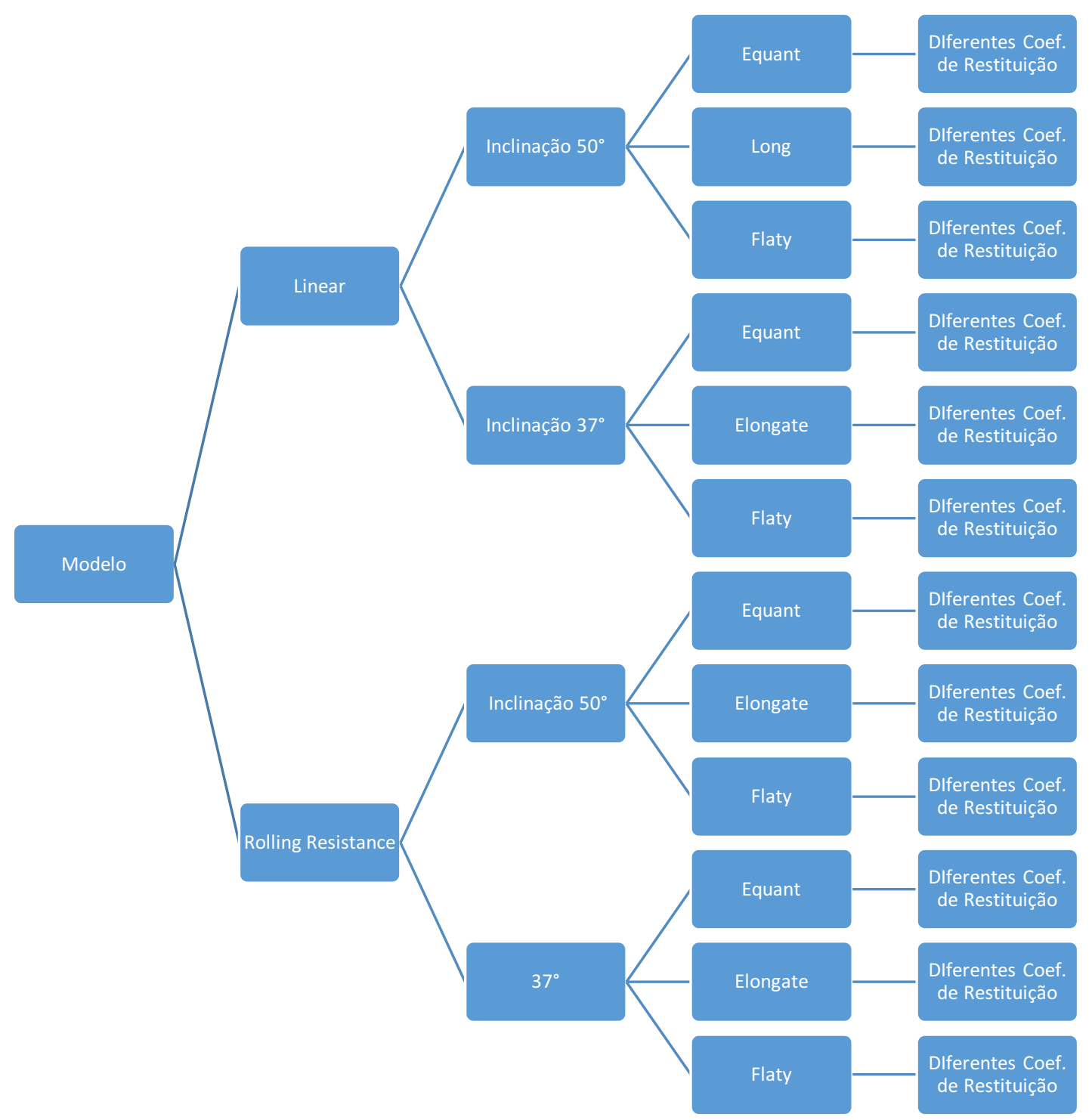

Figura 3.9 - Procedimentos para a realização das simulações de queda de blocos no modelo de elementos discretos.

\section{2}

\section{Análise de Queda de Blocos na BR 116}

A rodovia BR 116 se encontra no estado do Rio de Janeiro e liga os municípios de Magé e Teresópolis, atravessando a Serra do Mar. Houve desafios quanto a sua implementação, já que ela se encontra em um local de relevo acidentado, o que exigiu modificações significativas na topografia através de cortes no solo e rocha, deixando a região mais susceptível a desastres naturais.

O trecho entre os quilômetros 89 e 90 está muito susceptível a queda de bloco (Figura 3.10), o que acaba colocando em risco a vida de usuários dessa estrada. Este trecho possui cerca de 600 metros de extensão, sendo que sua parte inferior se 
encontra em uma altitude próxima a 820 metros e a superior se encontra próxima à altitude de 1290 metros, havendo um desnível de cerca de 470 metros.

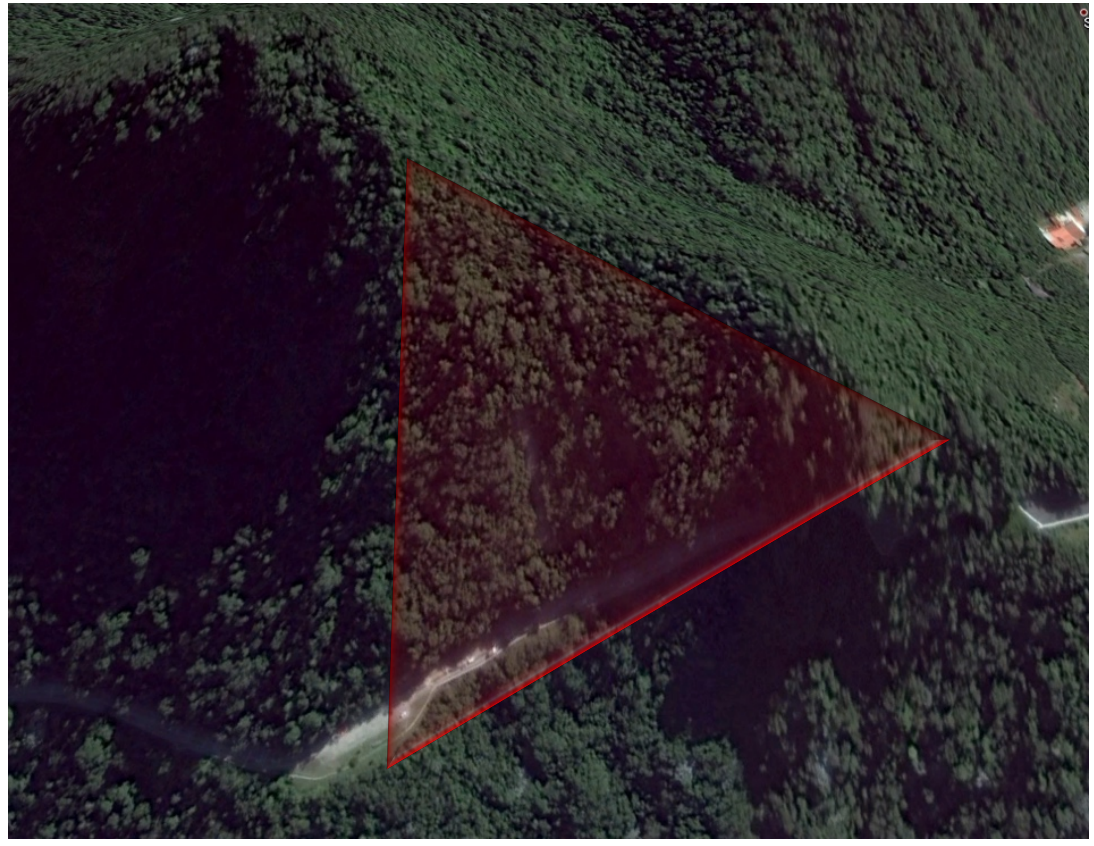

Figura 3.10 - Região susceptível a desastres naturais (Google Maps).

Na figura 3.11 é possível notar a cicatriz deixada pelo deslizamento que ocorreu na região em 2009. Este deslizamento consistiu na ruptura de uma camada fina de solo, que cobria uma camada rochosa. O deslizamento acarretou na queda de numerosos blocos, levando à morte de três pessoas que passavam pelo local.
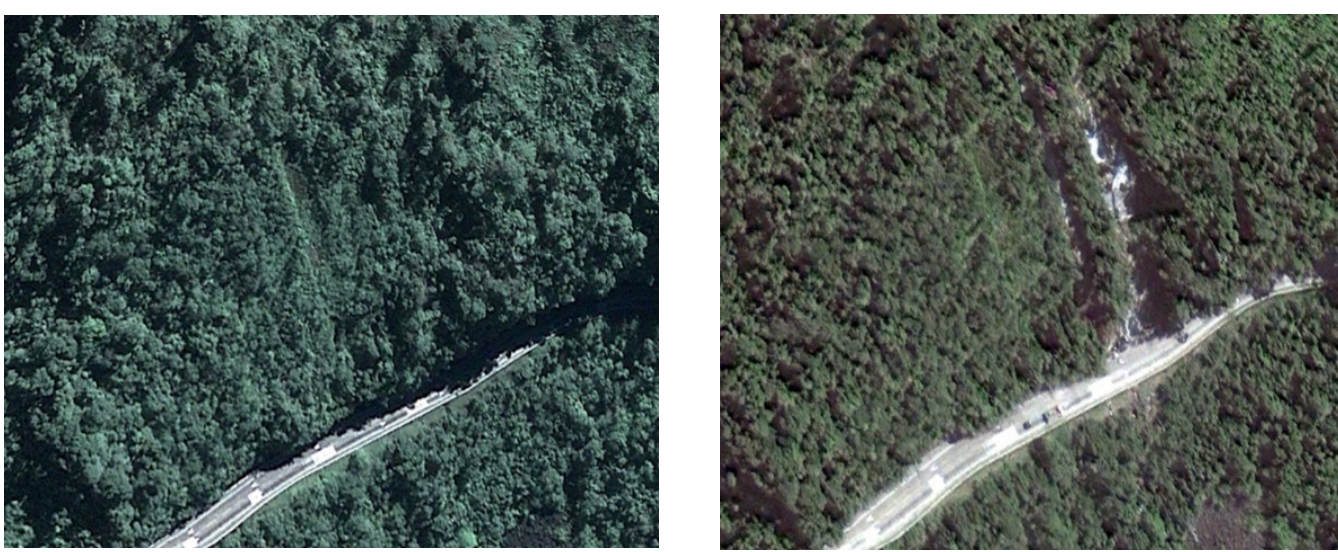

Figura 3.11 - Cicatriz deixada pelo deslizamento, antes (2009) e depois (2011) (Google Maps).

A análise numérica permite analisar a trajetória a qual o bloco percorre, assim como a energia cinética máxima alcançada por ele, sendo possível determinar qual o tipo de barreira de impacto pode ser utilizado para proteção da estrada. 
O levantamento da topografia da região foi realizado pela Concessionária Rio Teresópolis (CRT) em 2009 (Figura 3.12), entre os quilômetros 89 e 90 da BR 116. Este trecho se encontra no setor médio da rodovia e apresenta um segmento de alta declividade. Possui um solo muito raso (0,5 a 1,0 metro), caracterizado como saprolito. Formado através de depósitos antigos, apresentando exposições de afloramentos rochosos.

O estudo sobre a caracterização do local foi de alta dificuldade, devido à vegetação densa (floresta típica de mata Atlântica) a caracterização foi realizada em uma faixa ao longo da rodovia.

A petrografia da região é caracterizada por rochas metamórfica e ígneas, compostas de migmatito, contendo paleossoma/melanossoma de biotita-gnaise, anfibolitos e leptinitos, e nossoma/leuossoma de rocha gratinóide com granulometria fina a média (DRM 1980 apud CRT, 2009)

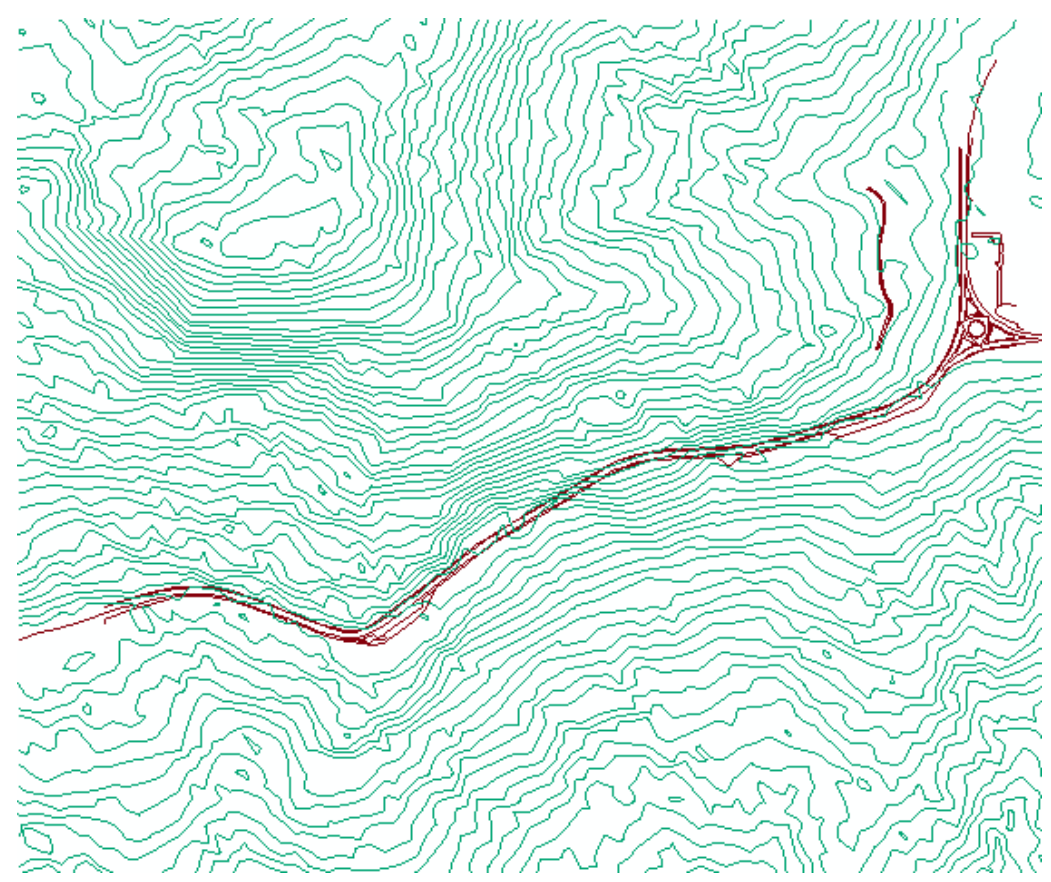

Figura 3.12 - Curvas de Nível BR 116.

Os blocos foram definidos de acordo com as rochas encontradas na região após o desastre. Foram realizadas aberturas no local para que fossem realizados os primeiros estudos topográficos. No trecho foram encontrados blocos de diferentes dimensões, variando entre os volumes de $0.5 \mathrm{mx} 0.5 \mathrm{mx} 0.5 \mathrm{~m}$ a $2 \mathrm{~m} \times 2 \mathrm{~m} \times 8 \mathrm{~m}$ (Villella 2011). As simulações foram realizadas com os blocos de maiores dimensões, já que 
eles causam um maior impacto, e em dois formatos geométricos (tabela 3.2), um mais longo e outro menos alongado.

Tabela 3.2 - Dimensões das rochas.

\begin{tabular}{|c|c|c|}
\hline & Rocha 1 & Rocha 2 \\
\hline Dimensões $(\mathrm{mxm \times m}):$ & $1.92 \times 1.92 \times 1.92$ & $5.19 \times 3.11 \times 2.6$ \\
\hline Massa Específica $\left(\mathrm{kg} / \mathrm{m}^{3}\right):$ & 2700 & 2700 \\
\hline
\end{tabular}

O ponto inicial da cicatriz do deslizamento foi definido como o ponto de lançamento dos blocos. Foi determinada a área atingida pelos blocos e a energia cinética total dos blocos na rodovia.

\subsection{1}

\section{Simulação no RAMMS}

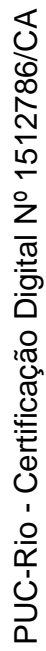

Foi determinada a área de influência da queda de acordo com a cicatriz deixada pelo bloco, e assim, foi obtida a topografia tridimensional a partir da ferramenta de conversão do Arcgis (Figura 3.13). O solo foi determinado como medium hard, já que ele possui uma camada de solo pouco profunda. Os blocos rochosos foram definidos através do banco de dados do programa respeitando a geometria definida anteriormente.
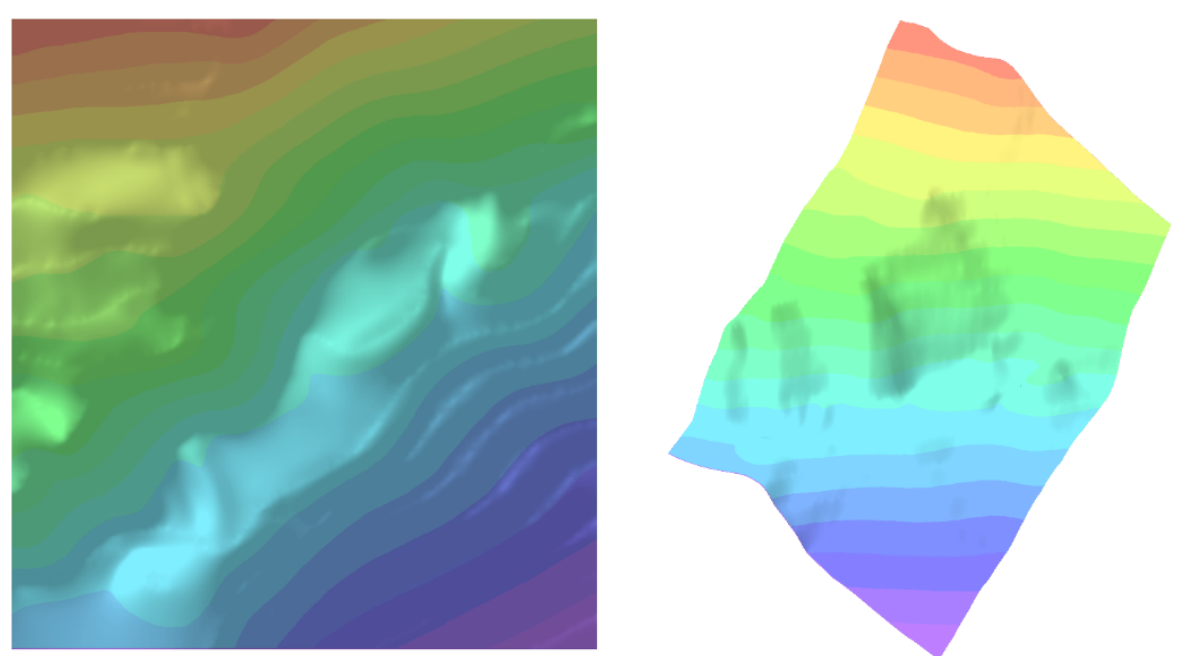

Figura 3.13 - Topografia da BR116 no software RAMMS. 


\subsection{2 \\ Simulação no PFC3D}

Para a transformação da topografia para seu uso no PFC3D também foi utilizado o Arcgis. Já que o PFC3D trabalha com superfícies triangulares, foi necessário obter as coordenadas de cada vértice dos triângulos que iriam compor a superfície.

Inicialmente, pontos foram criados num plano horizontal sob a superfície, formando quadrados. Em seguida, para cada ponto foram obtidas as coordenadas $\mathrm{x}$, y e $\mathrm{z}$ através da ferramenta de extração. Com cada vértice definido, o passo seguinte consistiu em exportar os dados em um arquivo Excel, contendo todos os pontos com suas respectivas coordenadas e altitudes. Por fim, foi criado um algoritmo para que fosse possível determinar a sequência de triângulo que forma a topografia final (Figura 3.14). Os blocos foram obtidos através do procedimento detalhado no item 3.1.2 respseitando a geometrias das rochas encontradas no local.
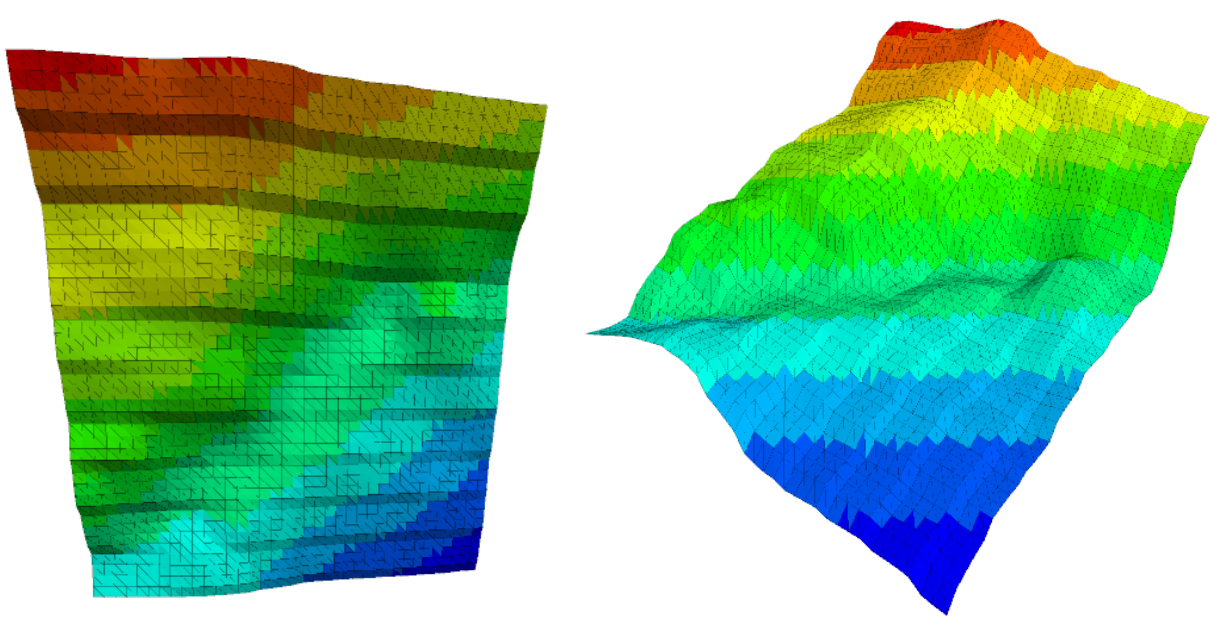

Figura 3.14 - Topografia tridimensional da BR116 no PFC3D.

\section{3}

\section{Análise dos Blocos Susceptíveis a Queda no Município de Petrópolis}

O mapeamento geotécnico da região foi realizado por Ribeiro (2013). Para sua realização foi necessário um levantamento topográfico do local feita pela CERJ/MONTREAL, imagem satélite do google earth de 2010 e equipamento para o levantamento através da técnica DGPS. A imagem aérea tem por finalidade a atualização e adição de construções mais recentes. 
Para o levantamento topográfico do terreno foi necessária a identificação da estação geodésica do IBGE mais próxima da área de interesse. A partir desta base foram obtidas as coordenadas seguintes.

O mapeamento geológico-geotécnico na região foi feito na escala 1:1000, seguindo as recomendações da IAEG (1976), de onde as informações sobre as unidades geotécnicas foram obtidas. As diferenciações da superfície são de muita importância, já que elas que vão definir o valor dos parâmetros que serão adotados.

Foi determinada também a curva granulométrica, limites de plasticidade e liquidez para a classificação do solo quanto ao Sistema de Classificação de Solos (SUCS), através de ensaios em amostras retiradas do campo (Ribeiro, 2013).

Foram coletados blocos de rocha para que ensaios de compressão simples e tilt test fossem realizados, e também para determinar a massa específica e caracterização megacóspica e microscópica das amostras.

A partir dos pontos coletados foi possível criar o Modelo Digital do Terreno (Figura 3.15) através de interpolação de curvas de nível. As curvas de nível estão organizadas segundo uma diferença de 10 metros entres si.
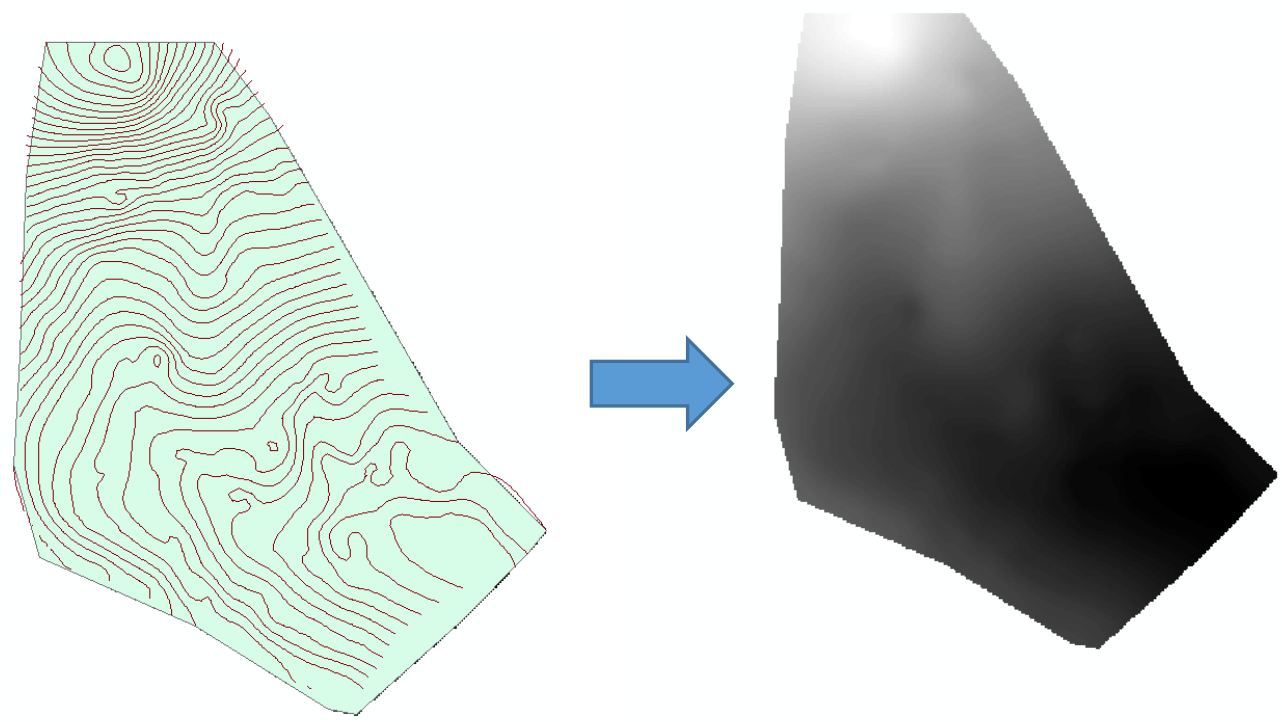

Figura 3.15 - Conversão das curvas de nível da topografia para o modelo tridimensional.

Com as curvas e os seus limites definidos, foi criado o mapa em 3D pelo mesmo processo que descrito no item 3.1.1. Na topografia de Petrópolis, através da caracterização do solo foram definidas regiões com diferentes características. A topografia foi dividida em três regiões. Uma região de característica rochosa, outra identificada pelo depósito de tálus e por último o solo residual. 
Com a divisão das regiões por características do solo, foi preciso delimitar as coordenadas de cada região para que fosse possível aplicar as propriedades do modelo de contato no programa PFC3D.

Para fazer a simulação dos blocos foi necessário determinar blocos rochosos que tivessem uma possibilidade real de queda (Figura 3.16). E assim foram determinadas a dimensão e as coordenadas de cada bloco na fotografia aérea com as coordenadas do centro de cada esfera, onde também foram medidas as dimensões de cada bloco nas posições horizontal e vertical.

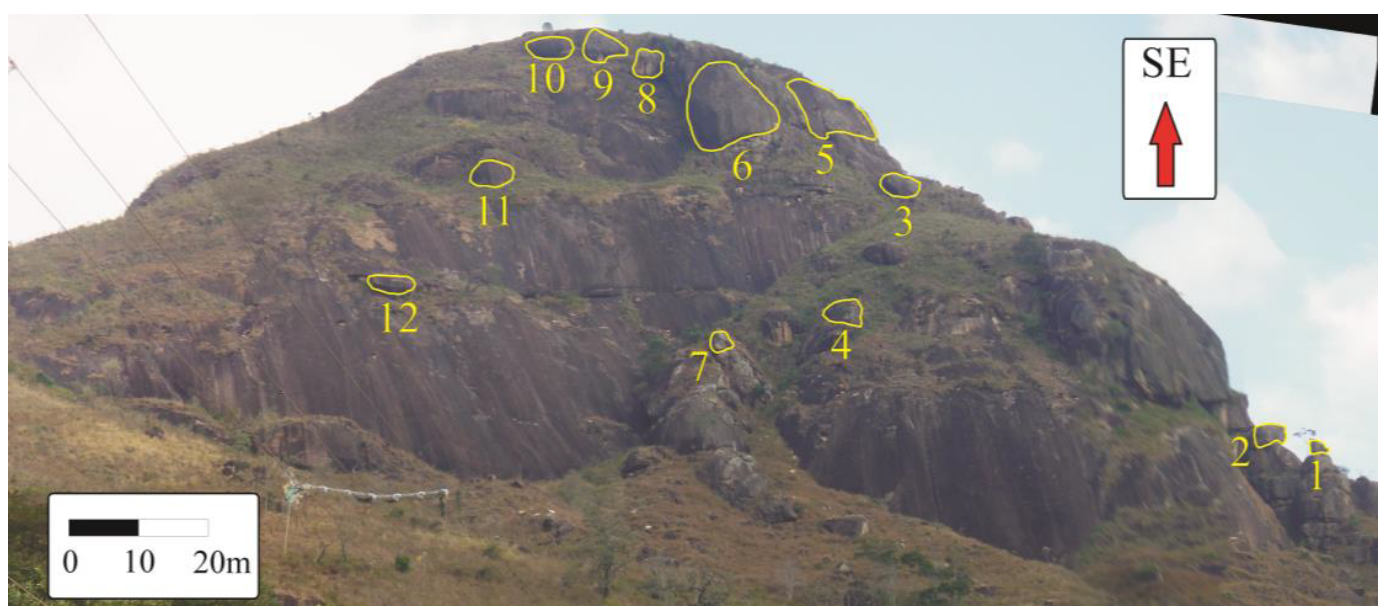

Figura 3.16 - Localização dos Blocos Susceptíveis a Queda.

No total foram identificados doze blocos, definindo suas coordenadas (tabela 33), em UTM, e também suas dimensões (tabela 3.4).

Tabela 3.3 - Coordenadas dos blocos (Ribeiro, 2013)

\begin{tabular}{|l|l|l|l|}
\hline \multirow{2}{*}{$\begin{array}{l}\text { No do } \\
\text { Bloco }\end{array}$} & \multicolumn{4}{|l}{ Coordenadas } & X & Y & Z \\
\hline 1 & 692086,10 & 7515255,79 & 1076,64 \\
\hline 2 & 692092,14 & 7515258,23 & 1075,58 \\
\hline 3 & 692188,79 & 7515135,76 & 1139,60 \\
\hline 4 & 692217,99 & 7515250,27 & 1088,76 \\
\hline 5 & 692210,85 & 7515095,16 & 1159,72 \\
\hline 6 & 692230,95 & 7515116,20 & 1156,19 \\
\hline 7 & 692234,74 & 7515256,14 & 1086,99 \\
\hline 8 & 692249,80 & 7515118,18 & 1158,37 \\
\hline 9 & 692259,66 & 7515112,16 & 1161,73 \\
\hline 10 & 692274,65 & 7515113,68 & 1162,37 \\
\hline 11 & 692292,02 & 7515208,47 & 1123,28 \\
\hline 12 & 692294,25 & 7515256,81 & 1097,78 \\
\hline
\end{tabular}


Tabela 3.4 - Dimensões dos blocos (Ribeiro, 2013)

\begin{tabular}{|l|l|l|l|l|l|}
\hline \multirow{2}{*}{ № do Bloco } & \multicolumn{2}{|l|}{ Diâmetro $(\mathrm{m})$} & \multirow{2}{*}{ Raio $(\mathrm{m})$} & $\begin{array}{l}\text { Volume } \\
\text { Aproximado } \\
\left(\mathrm{m}^{3}\right)\end{array}$ \\
\cline { 2 - 6 } & Horizontal & Vertical & Médio & & \\
\hline 1 & 3,9 & 5,7 & 4,8 & 2,40 & 57,5 \\
\hline 2 & 5,5 & 5,3 & 5,4 & 2,69 & 81,1 \\
\hline 3 & 11,4 & 12,4 & 11,9 & 5,96 & 885,7 \\
\hline 4 & 5,6 & 5,7 & 5,7 & 2,83 & 94,4 \\
\hline 5 & 25,2 & 23,8 & 24,5 & 12,26 & 7709,5 \\
\hline 6 & 23,3 & 20,1 & 21,7 & 10,85 & 5350,3 \\
\hline 7 & 8,0 & 6,1 & 7,1 & 3,53 & 183,5 \\
\hline 8 & 5,2 & 6,3 & 5,8 & 2,88 & 99,5 \\
\hline 9 & 5,5 & 8,8 & 7,2 & 3,58 & 191,4 \\
\hline 10 & 4,7 & 9,2 & 7,0 & 3,48 & 175,8 \\
\hline 11 & 11,1 & 10,4 & 10,8 & 5,38 & 650,5 \\
\hline 12 & 4,0 & 9,9 & 7,0 & 3,48 & 175,8 \\
\hline
\end{tabular}

\subsection{1}

\section{Simulação no RAMMS}

Para a simulação do caso no programa RAMMS foi necessário transformar a topografia e os blocos em formatos compatíveis com o software. O terreno tridimensional foi transformado para o formato ESRI (Figura 3.17) através de uma ferramenta de conversão dentro do programa Arcgis.

O terreno foi dividido de acordo com o tipo de solos caracterizado por Ribeiro (2013), para cada região foi inserido um tipo de solo diferente definido pelo software RAMMS. As regiões foram criadas em formato de shapefile e assim, importadas no software RAMMS (Figura 3.18). 


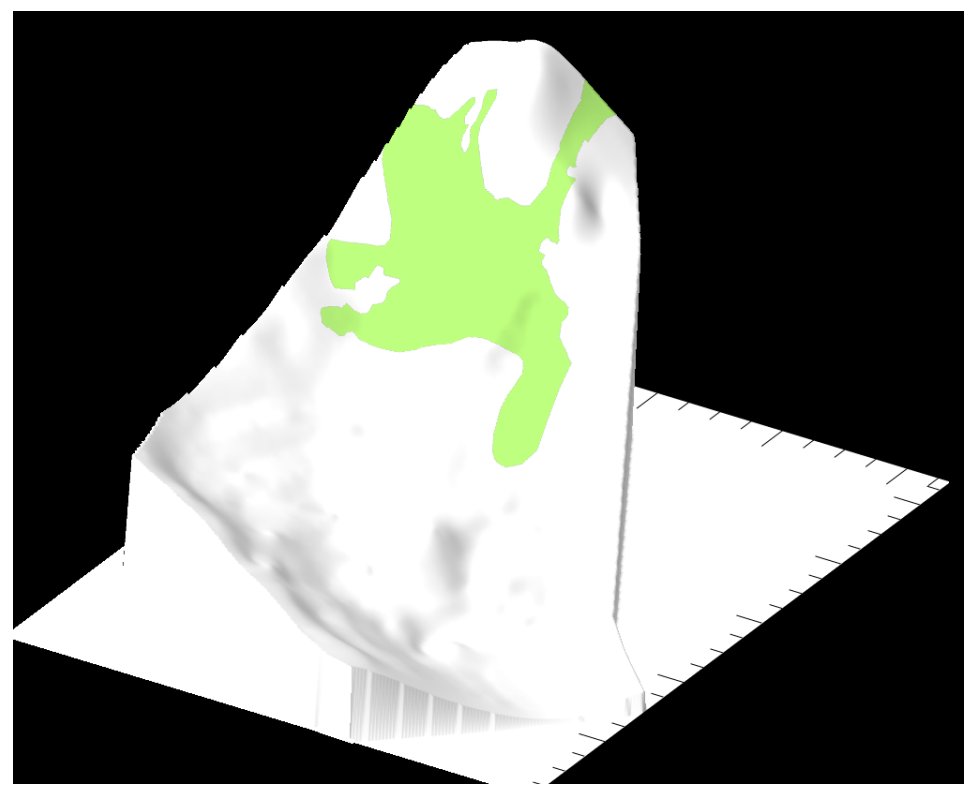

Figura 3.17 - Região de depósito de tálus definida no RAMMS

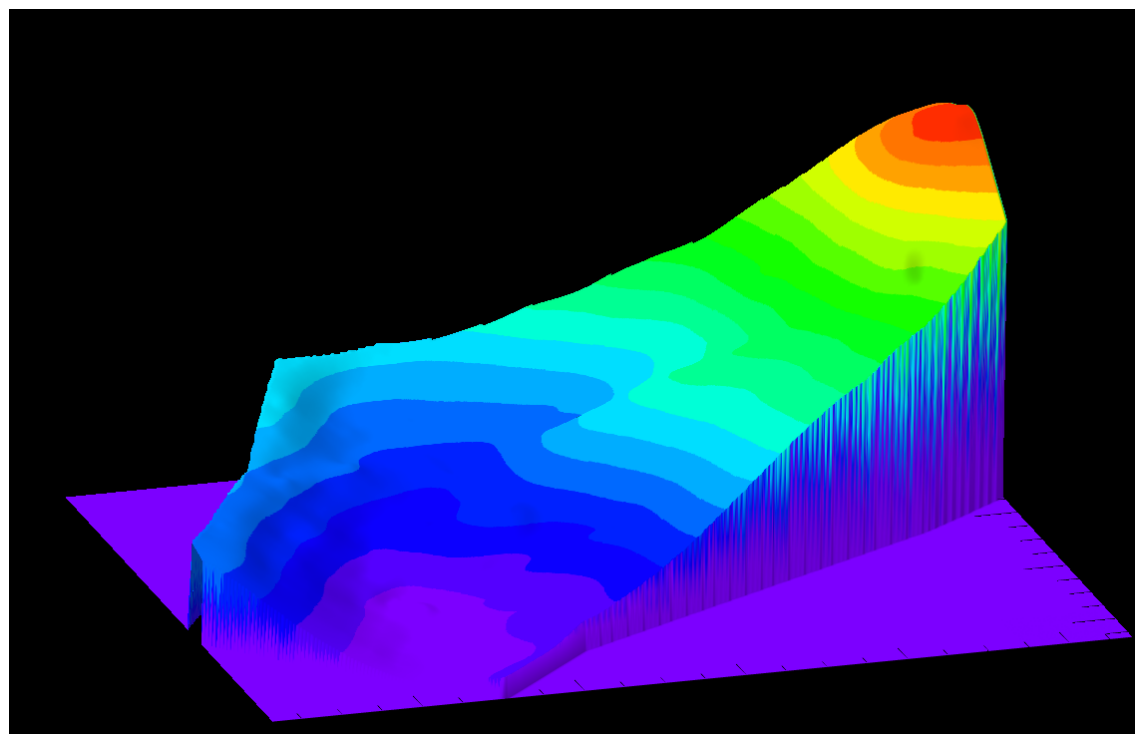

Figura 3.18 - Terreno no RAMMS.

A modelagem dos blocos foi feita respeitando as dimensões da tabela 3.3. De acordo com as dimensões em cada eixo do bloco foi determinada a geometria do bloco usada no programa, dentre elas equant, long e flat.

O software RAMMS simula somente blocos com volume máximo de $100 \mathrm{~m}^{3}$, como não foi possível simular o volume verdadeiro, foi mantida a massa original dos blocos. Variou-se a massa específica de acordo com o volume da rocha. A massa específica original dos blocos foi definida por Ribeiro (2013), sendo de 2700 $\mathrm{kg} / \mathrm{m}^{3}$. 
O movimento dos blocos se inicia devido somente a ação da gravidade, havendo perda de energia somente quando a rocha entra em contato com o solo.

\subsection{2}

\section{Simulação no PFC3D}

Para a transformação da topografia para seu uso no PFC3D também foi utilizado o Arcgis. A transformação foi realizada através do mesmo procedimento citado no caso da BR116, utilizando os pontos sob a topografia (Figura 3.19) e depois importando os triângulos para o PFC3D (Figura 3.20). Com a diferença de que neste caso, foi preciso definir as regiões para cada tipo de solo, para que assim, pudesse inserir as características do modelo de contato utilizado. A criação dos blocos rochosos obedeceu ao procedimento detalhado no item 3.1.2, usando as geometrias determinadas na região rochosa do bairro Glória.

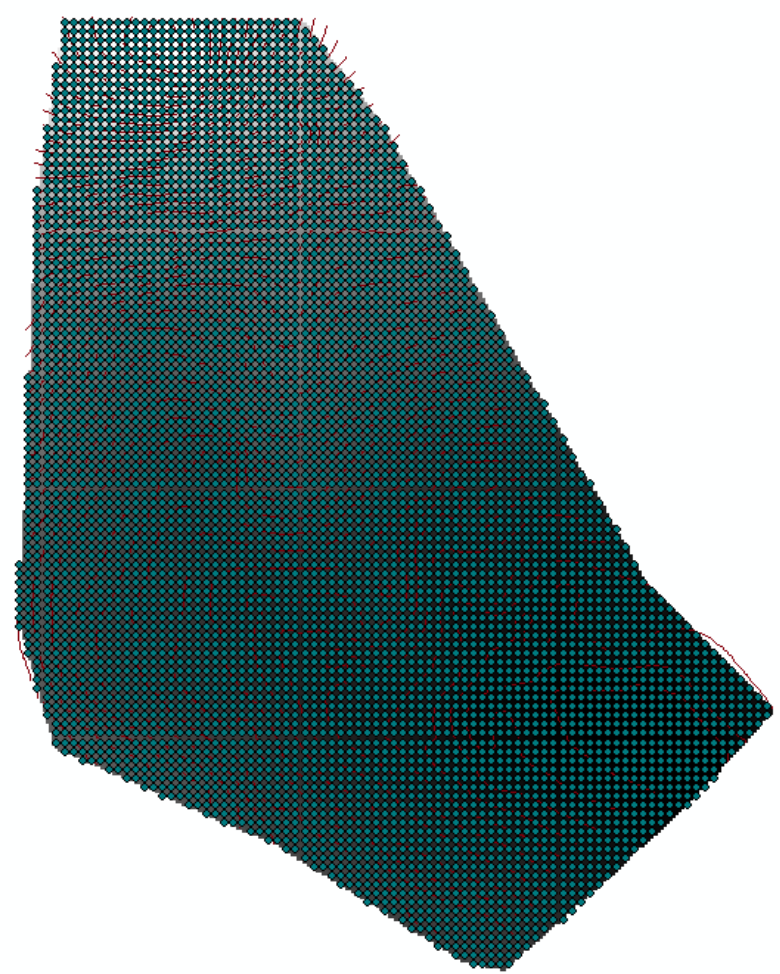

Figura 3.19 - Pontos inseridos na topografia. 


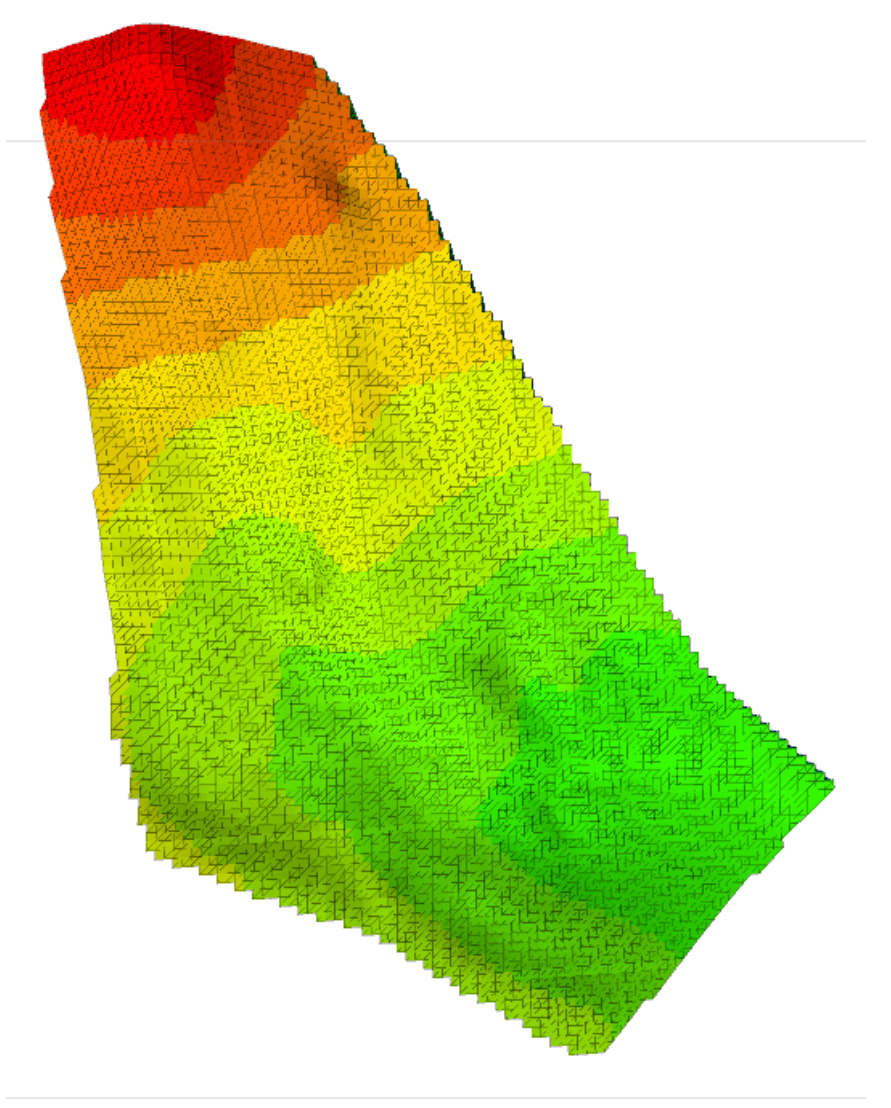

Figura 3.20 - Superfície formada por triângulos.

Foram realizados dois diferentes tipos de simulações no PFC3D, cada um com um modelo diferente. O primeiro modelo utilizado foi o linear, os valores dos parâmetros utilizados estão na tabela 3.4.

Na segunda parte foi utilizado o modelo linear com a resistência ao rolamento, onde os valores de atrito de resistência ao momento foram determinados através das comparações realizadas no tópico 3.1. Para cada terreno foi determinado um diferente coeficiente de resistência ao rolamento.

\section{4}

\section{O Efeito das Árvores em Queda de Blocos}

Uma importante condição aplicada para simular queda de blocos é o uso de florestas para retardar a distância percorrida por queda de blocos rochosos (Stoffel et al., 2006). As árvores são barreiras naturais, servem para dissipar energia através de impactos e ruptura de tronco de árvores (Johnsson, 2007). Tanto que pequenos blocos podem ser retidos por florestas se elas forem significativamente densas 
(Radtke et al, 2014). As árvores, através de suas cicatrizes, podem dar dicas de eventos de queda de blocos passados (Stoffel and Perret, 2006).

Uma única arvore dissipa energia de diferentes maneiras durante o impacto: rotação e translação pelo sistema radicular, deformação e oscilação através do tronco da árvore, e penetração local da rocha no local de impacto (Brauner et al, 2005; Dorren et al, 2006; Foetzki 2004).

\subsection{1}

\section{Simulação de Árvores como Blocos Rígidos no PFC3D}

Para a simulação foram criados modelos simples para analisar como as árvores podem afetar a trajetória da queda de blocos no modelo do PFC3D. A árvore foi representada por um cilindro preenchido por partículas (Figura 3.21), sendo indestrutíveis e fixas na superfície. Foram lançados blocos de rochosos de geometria equant em um plano inclinado de $50^{\circ}$. E árvores foram inseridas de modo que interferissem na distância percorrida pelo bloco (Figura 3.21).

Foram adotados modelos de contato linear para os impactos superfíciepartículas e partículas-partículas. Em ambos os casos o coeficiente de restituição adotado foi igual a 0 , havendo perda total de energia durante o impacto.

Foi realizada uma comparação dos eventos com e sem a presença de árvores. $\mathrm{O}$ alcance foi analisado, discutindo a trajetória, a zona de deposição e o efeito das árvores quanto a perda de energia cinética do sistema.
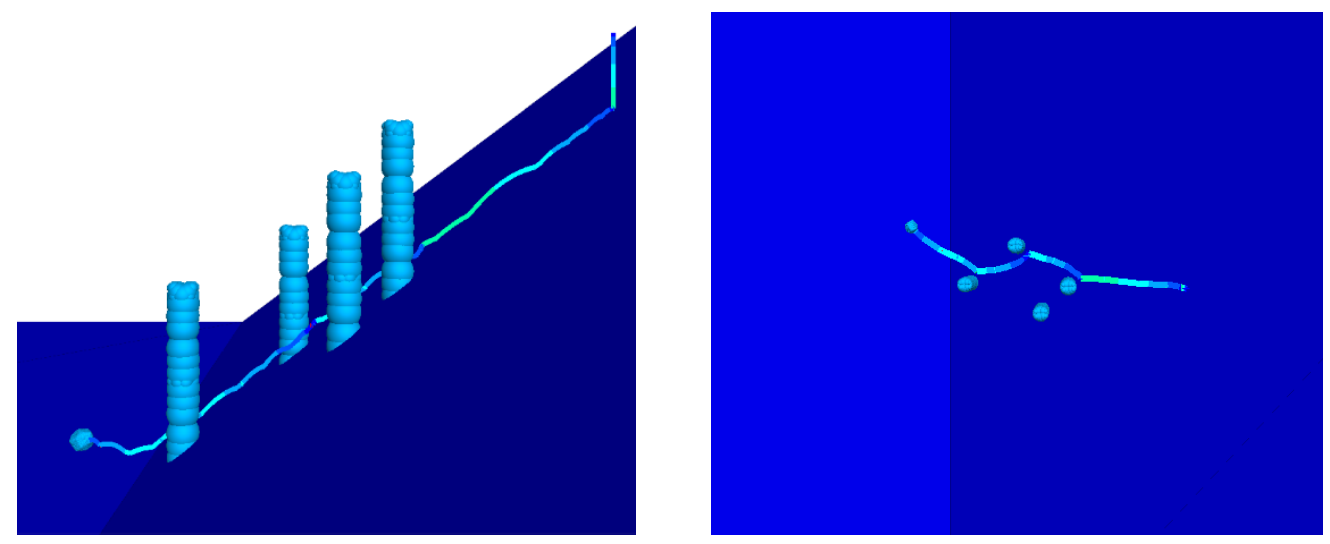

Figura 3.21 - Efeito de árvores em queda de blocos. 


\subsection{2 \\ Efeitos da Vegetação para Casos Reais no Estado do Rio de Janeiro através do Software RAMMS}

Para a simulação dos efeitos da vegetação no software RAMMS, um caso real foi usado como modelo. Para esta análise foram realizadas duas simulações, cada uma simulando uma característica diferente da encosta.

O caso adotado foi o de um deslizamento que ocorreu no munícipio de Petrópolis (Figura 3.22), o que acabou afetando residências mais próximas à encosta. O deslizamento acabou por retirar a vegetação superficial do solo, deixando somente a camada rochosa.

As simulações visam analisar os efeitos da presença de vegetação como um meio de dissipar a energia do sistema. Primeiro foram realizadas simulações com a presença de vegetação na base da encosta, e depois outra simulação sem a presença da vegetação.

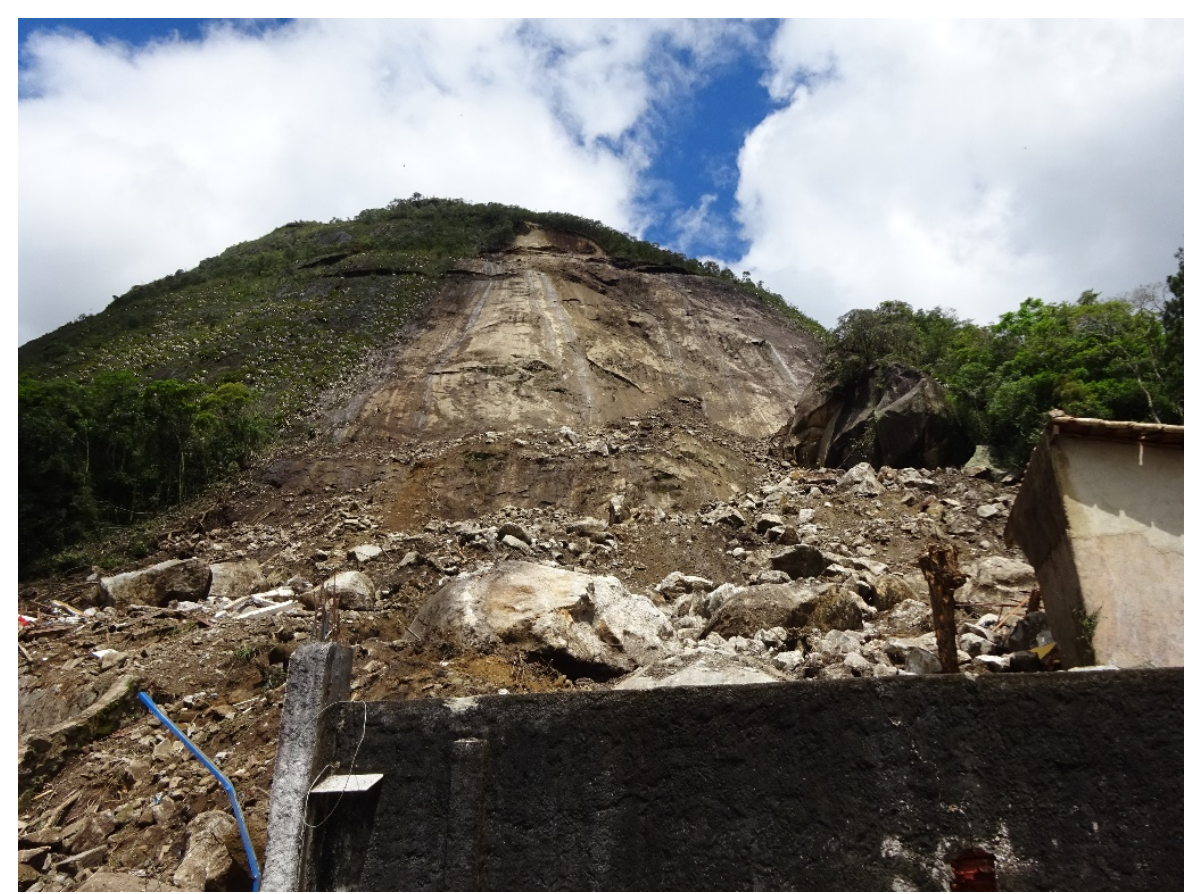

Figura 3.22 - Deslizamento no munícipio de Petrópolis.

O primeiro caso para a avaliação foi a de presença de vegetação mais próxima à superfície plana, onde se encontram as residências. Foi criada uma superfície com inclinação igual a 70 graus, devido à alta declividade do local, e em seguida foi determinada a região onde se encontra a vegetação, com o topo da enconsta rochoso. O esquema da superfície se encontra na figura 3.23. 


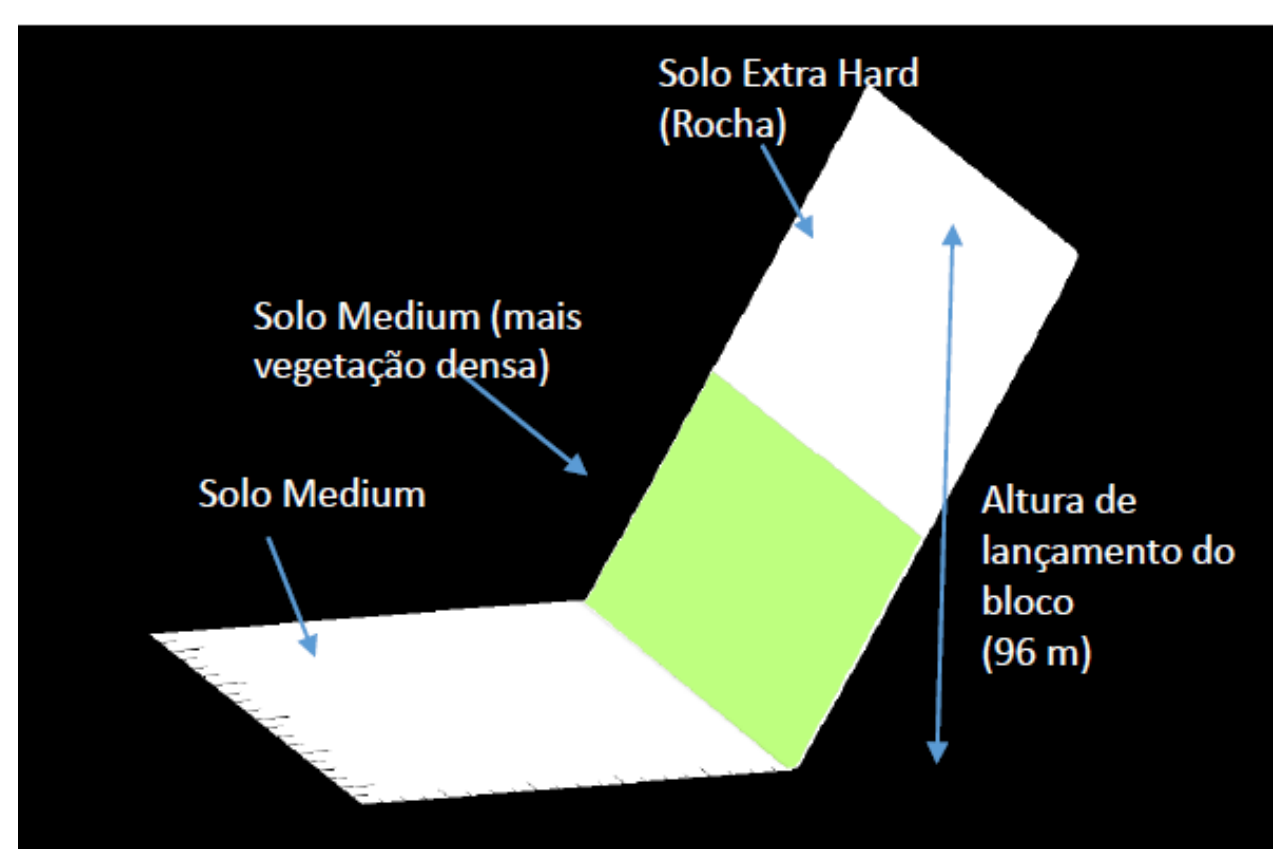

Figura 3.23 - Topografia com a presença de vegetação densa.

E por fim foram realizadas simulações sem a presença da vegetação (figura 3.24). Essa simulação visa analisar os efeitos da queda quando a vegetação é retirada do seu local natural, como aconteceu com o deslizamento, e também, como foi dito, para analisar com a simulação onde a vegetação foi inserida.

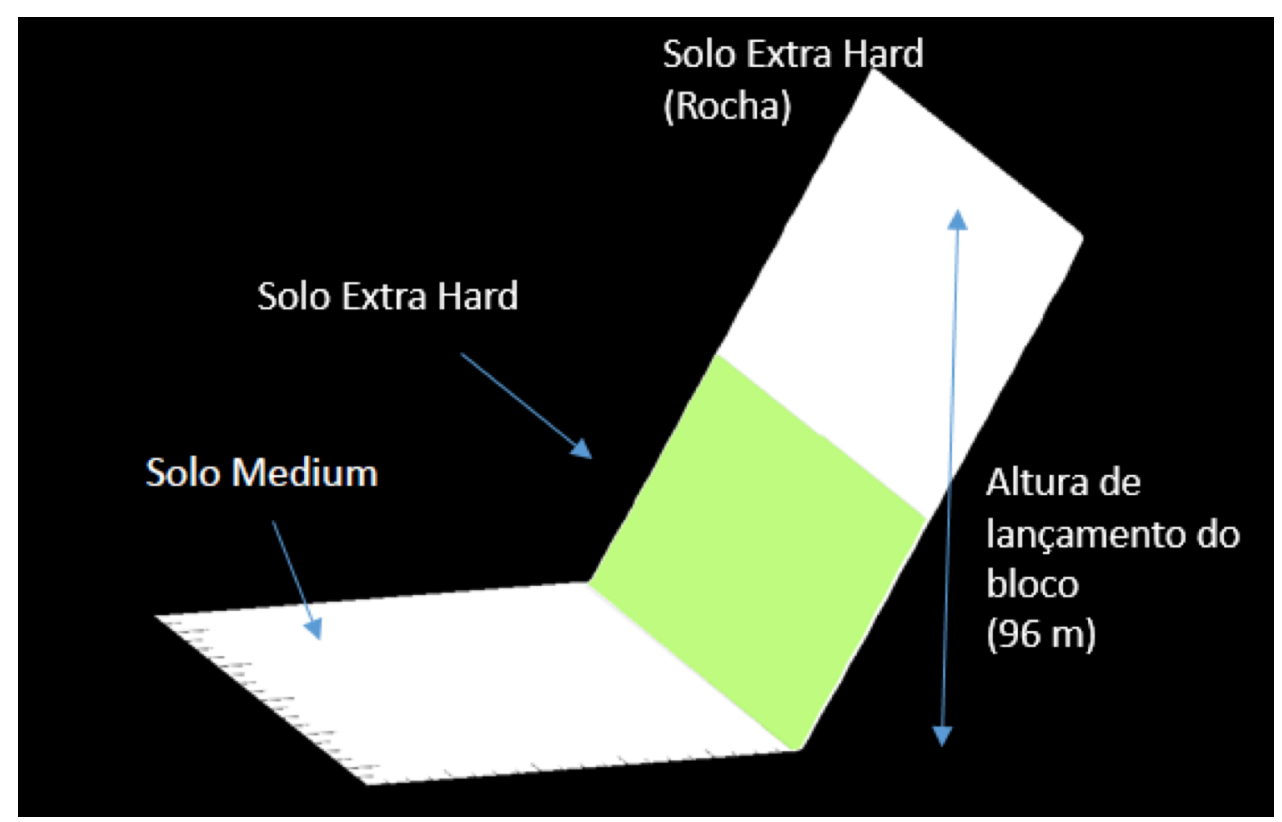

Figura 3.22 - Topografia sem a presença da vegetação.

Os blocos utilizados na simulação foram de geometria long, devido à presença de grande material rochoso mais alongados na base da encosta devido ao 
deslizamento. A massa específica das rochas utilizada foi de $2700 \mathrm{~kg} / \mathrm{m}^{3}$ e volume de $20 \mathrm{~m}^{3}$. 


\section{4 \\ Resultados e Discussões}

4.1

Considerações Iniciais

Neste capítulo serão apresentados os resultados dos experimentos propostos. A primeira parte consiste nos resultados comparativos entre os dois modelos utilizando superfícies simples e medindo o alcance. Depois foram realizados experimentos de casos reias, um na BR116 e outro no bairro Glória no município de Petrópolis. E no último item estão representados os resultados do efeito da vegetação através dos dois modelos.

\section{2}

\section{Análises comparativas entre o RAMMS e o PFC3D}

Os resultados da comparação estão dispostos da seguinte forma. Primeiro foram realizados experimentos utilizando somente o modelo linear para o método de elementos discretos, na segunda parte foi adicionado a resistência ao rolamento. Os gráficos possuem dois eixos verticais, o da esquerda com o coeficiente de arraste do software RAMMS e o direito com o coeficiente de restituição do modelo linear no PFC3D, quando adicionada a resistência ao rolamento o eixo da direita é representa o coeficiente de resistência ao rolamento.

\subsection{1}

\section{Modelo Linear}

\subsubsection{1}

\section{Plano incilinado em $37^{\circ}$}

A figura 4.1 mostra o alcance de blocos equant em um plano inclinado de $37^{\circ}$. No método de elementos discretos os blocos tendem a percorrer uma maior distância, ocorrendo uma menor perda de energia que no modelo do software RAMMS. No software RAMMS o bloco perde energia de uma forma mais rápida, alcançando menores distâncias. O valor do parâmetro no PFC3D, o coeficiente de 
restituição (equação 2.15), afeta o movimento do bloco mais efetivamente que o coeficiente de arraste no software RAMMS.

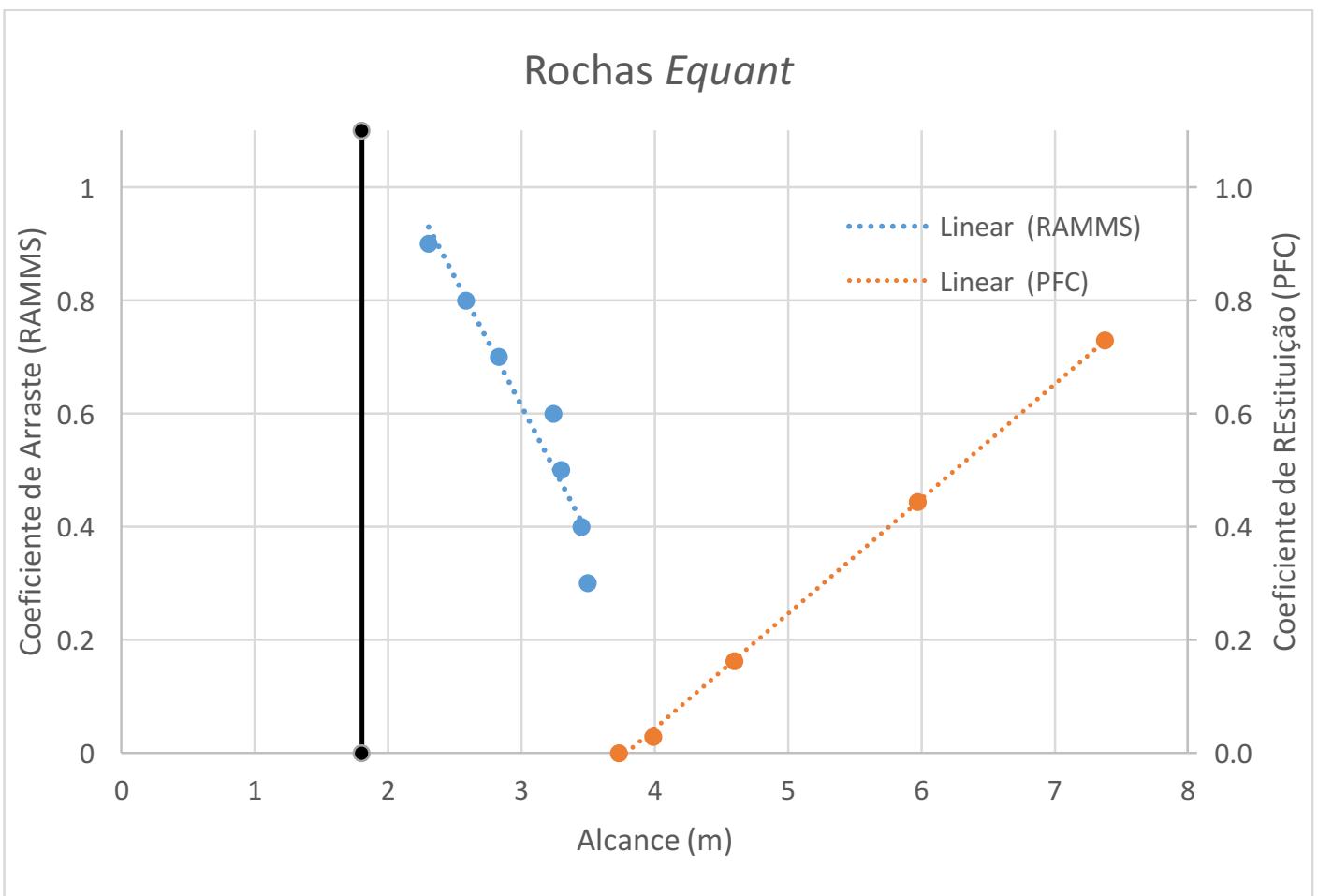

Figura 4.1 - Rochas Equant lançadas em um plano inclinado de $37^{\circ}$.

Para rochas de geometria long, a figura 4.2 mostra que há uma discrepância entre ambos os modelos. No modelo do PFC3D, o bloco, em todos os casos, atinge o final da superfície inclinada e o coeficiente de restituição altera pouco a distância percorrida do bloco. Já no software RAMMS, grande parte dos blocos rochosos ficam estacionados na superfície inclinada e o coeficiente de arraste possui grande influência na distância percorrida pelo bloco. 


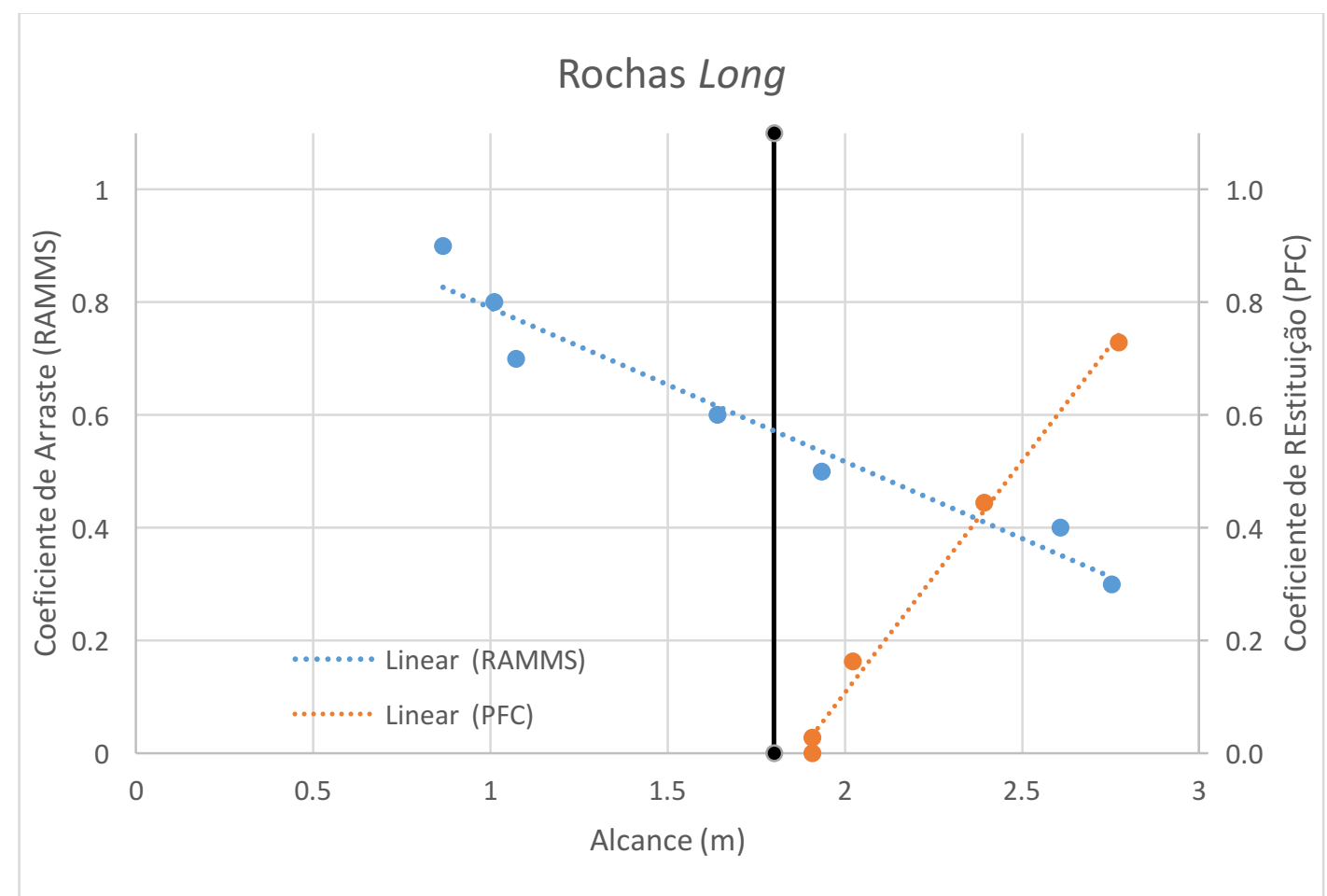

Figura 4.2 - Rochas Long lançadas em um plano inclinado de $37^{\circ}$.

O comportamento de rochas flat, representado na figura 4.3, demonstra também uma grande diferença entre os dois modelos. No programa de modelagem PFC3D, os blocos se estacionaram na superfície plana e o aumento do coeficiente de restituição alterou pouco a distância percorrida. Já no software RAMMS muitos blocos perderam o movimento na superfície inclinada e a mudança do coeficiente de arraste alterou significativamente o alcance da rocha. 


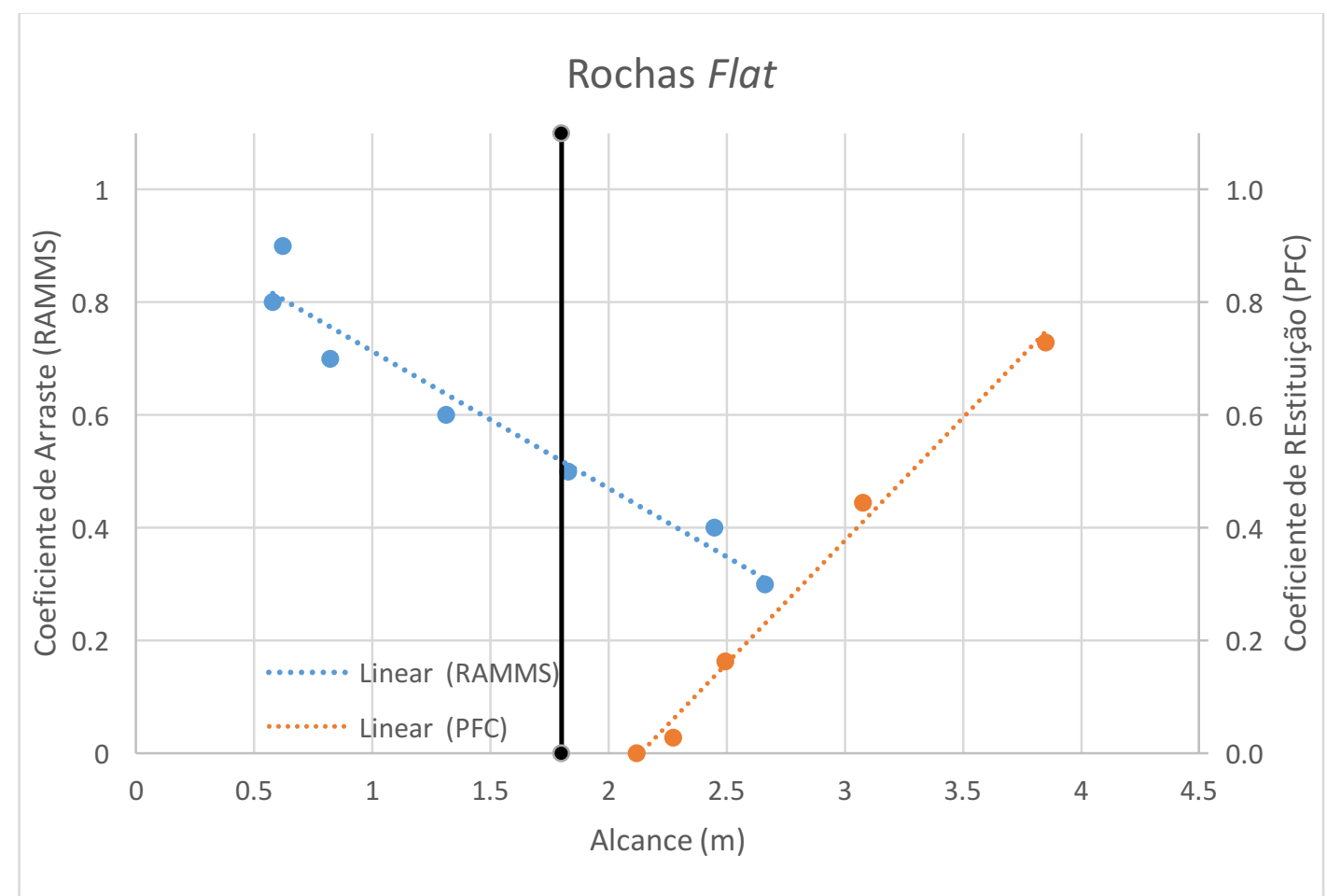

Figura 4.3 - Rochas Flat lançadas em um plano inclinado de $37^{\circ}$.

$\mathrm{Na}$ figura 4.4, onde foram realizadas simulações de rochas com diferentes geometrias em um plano inclinado de $37^{\circ}$ no modelo de simulações RAMMS, observa-se que os blocos de geometria long e flat têm pouca diferença quanto o alcance dos blocos, vários deles perdem toda a sua energia ainda na superfície inclinada e a distância alcançada depende muito do coeficiente de arraste. Para blocos de geometria equant, todos alcançam a superfície plana e o coeficiente de arraste possui uma influência menor no alcance que nas rochas de geometria mais alongada, mas ainda assim, possui uma certa relevância. 


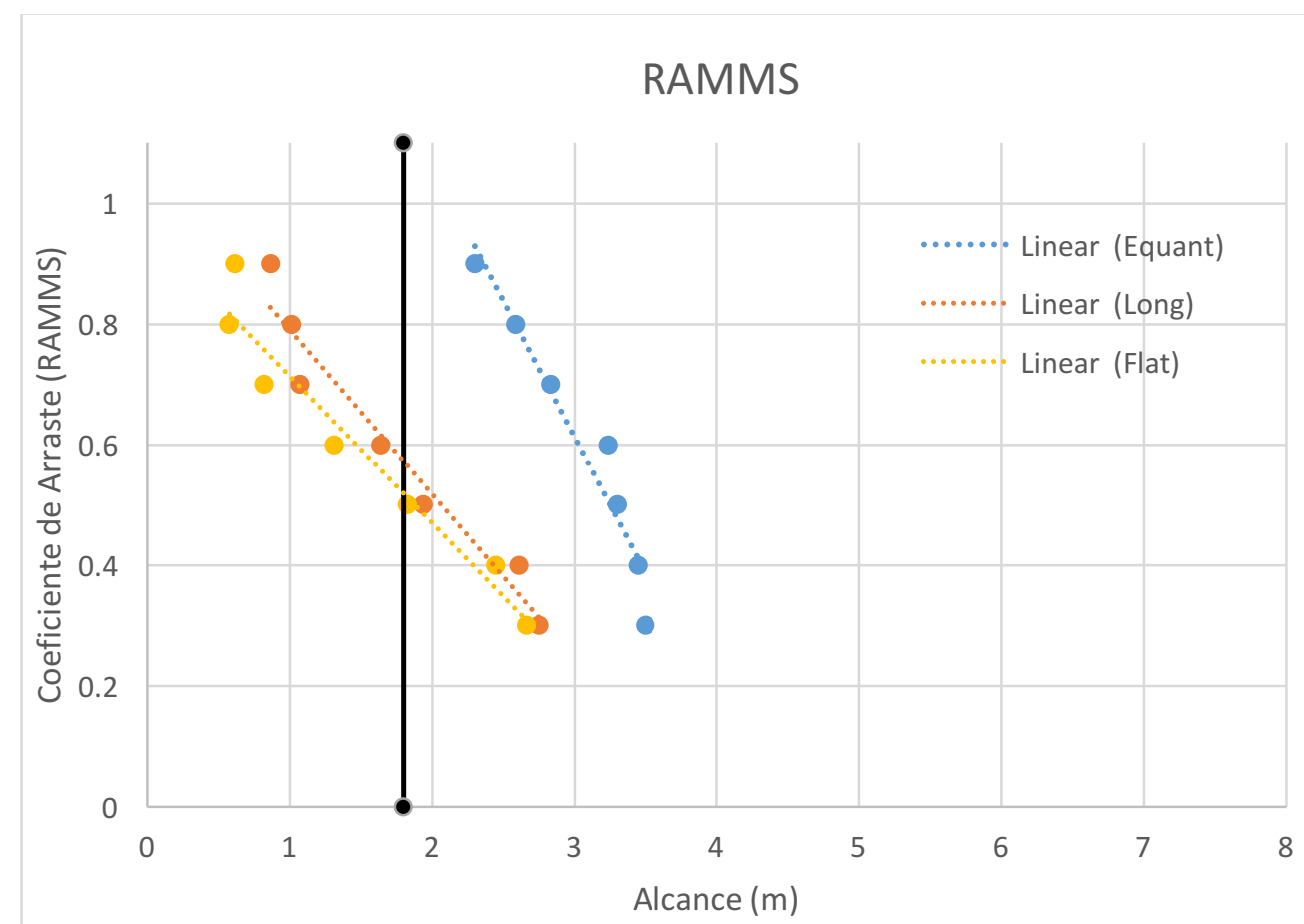

Figura 4.4 - Alcance das rochas de diferentes geometrias em um plano inclinado de $37^{\circ}$ no modelo de simulação RAMMS.

No PFC3D, entende-se pela figura 4.5, que todos os blocos rochosos alcançaram a superfície plana. Os blocos long e flat apresentaram grande semelhança entre si, com as rochas de geometria flat alcançando uma distância maior. O coeficiente de arraste afeta pouco a distância final alcançada para estes tipos de rochas. Os blocos de geometria equant percorreram uma trajetória mais extensa e o coeficiente de restituição possui uma grande influência no alcance do maciço. 


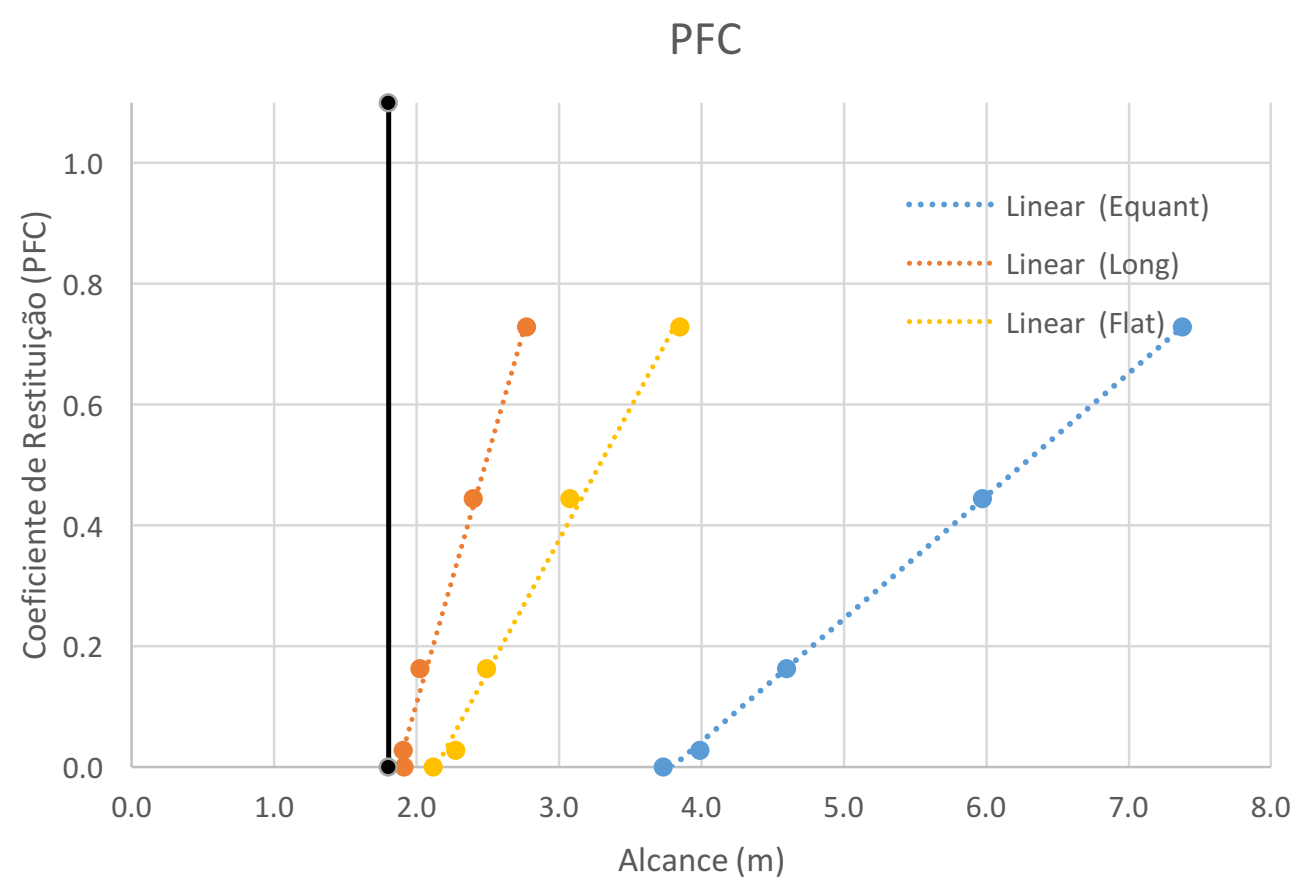

Figura 4.5 - Alcance das rochas de diferentes geometrias em um plano inclinado de $37^{\circ}$ no modelo de simulação PFC.

\subsubsection{2}

Plano inclinado em 50 graus

$\mathrm{O}$ experimento com a superfície inclinada de $50^{\circ}$ e com rochas de formato equant, resultou no alcance de blocos representado pela figura 4.6. Todas as rochas desceram completamente a superfície inclinada chegando a parte plana, já que todos os pontos se encontram após a linha escura, o qual define essa transição. Observase uma certa relação entre ambos os parâmetros, já que as linhas de tendência cobrem praticamente a mesma trajetória. 


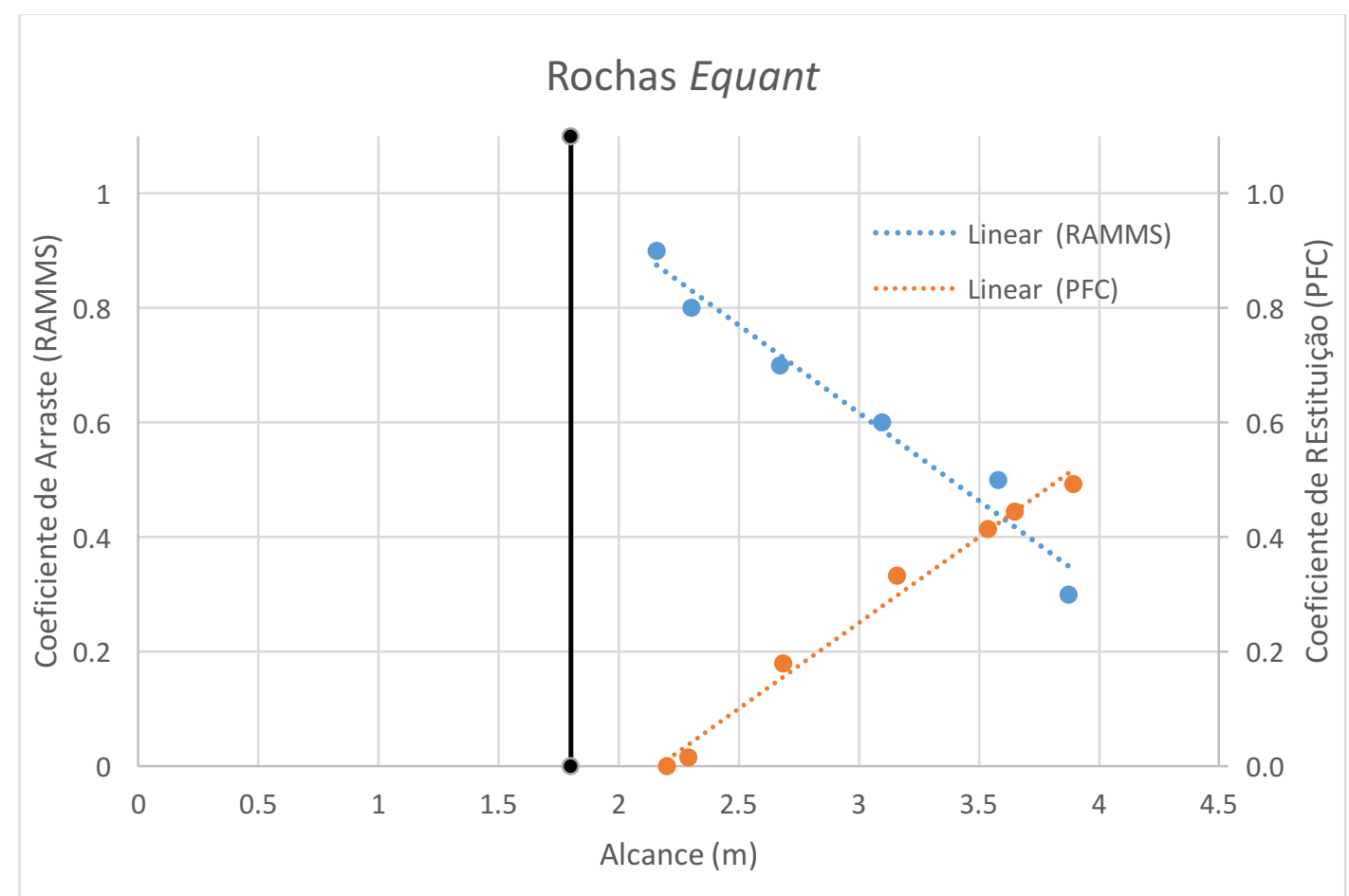

Figura 4.6 - Rochas Equant lançadas em um plano inclinado de $50^{\circ}$.

Para Rochas Long há uma diferença quanto ao comportamento entre os dois casos. No gráfico 4.7 é clara a diferença entre as inclinações das duas linhas de tendência, o aumento do coeficiente de restituição no PFC3D faz com que a distância percorrida não aumente rapidamente, como ocorre com o aumento do valor do coeficiente de arraste no software RAMMS. Outro ponto importante é o de que para um valor alto do coeficiente de arraste, o bloco não desce a superfície, este caso está relacionado a geometria do bloco, o coeficiente de atrito e também a inclinação da superfície, o fato dela não ser muito íngreme. 


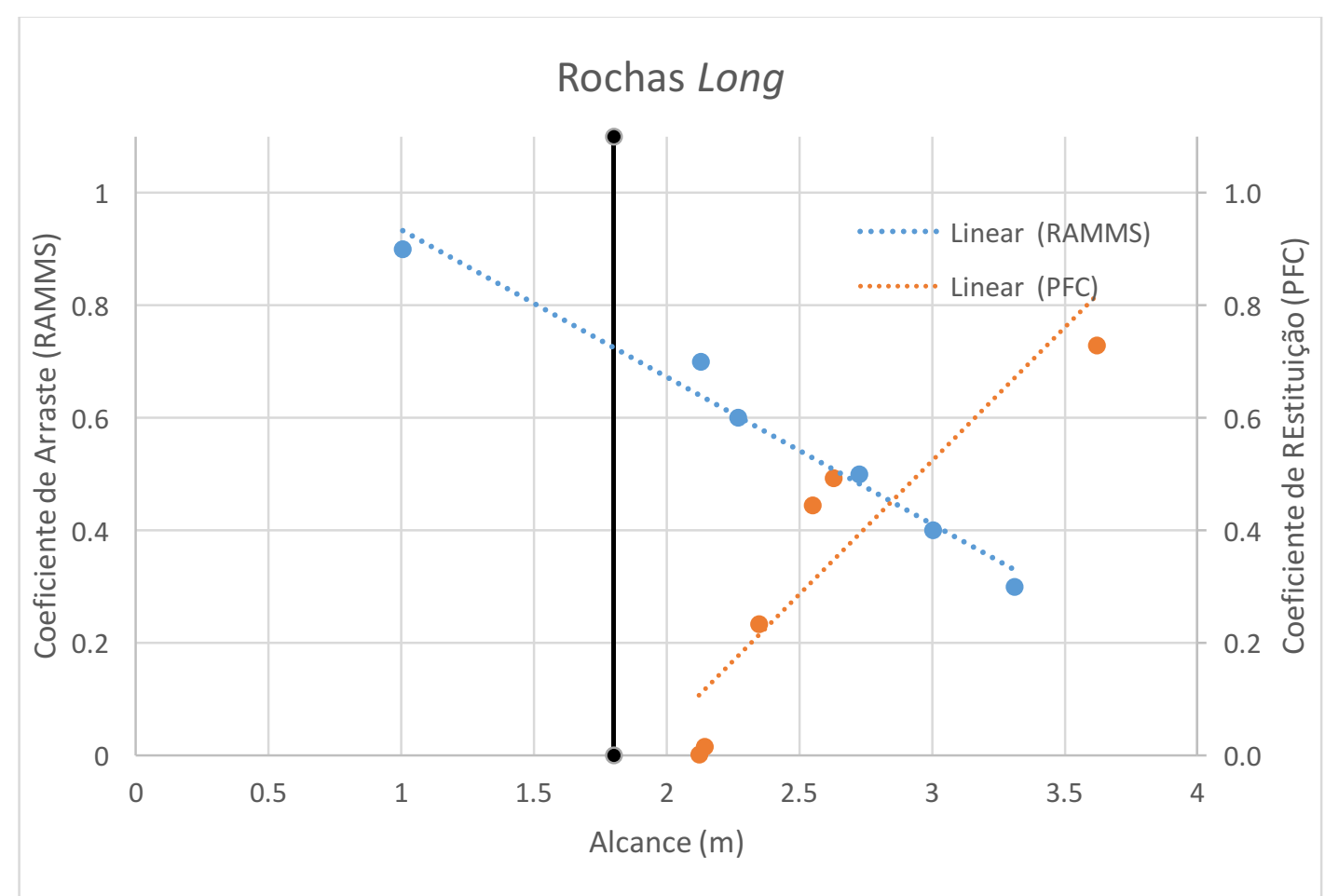

Figura 4.7 - Rochas Long lançadas em um plano inclinado de $50^{\circ}$.

Há uma maior diferença também entra os modelos quando as rochas flat são comparadas como mostra a figura 4.8. As inclinações das linhas de tendência são semelhantes, mostrando rochas com esta geometria, o coeficiente de arraste e o coeficiente de restituição possuem a mesma influência no alcance dos blocos. Notase também nesta comparação que blocos no software RAMMS se estacionam antes da superfície sem inclinação, indicando uma maior perda de energia no sistema 


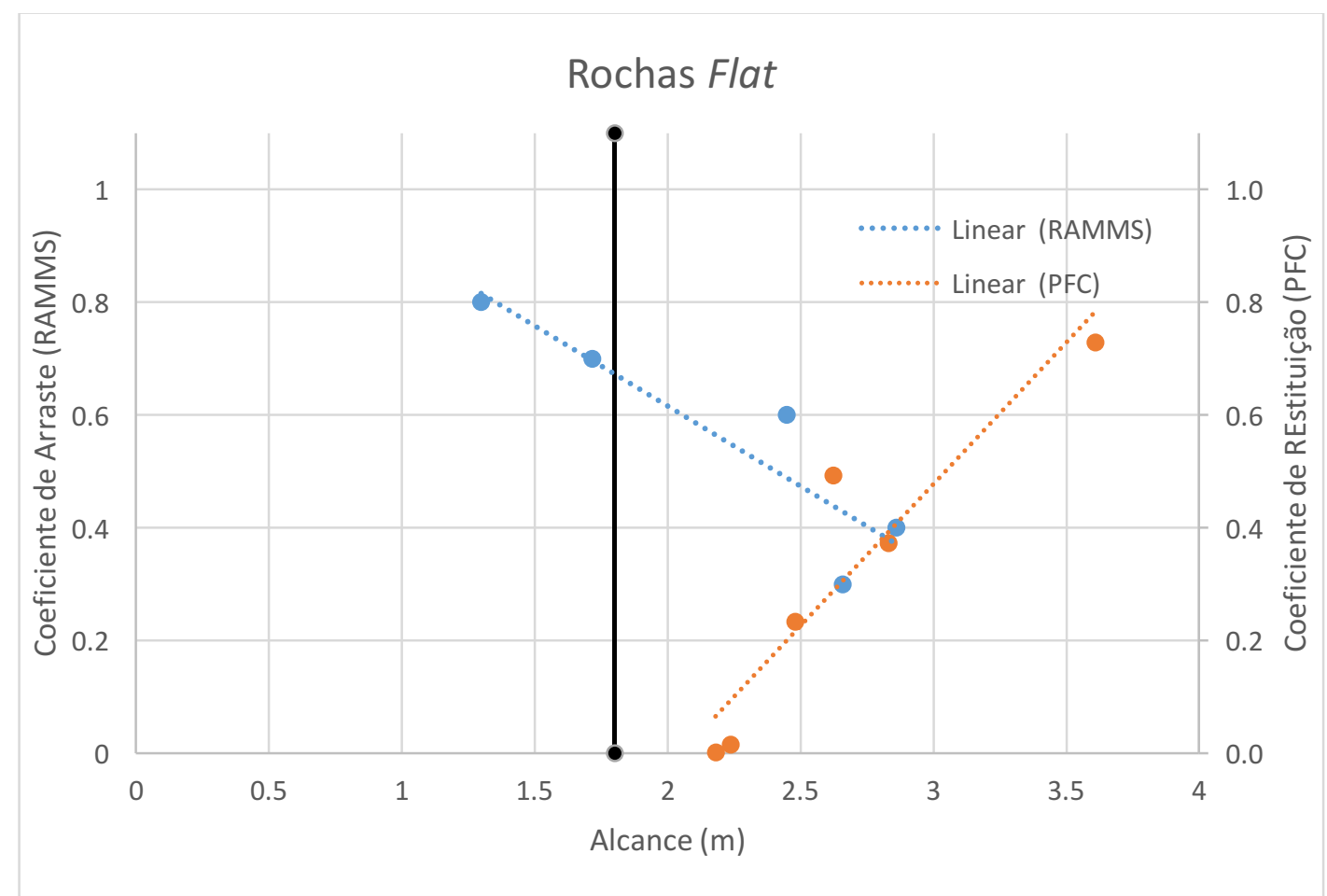

Figura 4.8 - Rochas Flat lançadas em um plano inclinado de $50^{\circ}$.

$\mathrm{Na}$ figura 4.9 é possível analisar a influência da geometria no software RAMMS. As rochas equant possuem uma tendência de maior rolamento, devido ao formato dos blocos, alcançando maiores distâncias. Já os blocos long e flat possuem uma perda de energia cinética mais rápida, em geral, acabam perdendo velocidade antes. 


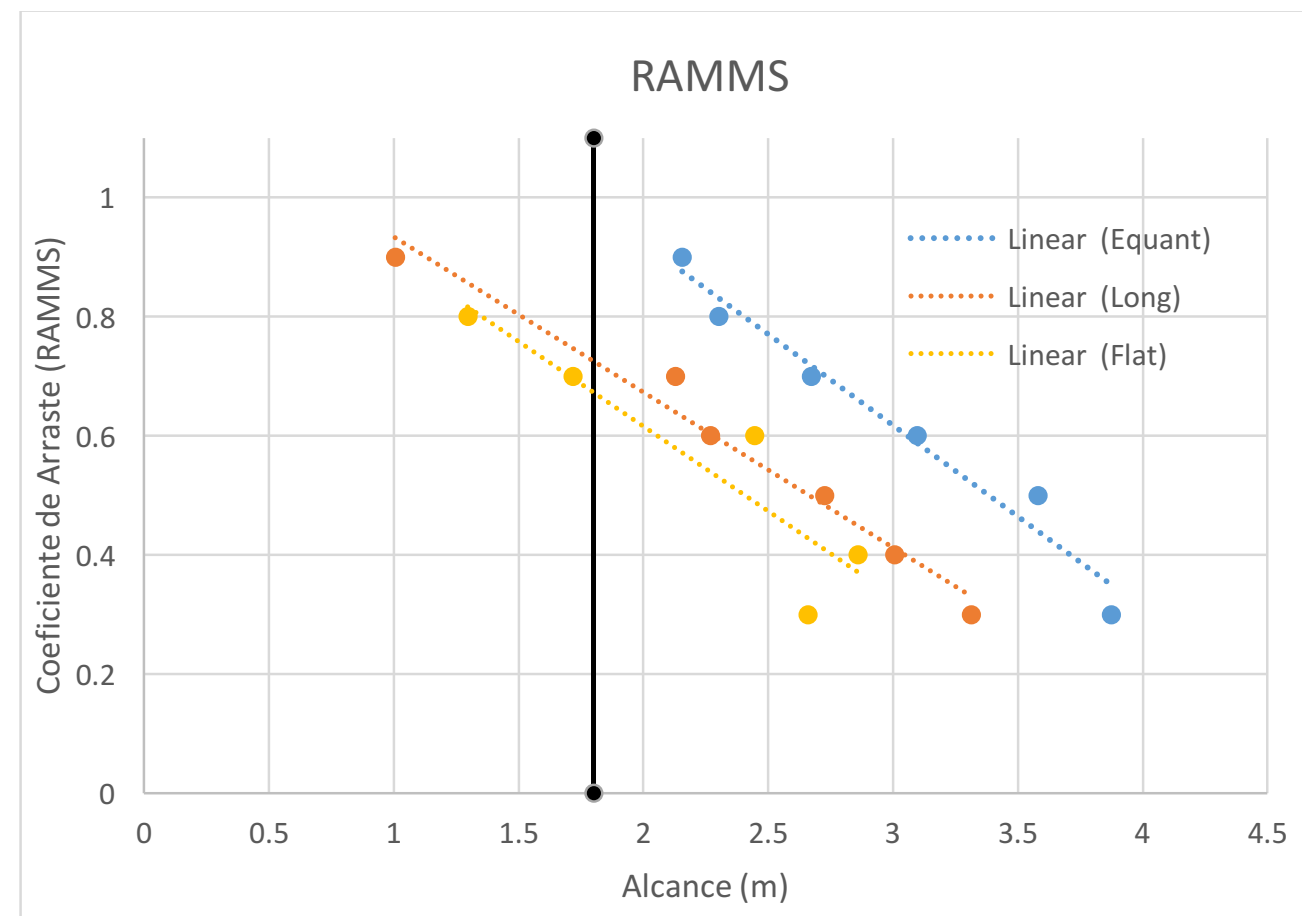

Figura 4.9 - Distância percorrida pelos blocos em um plano inclinado em $50^{\circ}$ no software RAMMS.

A figura 4.10 representa a distância percorrida pelos blocos de diferentes geometrias no programa PFC3D. Há uma semelhança entre os blocos flat e long, e uma maior diferença quantos blocos equant, mas no geral, eles percorreram uma distância equivalente. Nota-se que o coeficiente de restituição tem uma menor influência nos blocos mais alongados, já que uma pequena mudança no parâmetro produz uma distância percorrida menor nestes tipos de blocos do que nos blocos equant. 


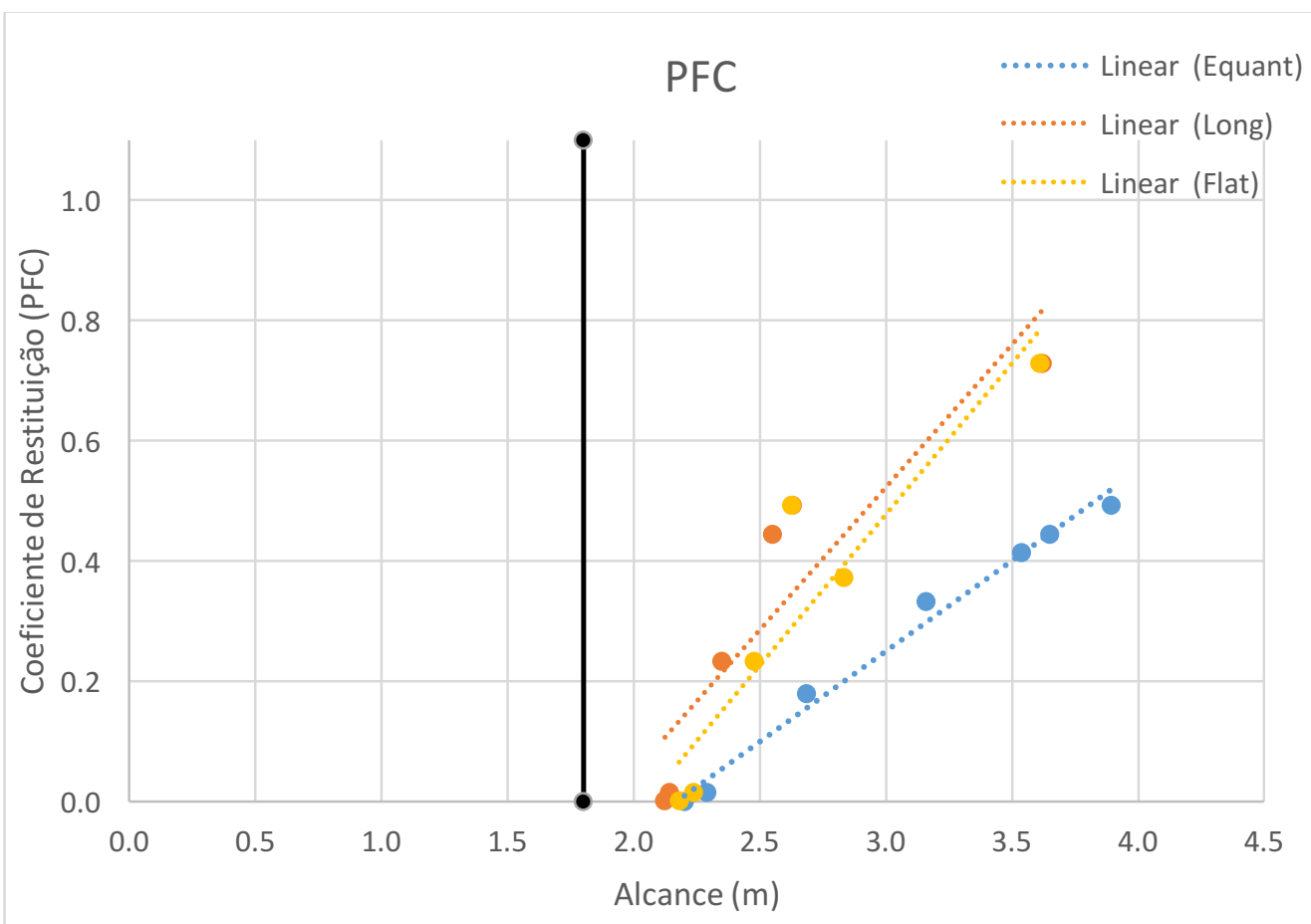

Figura 4.10 - Distância percorrida pelos blocos em um plano inclinado em $50^{\circ}$ no software PFC.

\subsection{2}

Modelo Linear com Resistência ao Rolamento

\subsubsection{1}

Plano Inclinado em 37 graus

$\mathrm{Na}$ figura 4.11 é possível relacionar o coeficiente de arraste no software RAMMS e o coeficiente de resistência ao rolamento (CRR) no software PFC3D para rochas equant lançadas em plano inclinado de $37^{\circ}$. Para este tipo de bloco percebe-se que no software RAMMS os blocos chegam até a superfície plana para qualquer que seja o valor do parâmetro. Já através do método linear com resistência ao rolamento o bloco fica estacionado na superfície inclinada para CRR maiores que 1,9. Para alcançar a mesma distância que a simulação do software RAMMS o valor de CRR teria que variar entre 1,8 e 3,5. 


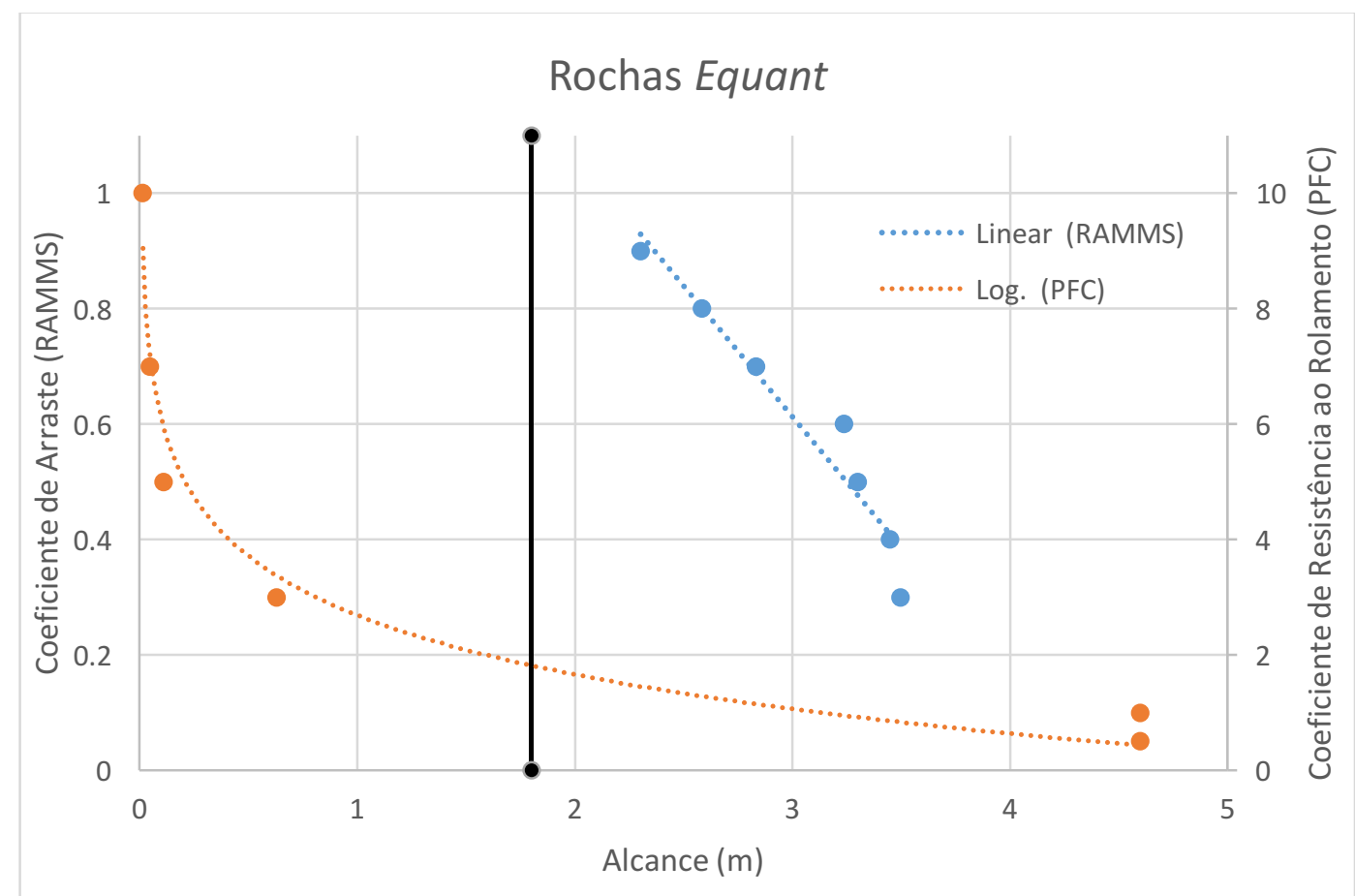

Figura 4.11 - Relação do coeficiente de arraste e de resistência de rolamento para rochas equant em superfície inclinada de $37^{\circ}$.

Já para rochas de geometria long em uma superfície inclinada de $37^{\circ}$, no modelo de simulação do software RAMMS a grande maioria dos blocos alcança a superfície plana, como indica a figura 4.12. No programa PFC3D a grande maioria fica estacionada na superfície inclinada, chegando ao fim do plano inclinado para valores menores que 1,7. Para alcançar distâncias próximas ao do software RAMMS o parâmetro CRR teria que ser menor que 2,1 no PFC3D. Mesmo com CRR sendo igual a zero, não seria possível o bloco alcançar a distância máxima atingida no software RAMMS. 


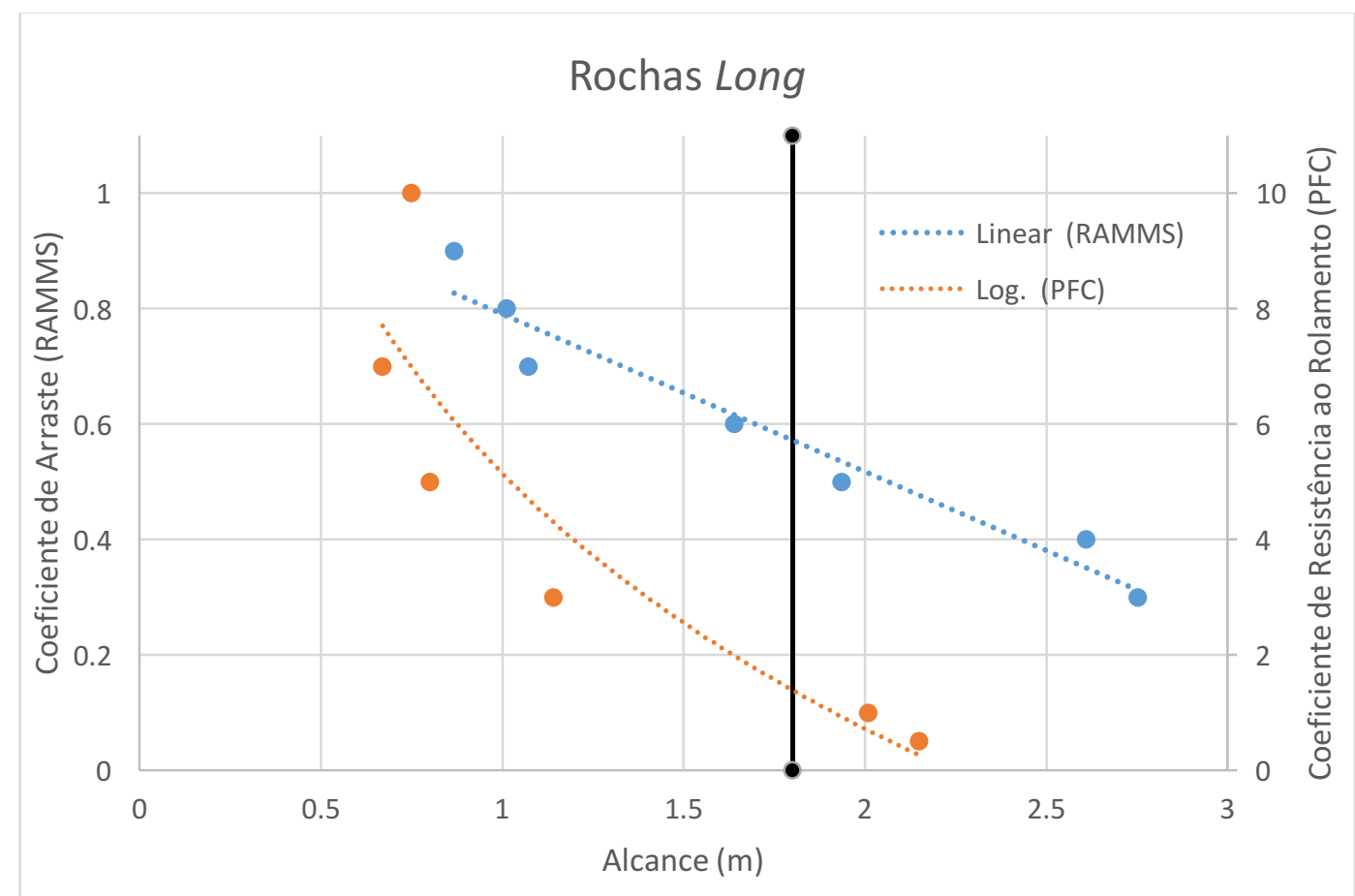

Figura 4.12 - Relação do coeficiente de arraste e de resistência de rolamento para rochas long em superfície inclinada de $37^{\circ}$.

Nas simulações com rochas flat em uma superfície inclinada de $37^{\circ}$ grande parte dos blocos ficou estacionada na superfície inclinada no software RAMMS, como observa-se na figura 4.13. No modelo de elementos discretos os blocos rochosos alcançam a superfície sem inclinação para valores de CRR menores que 2,1. Para valores entre 2,1 e 3,2 do CRR é possível que as rochas atinjam o mesmo alcance que no software RAMMS. 


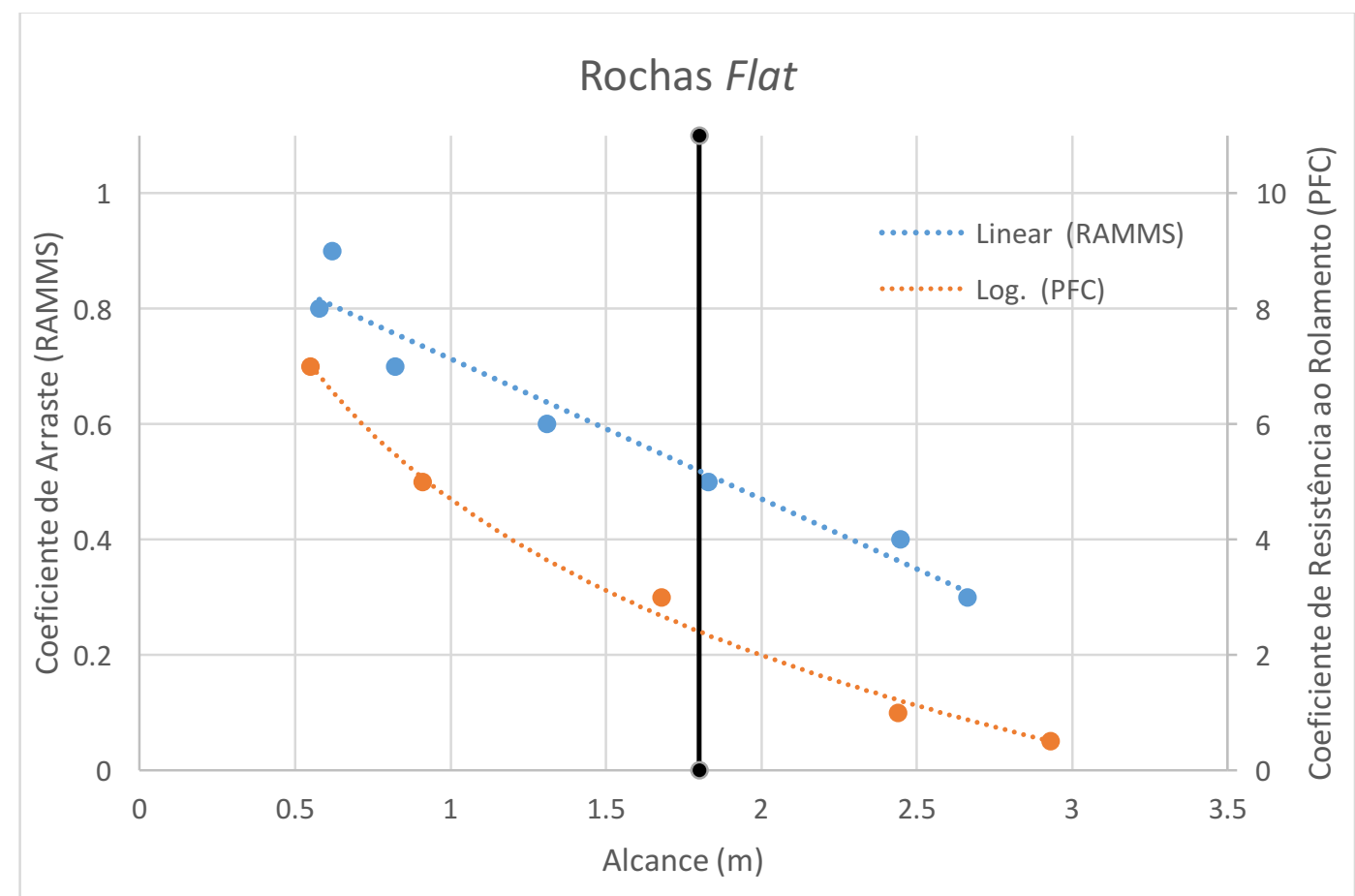

Figura 4.13 - Relação do coeficiente de arraste e de resistênciaa de rolamento para rochas flat em superfície inclinada de $37^{\circ}$.

No PFC3D, observa-se na figura 4.14 que os blocos, para todos os tipos de geometria, tendem a ficar estacionados na superfície inclinada para valores similares de CRR, entre 1,8 e 2,2. As rochas de geometria equant atingem maiores distâncias, sendo também mais influenciadas pelos valores de CRR. Já as do tipo flat e long se estacionam próximas ao final da superfície inclinada mesmo com valores baixos de CRR. 


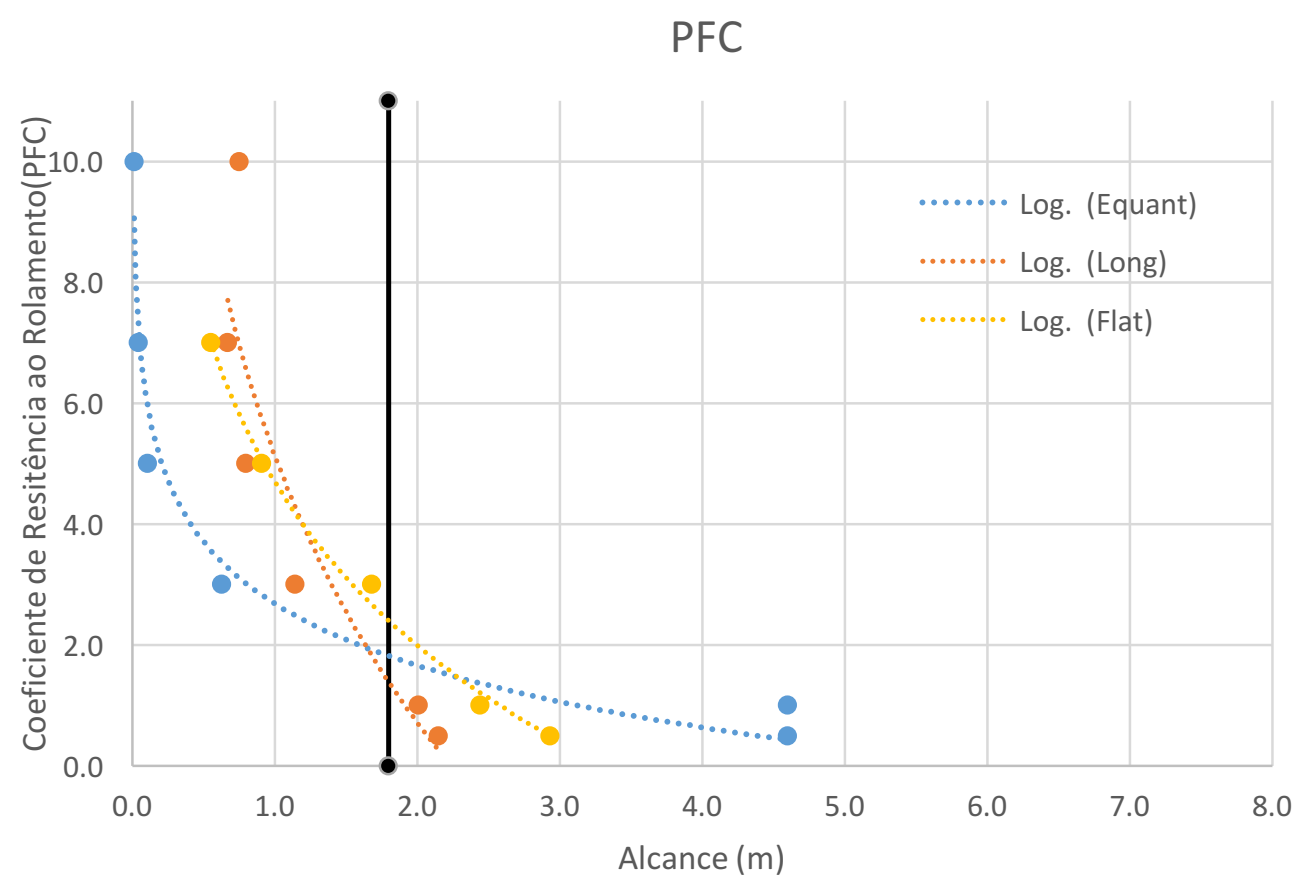

Figura 4.14 - Relação entre a distância e o coeficiente de resistência ao rolamento para rochas de diferentes geometrias em uma superfície inclinada de $37^{\circ}$ lançados através do software PFC.

\subsubsection{2}

\section{Plano Inclinado em 50 graus}

A figura 4.15 mostra que para os blocos equant em uma superfície inclinada de $50^{\circ}$ tendem a se depositar na superfície plana no software RAMMS, para qualquer valor do coeficiente de arraste. No método do DEM, para valores menores que 2,8 o bloco alcança a superfície não inclinada. No PFC3D a rocha atinge a mesma distância que no software RAMMS para valores de CRR entre 2,5 e 1,5. 


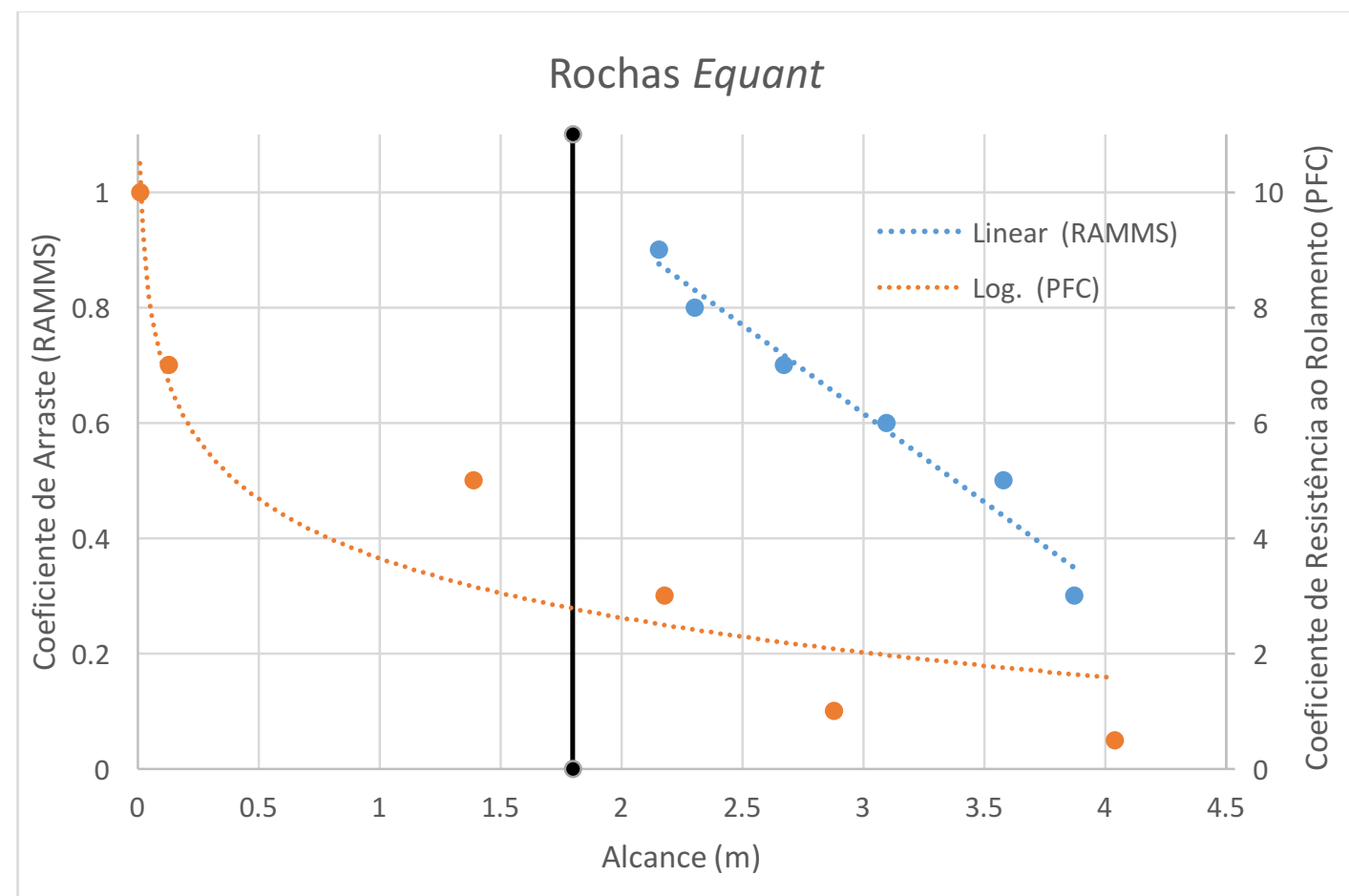

Figura 4.15 - Relação do coeficiente de arraste e de resistência de rolamento para rochas equant em superfície inclinada de $50^{\circ}$.

Para as rochas de geometria long, no software RAMMS poucos blocos ficaram estacionados na superfície inclinada, como mostra a figura 4.16, com a maioria atingindo a superfície não inclinada. Já no modelo de elementos discretos a maioria das rochas também alcançaram a superfície não inclinada e o CRR no modelo afetou menos o alcance do que o coeficiente de partículas no software RAMMS. Não é possível determinar valores de CRR para que o alcance dos blocos em ambos os modelos seja o mesmo, já que a linha de tendência na simulação do programa PFC3D não atinge os extremos do alcance da linha de tendência do simulador RAMMS, mas os valores de CRR entre 0 e 10 conseguem abranger grande parte desta trajetória. 


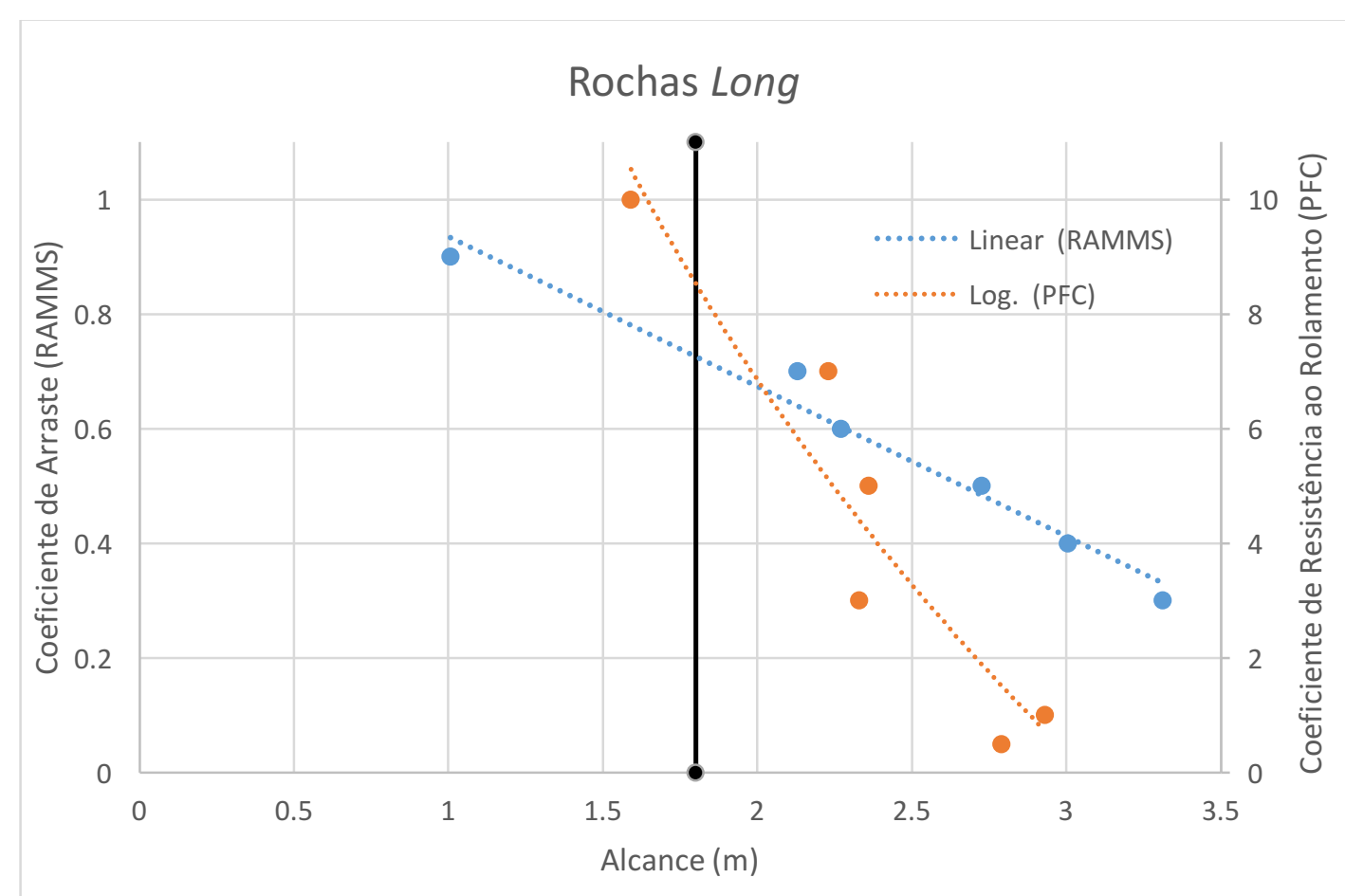

Figura 4.16 - Relação do coeficiente de arraste e de resistência de rolamento para rochas long em superfície inclinada de $50^{\circ}$.

A figura 4.17 mostra que os blocos rochosos de geometria flat, em sua maioria, alcançam a superfície plana no software RAMMS. Na modelagem do PFC3D, para valores do CRR menores que 9, os blocos chegaram a superfície sem declividade. Para alcançar as mesmas distâncias que no software RAMMS, os valores do CRR teriam que ser maiores que 3,5, e mesmo assim não alcançariam a distância mínima do simulador RAMMS. 


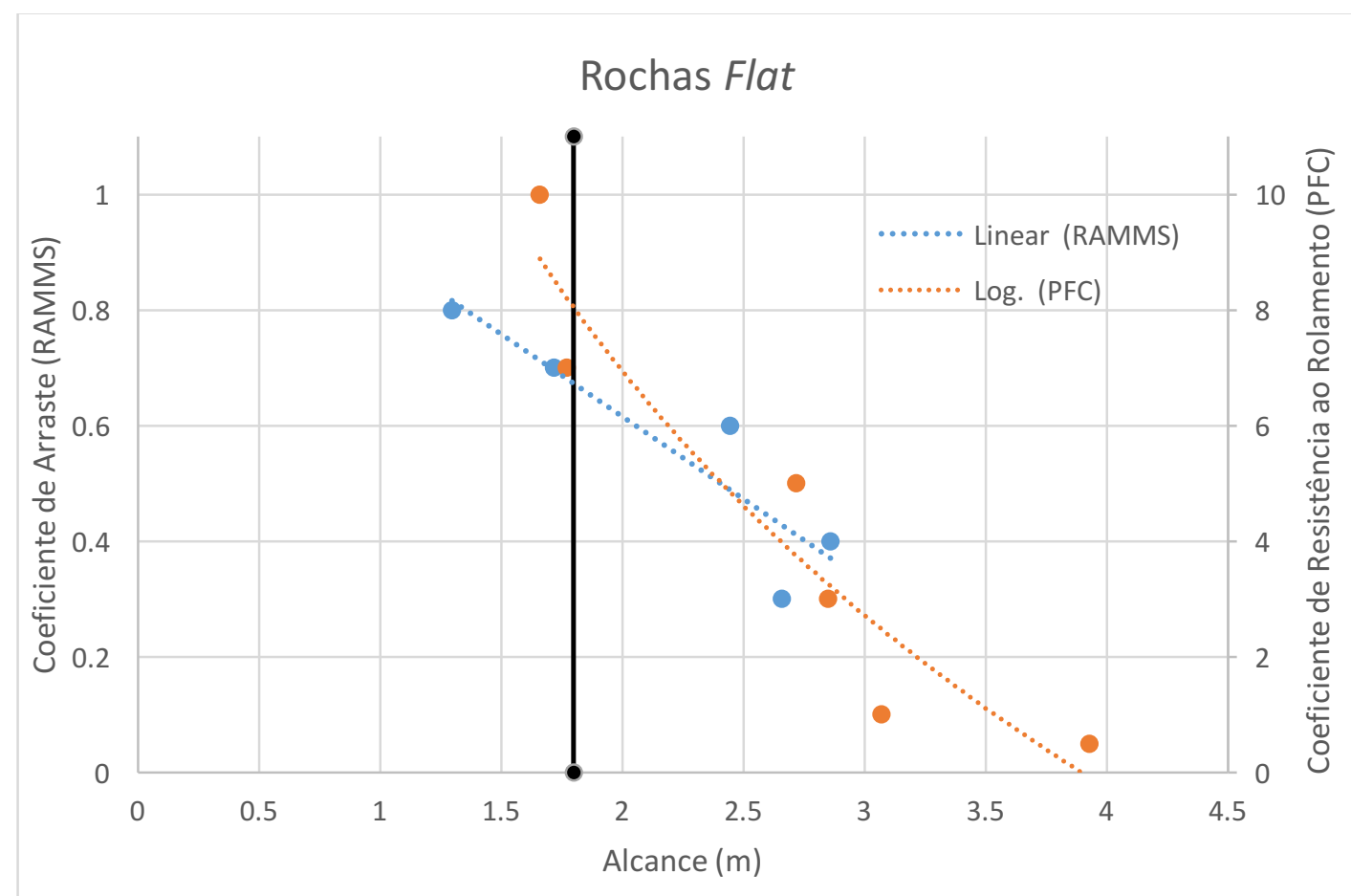

Figura 4.17 - Relação do coeficiente de arraste e de resistência de rolamento para rochas flat em superfície inclinada de $50^{\circ}$.

A figura 4.18 mostra a relação do coeficiente de resistência ao rolamento versus distância para diferente geometria de blocos rochosos. Observa-se que o coeficiente tem grande influência em blocos equant e ser pouco efetivo em blocos long e flat. Havendo uma certa dificuldade para cessar a energia cinética dos blocos alongados na superfície inclinada. 


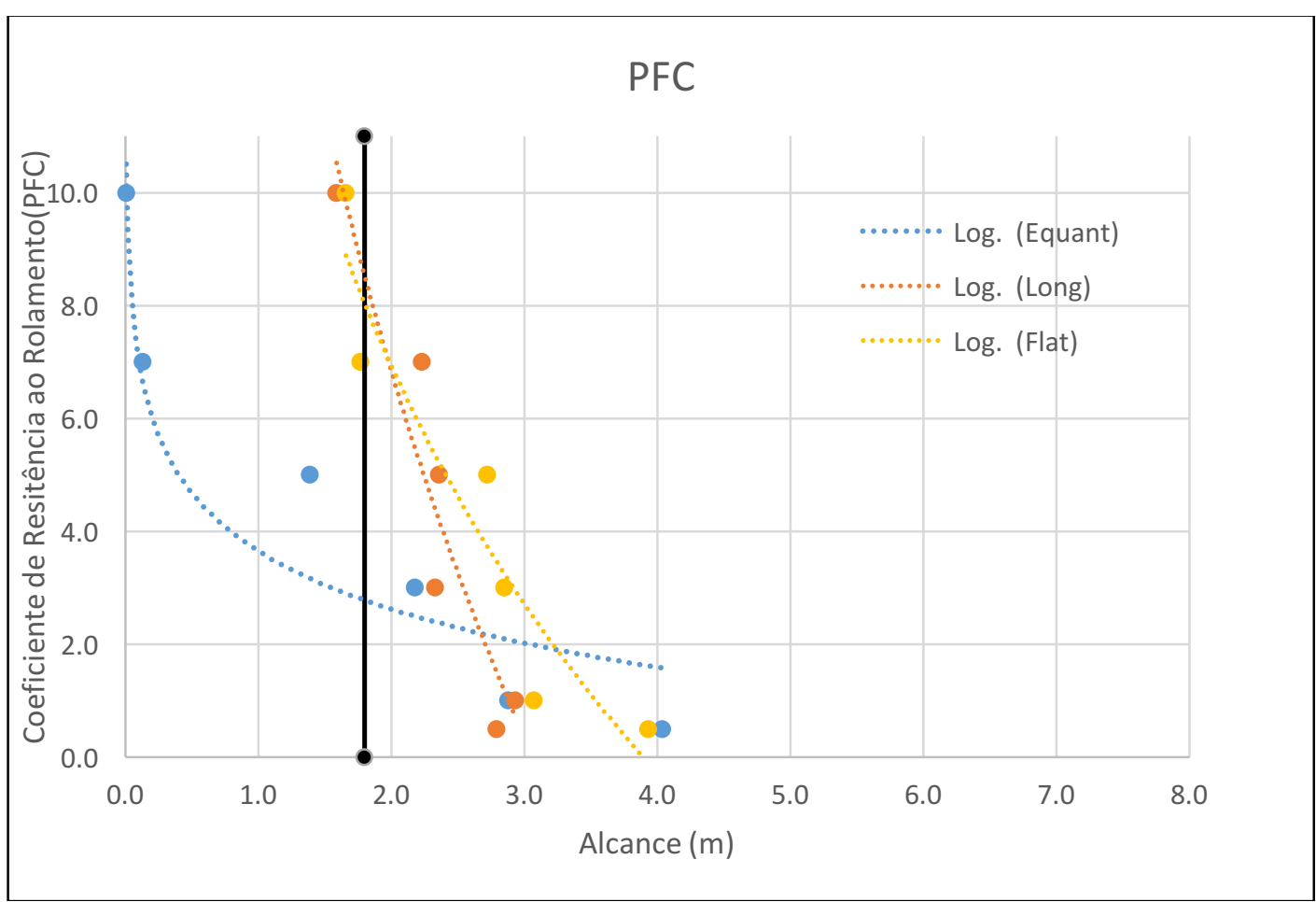

Figura 4.18 - Relação entre a distância e o coeficiente de resistência ao rolamento para rochas de diferentes geometrias em uma superfície inclinada de $50^{\circ}$ lançados através do software PFC.

\subsection{3}

Observações

Algumas observações quanto a inclinação da superfície, geometria dos blocos e os modelos dinâmicos utilizados serão feitas nesta seção, comparando-os com algumas análises realizadas por diferentes autores.

\subsubsection{1}

\section{Inclinação da superfície}

Através de observações realizadas nos experimentos de plano inclinado de $50^{\circ}$ nota-se que os blocos tendem a alcançar a superfície não inclinada, diferente do plano com inclinação de $37^{\circ}$. Isto ocorre devido à capacidade do bloco de obter maior velocidade devido à superfície mais íngreme.

Ritchie (1963) já tinha observado que a inclinação do plano afeta todos os tipos de movimento da rocha durante o percurso e respectivamente, a potencial distância a ser percorrida e a dispersão das trajetórias.

Glover (2015) fez uma série de experimentos em campo com blocos rochosos em topografias inclinadas e concluiu que os alcances são maiores para rochas equant, em ambos os casos, em distância longitudinal e em dispersão. Notou-se 
também que embora as rochas mais alongadas produzam alta dispersão lateral. Baixa dispersão (rochas long e platy) é identificada pela orientação do lançamento na qual o maior momento de inercia da rocha é paralelo a linha do plano. Isto ocorre devido a capacidade do bloco de obter uma velocidade angular maior dependendo do eixo de rotação.

\subsubsection{2}

\section{Geometria dos Blocos}

Quanto aos blocos equant, eles tendem a alcançar distâncias mais longas em ambos os programas de modelagem e dificilmente ficam estacionadas na superfície inclinada. No software RAMMS os blocos equant perdem toda a sua energia cinética somente na superfície sem declividade. O mesmo ocorreu no PFC3D quando foi usado somente o método linear, qualquer que seja o coeficiente de restituição, as rochas só se depositaram na superfície sem inclinação. Já com a adição da força de resistência ao rolamento, as rochas se mostraram muito sensíveis à adição deste mecanismo, sendo possível fazer com que elas se depositem na superfície íngreme.

Os blocos não simétricos, long e platy, devido a sua geometria, alcançam menores distâncias, em muitos casos ficando estacionadas no plano inclinado. No software RAMMS, grande parte dos blocos ficou estacionada na superfície com declividade. Quando modelado no programa PFC3D com o modelo linear, os blocos se depositaram somente na superfície sem declividade. Ao adicionar a resistência ao rolamento, foi possível fazer com que os blocos perdessem a totalidade da sua energia cinética ainda na superfície inclinada.

\subsubsection{3}

\section{Modelos Dinâmicos}

Fazendo uma breve comparação dos modelos do PFC3D e do RAMMS através dos gráficos acima, percebeu que o software RAMMS apresentou grande perda de energia, através dos mecanismos inseridos no modelo em superfícies inclinadas durante o processo de contato rocha-superfície, o que o modelo linear no programa PFC3D não foi capaz de reproduzir. Com a adição da resistência ao rolamento foi possível acrescentar essa perda de energia no sistema para que ele conseguisse representar os diferentes mecanismos que ocorrem na queda de blocos. 


\section{3 Análise de Queda de Blocos na BR116}

Nste tópico são apresentados os resultados do deslizamento de blocos na BR116. Primeiro as simulações foram realizadas com blocos de geomteria equant e depois de geometria long, que são os principais formatos de blocos encontradas na região após o evento ter ocorrido. Os blocos foram inseridos no mesmo local de onde o evento real se inciou, sendo a gravidade a única força que agiu inicialmente no bloco.

Na primeira parte da simulação onde as modelagens ocorreram com os blocos equant, as rochas foram lançadas do ponto de origem e foram analisadas as suas trajetórias e a energia cinética com que os blocos atingiam a rodovia. Foi feito uma investigação também quanto à similaridade da simulação numérica com o caso real.

$\mathrm{Na}$ figura 4.19 encontram-se as simulações realizadas no software RAMMS. Nota-se que o bloco chega até a rodovia com alta energia e com energia suficiente para prosseguir o caminho após a rodovia. A maioria dos blocos tende a seguir o mesmo caminho com pequenas alterações, próximas a cicatriz deixada pelo evento, que está representado pelo traço vermelho, causando pequenas distorções laterais. Poucas rochas se desviam, e quando isso ocorre, as rochas já se encontram próximas a rodovia. Os blocos chegam na região da rodovia com energia cinética que variava entre 4900 e $6900 \mathrm{~kJ}$. 


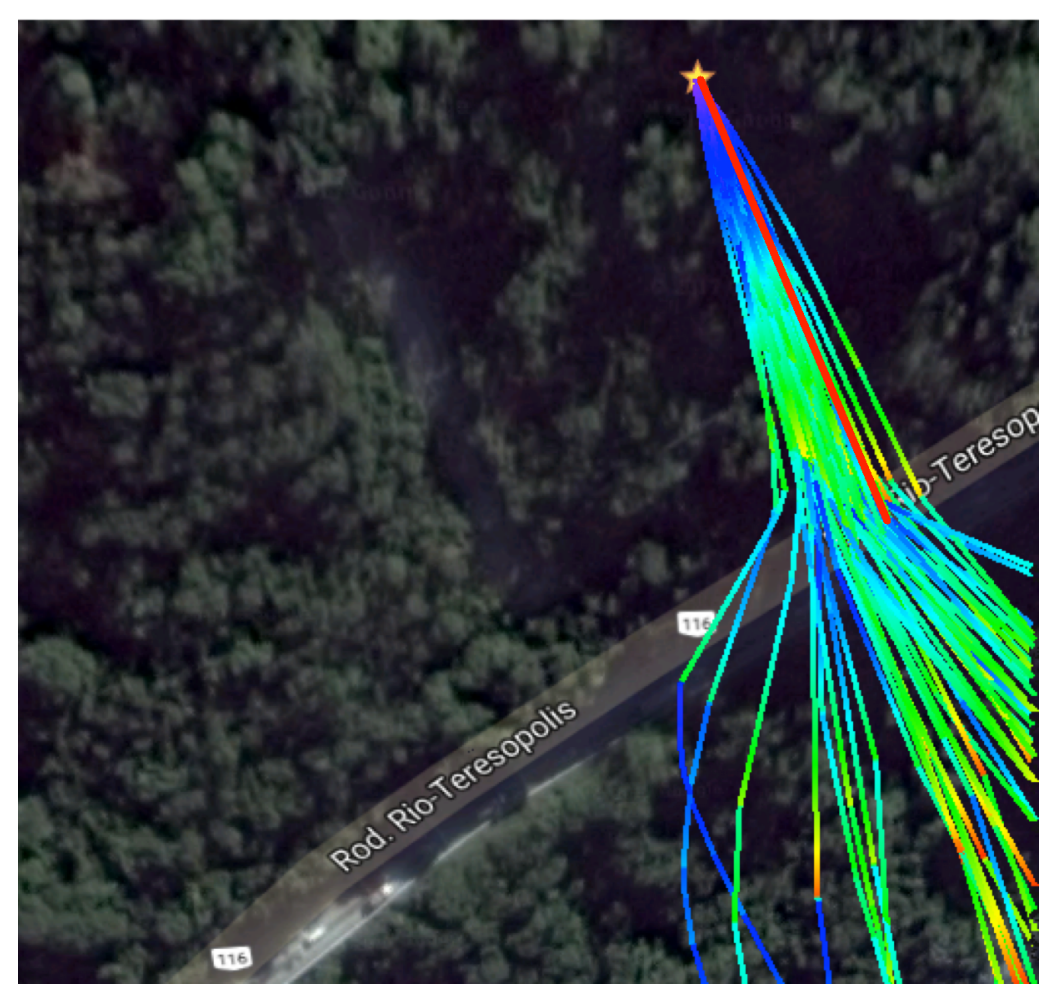

Figura 4.19 - Trajetória de queda de blocos equant na BR116 através do RAMMS (Google Maps).

Para obter os valores do coeficiente de resistência ao rolamento para simulação no programa PFC3D foram utilizadas as comparações do item 4.2. Em que para um determinado alcance de um bloco de uma certa geometria em um tipo de solo, que possui um específico coeficiente de arraste, no software RAMMS, determina-se o coeficiente de resistência ao rolamento para este bloco com a mesma geometria que possui este mesmo alcance no programa PFC3D.

A figura 4.20 explica como os valores do coeficiente de resistência ao rolamento foram determinados. Para um tipo de solo específico foi obtido o valor do coeficiente de arraste correspondente no software RAMMS, no caso, um solo medium de coeficiente de arraste igual a 0.6 , assim foi traçada uma reta até a linha de tendência dos experimentos realizados no software RAMMS e verificado o seu alcance, neste caso $2.35 \mathrm{~m}$. Com o alcance determinado foi possível obter o valor do coeficiente de resistência ao rolamento na linha de tendência do programa PFC3D, CRR igual a 4.5 no exemplo. A tabela 4.1 representa os valores utilizados nos experimentos deste trabalho. 


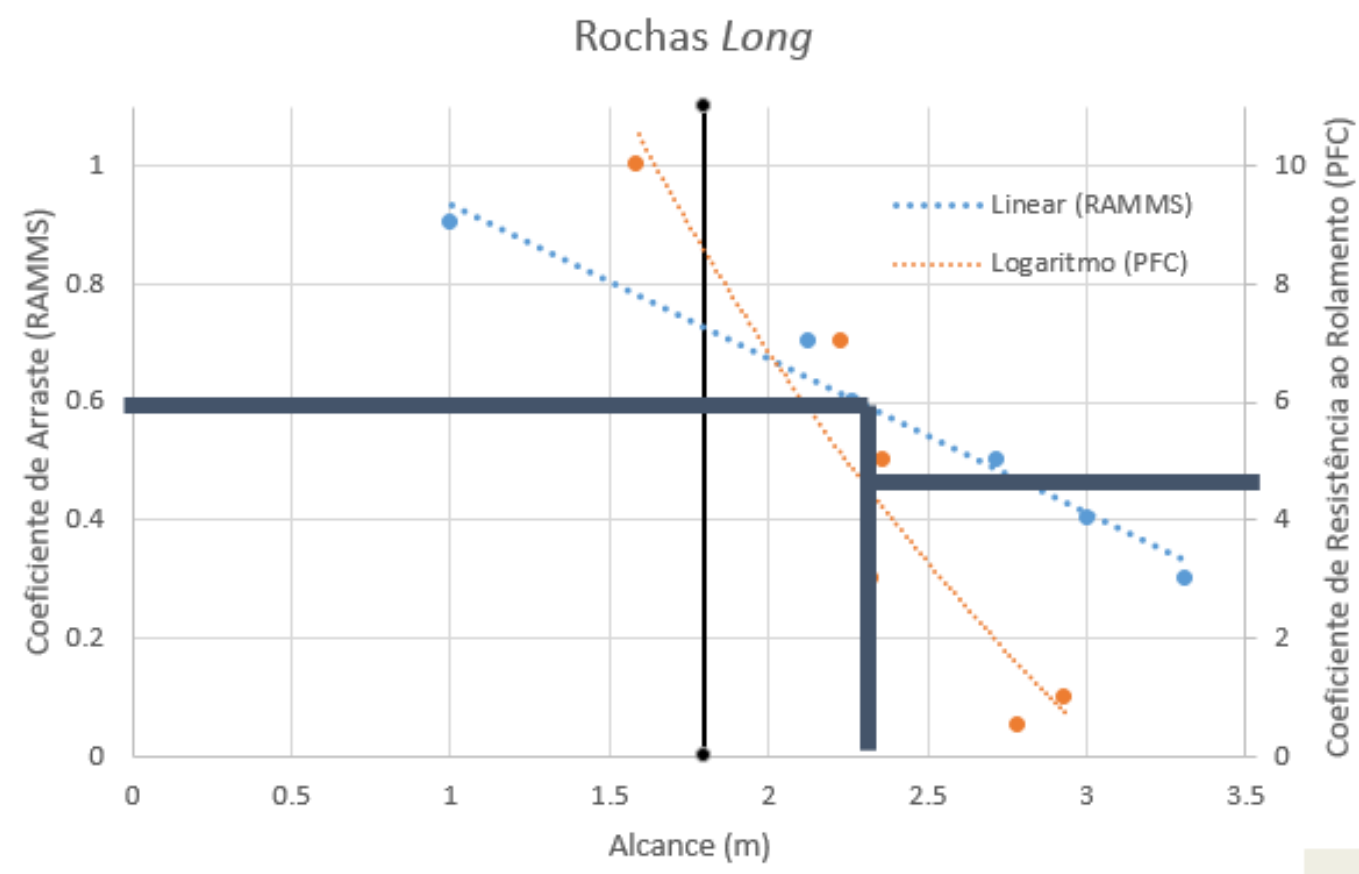

Figura 4.20 - Determinação do valor do coeficiente de resistência ao rolamento.

Tabela 4.1 - Coeficientes de resistência ao rolamento equivalente para diferentes blocos e solos.

\begin{tabular}{|c|c|c|c|}
\hline \multirow{2}{*}{ Solos } & \multirow{2}{*}{ Coef de arraste } & Blocos Long & Bloco Equant \\
\hline & & \multicolumn{2}{|c|}{ Coeficiente de resistência ao rolamento } \\
\hline Extra Hard & 0.6 & 5.2 & 2 \\
\hline Hard & 0.5 & 2 & 1.85 \\
\hline Medium Hard & 0.4 & 0.5 & 1.7 \\
\hline Medium & 0.3 & 0 & 1.5 \\
\hline
\end{tabular}

A figura 4.21 mostra a trajetória do bloco quando simulado no PFC3D. A maioria dos blocos percorre a mesma trajetória, apenas uma entre as dez rochas percorreu um caminho diferente, chegando a estacionar um pouco depois da rodovia. A energia máxima alcançada por um bloco quando este se encontra na altitude da rodovia foi de $3430 \mathrm{~kJ}$. 


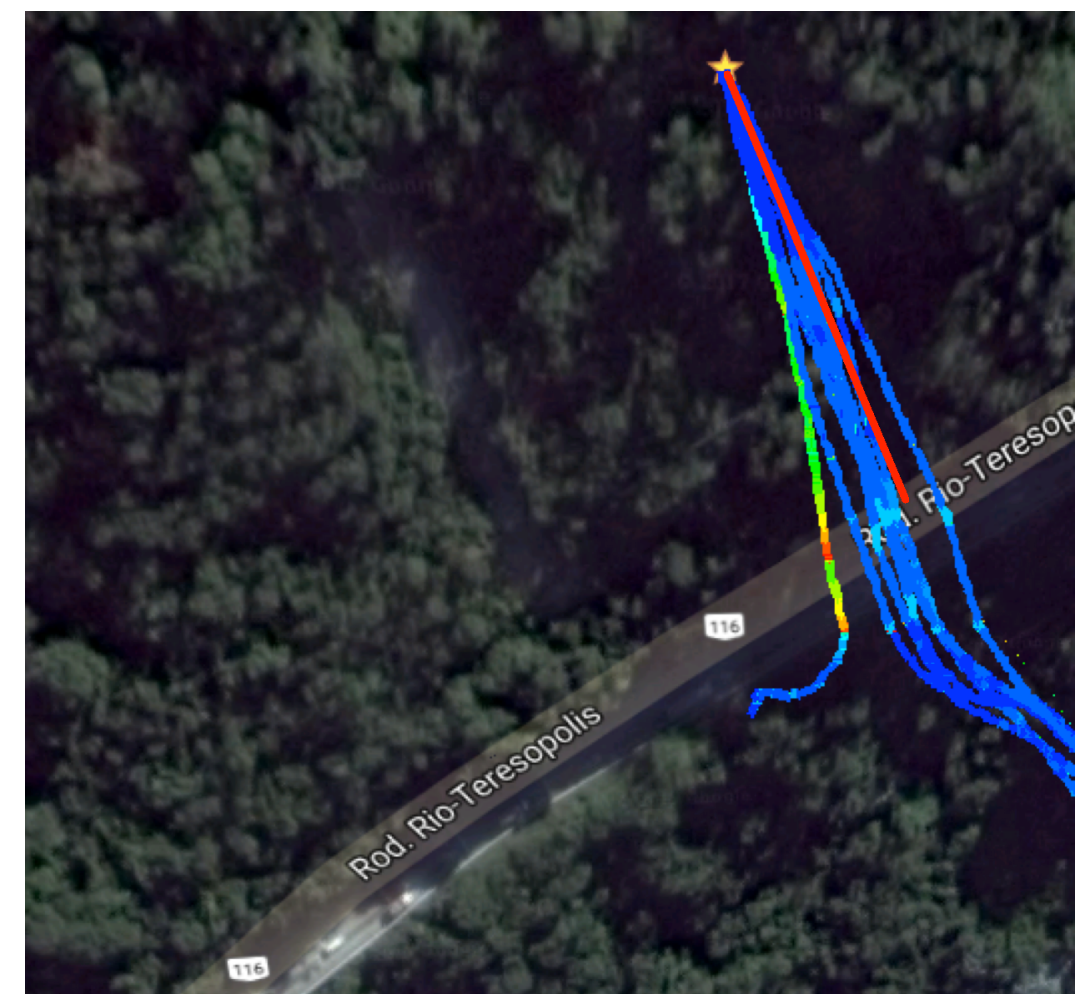

Figura 4.21 - Trajetória de queda de blocos equant na BR116 através PFC3D (Google Maps).

Observando as duas simulações é perceptível a semelhança da trajetória entre os dois modelos, e com poucos modelos trilhando um caminho diferente. Já a energia cinética máxima entre as duas análises numérica possui grande diferença. No RAMMS, a energia cinética é muito maior que no PFC3D, que apresenta uma alta perda de energia no sistema com resistência ao rolamento.

A figura 4.22 mostra a simulação de blocos long no software RAMMS. A maioria ds blocos tendeu para a mesma direção, próxima a cicatriz deixada pelo evento, que está representado pelo traço preto, com somente um dentre os cinquenta blocos se desviando por um caminho diferente. A energia cinética máxima que chega a atingir a rodovia é de $30000 \mathrm{~kJ}$. 


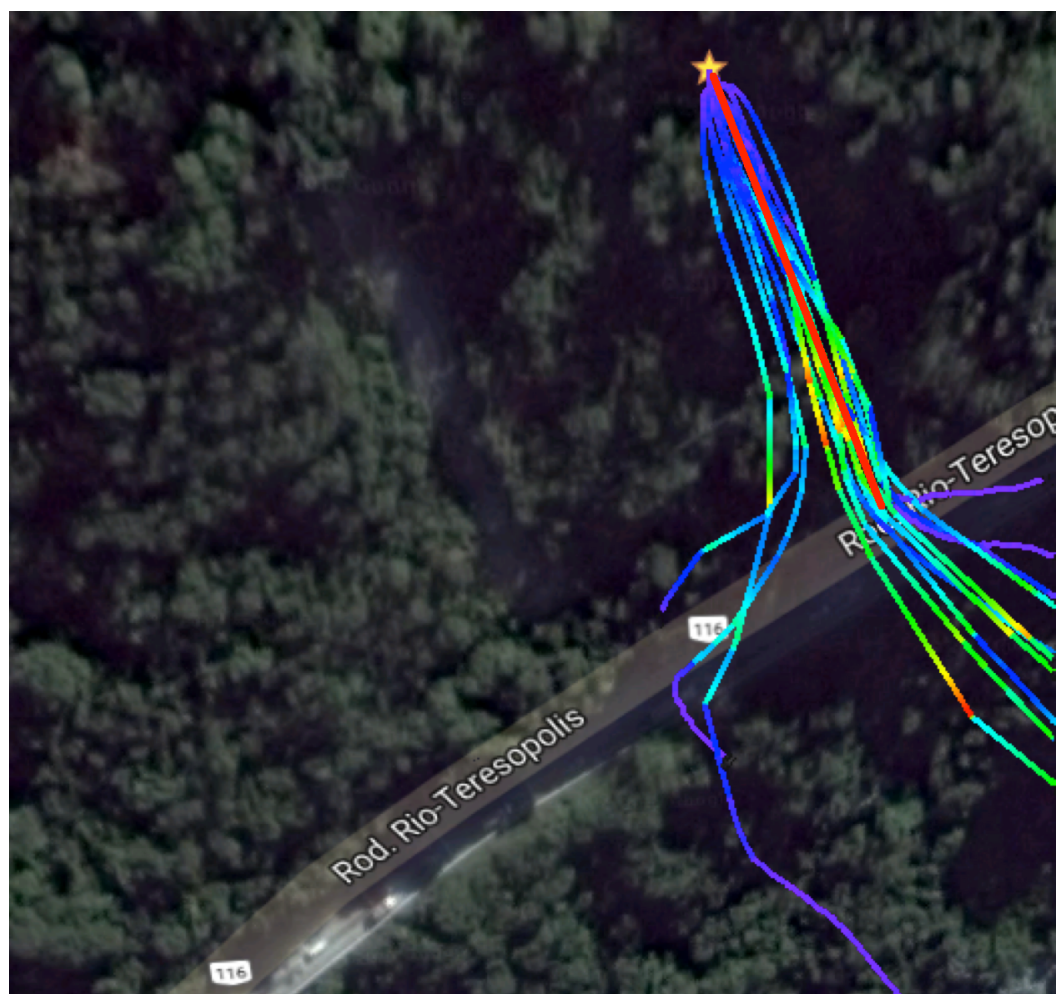

Figura 4.22 - Trajetória de queda de blocos long na BR116 através do RAMMS (Google Maps).

$\mathrm{Na}$ figura 4.23, que apresenta o resultado da simulação de blocos long com o PFC3D, os blocos tendem a seguir a mesma direção, com poucos se esquivando desta trajetória. A energia máxima alcançada por um bloco próximo à rodovia foi de $33000 \mathrm{~kJ}$, apesar do valor alto, a grande maioria apresentou valores bem mais baixos, demonstrando também que está havendo grande perda de energia neste sistema. 


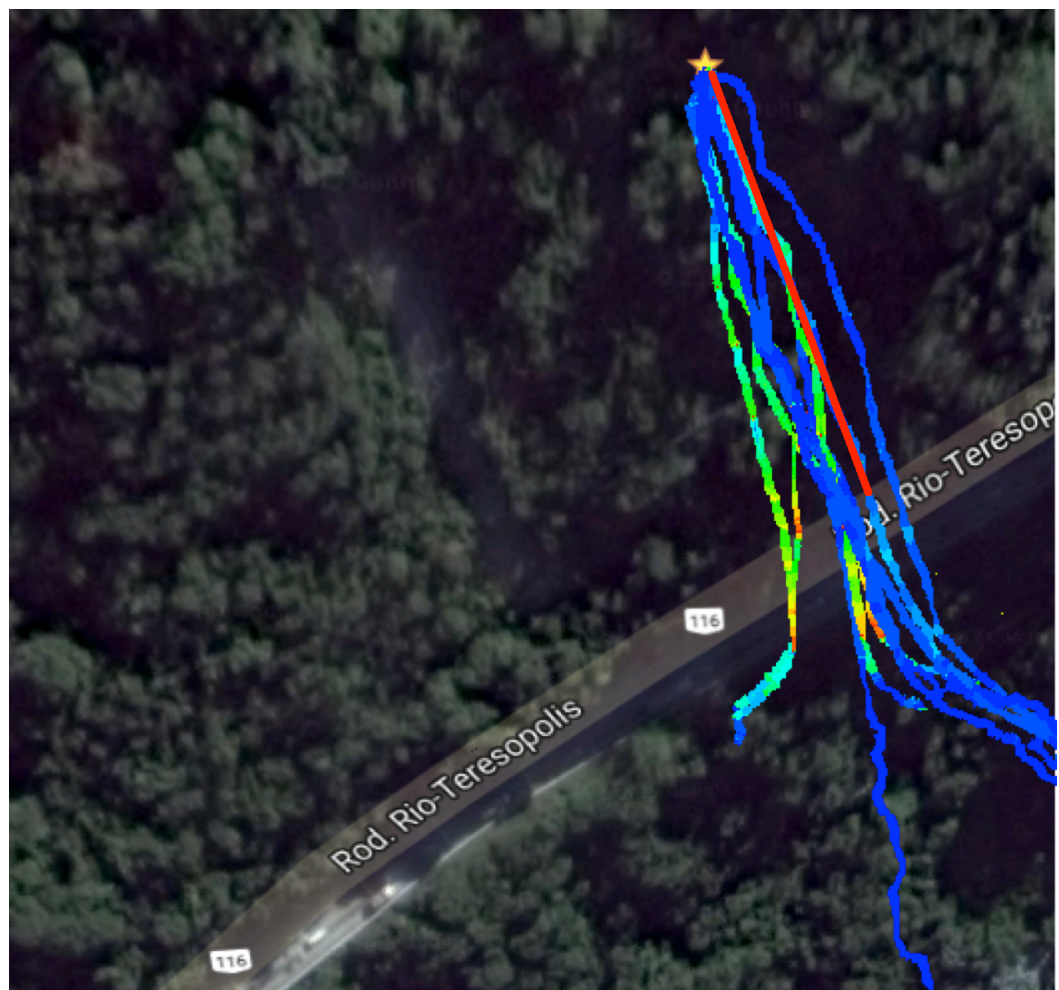

Figura 4.23 - Trajetória de queda de blocos long na BR116 através do PFC3D (Google Maps).

Em ambos os modelos, a trajetória dos blocos foi bem próxima, mas a energia cinética apresentou uma grande diferença entre as diferentes simulações. Uma maior perda de energia cinética ocorre no modelo com a força de resistência ao rolamento, nota-se então, que o valor adotado para o coeficiente de resistência ao rolamento, está fazendo com que o sistema perca mais energia que o necessário.

Villela (2011) realizou uma análise, através do software Rockfall, do impacto dos blocos nas rodovias. Foi definida uma área de susceptibilidade de blocos, realizando várias simulações em $2 \mathrm{D}$ do impacto dos blocos na rodovia, dividiu-se as simulações em 12 seções. Criando no final das simulações uma envoltória de energia (Figura 4.24). 


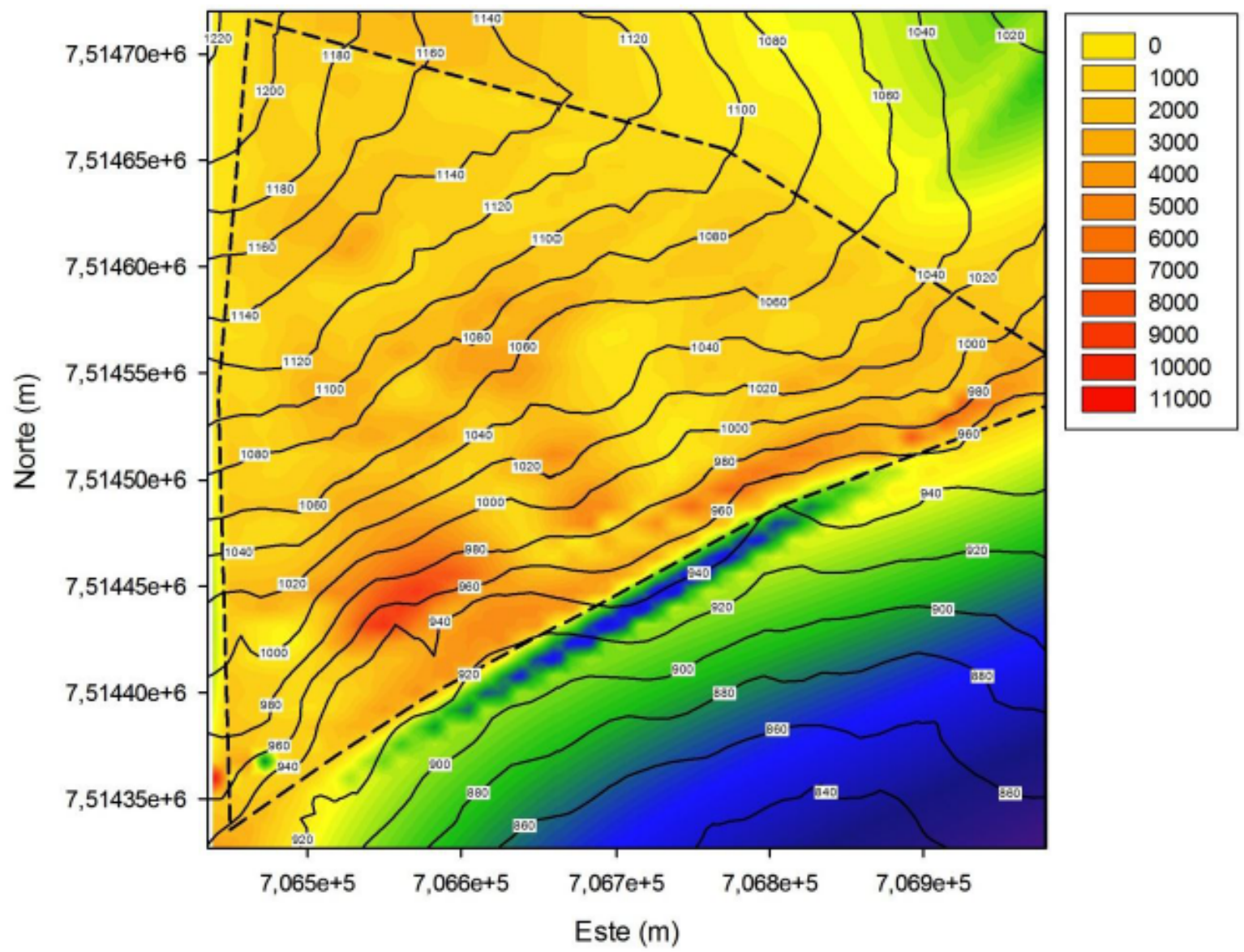

Figura 4.24 - Mapa de isoenergias em kJ considerando camada de solo em toda a superfície (Villela 2011).

Na região onde os blocos se depositaram, Villela (2011) encontrou valores para a energia cinética próximos a 3000 kJ. Este valores estão mais próximos aos obtidos pelos blocos equant no RAMMS.

\section{4}

\section{Análise dos Blocos Susceptíveis a Queda no Município de Petrópolis}

De acordo com as propriedades de cada bloco, doze blocos propensos a queda, foram criados para analisar suas trajetórias e zonas de deposição através de simulações numéricas. Cada bloco foi inserido em sua posição inicial, com velocidade nula; a partir da sua configuração geométrica e inclinação da topografia, seus movimentos iam sendo determinados pelos programas.

Nas primeiras simulações, onde foram realizadas as simulações no software RAMMS, a grande maioria dos blocos atingiram uma longa distância, com grande parte dos blocos chegando a parte mais baixa da região, alcançando as residências. 
Quando o modelo foi realizado com o PFC3D utilizando o modelo linear, os blocos desceram até a parte mais plana da topografia, o que era esperado, já que não há nenhum mecanismo para retardar o rolamento dos blocos. Quando a simulação é comparada com a do modelo RAMMS, percebe-se uma grande semelhança entre os dois programas quanto ao trajeto, mas com os blocos do PFC3D percorrendo uma distância maior.

Através do modelo linear com resistência ao rolamento usando o coeficiente de resistência ao rolamento determinado na primeira parte do trabalho, o retardamento da velocidade do bloco se mostra muito alto quando comparado ao da simulação do RAMMS, a distância percorrida no PFC3D é muito menor que no RAMMS. Os parâmetros determinados no item 4.1 acabaram superestimando a força de resistência ao rolamento, fazendo com que os blocos perdessem todo o seu movimento rapidamente.

A figura 4.25 ilustra uma comparação entre a simulação no PFC3D usando somente o modelo linear com a simulação no software RAMMS. Observa-se que os blocos do PFC3D atingem maiores distâncias, com as rochas perdendo mais velocidade no RAMMS. É notável a semelhança entre a trajetória nos dois programas, com os blocos percorrendo o mesmo trajeto.
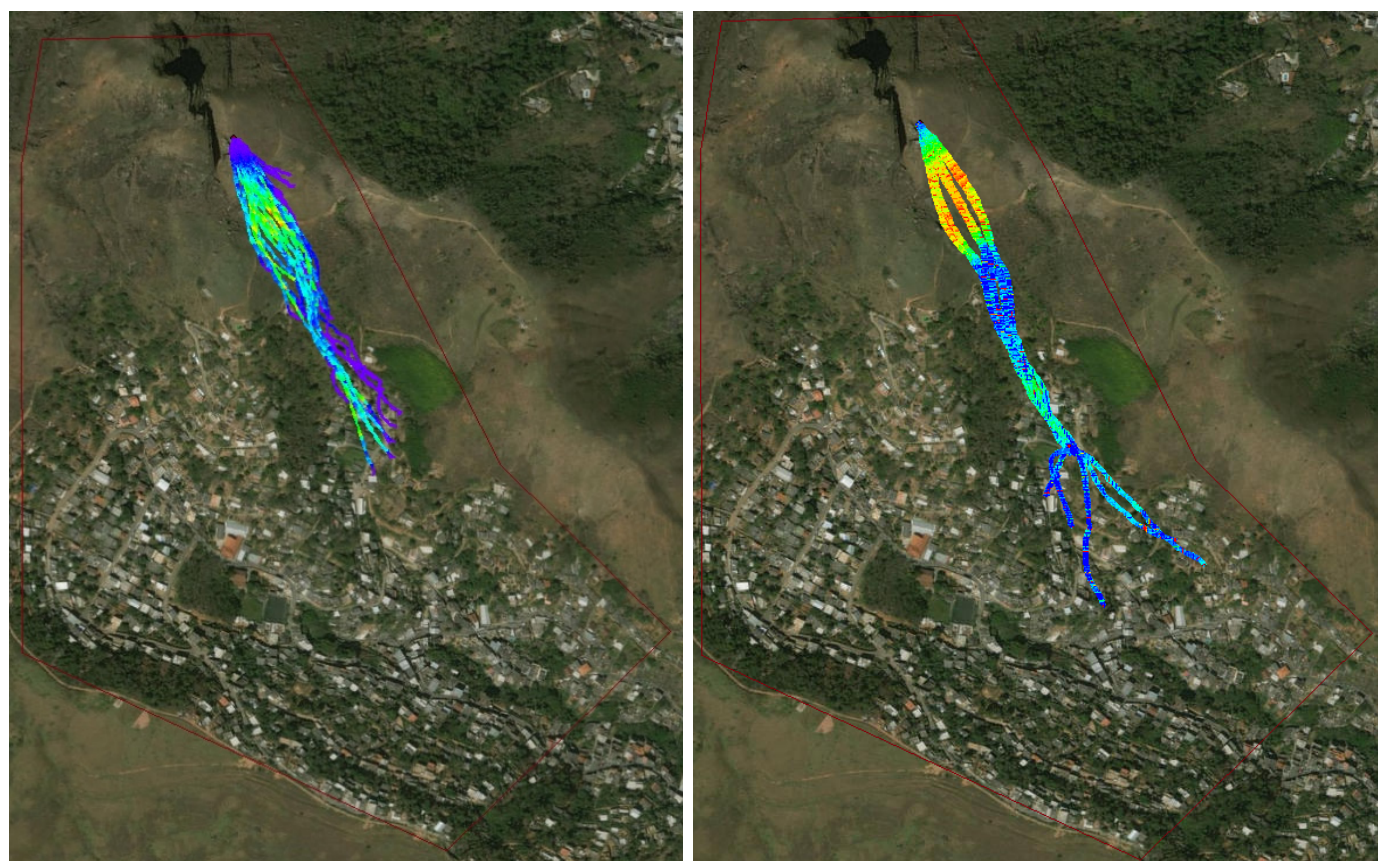

Figura 4.25 - Trajetória do bloco 1 no software RAMMS e no programa PFC3D com modelo linear. 
Todos os blocos simulados no PFC3D com o método linear se depositaram na parte mais horizontal da topografia, como mostra a figura 4.26, que ilustra a trajetória dos blocos 3 e 4 . Isto ocorreu devido a falta de um mecanismo que fizesse com que o bloco perdesse energia cinética enquanto estivesse rolando.

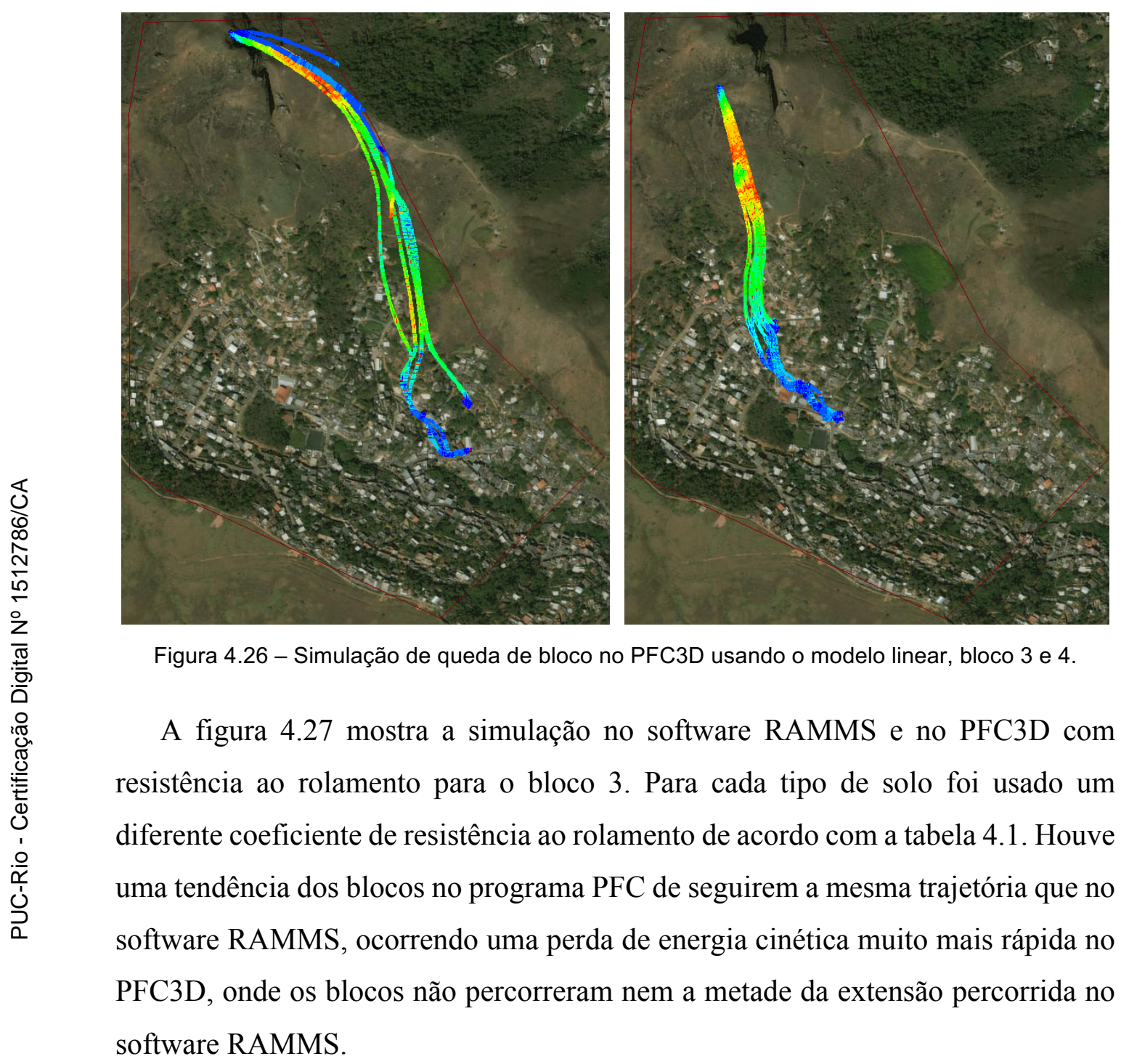



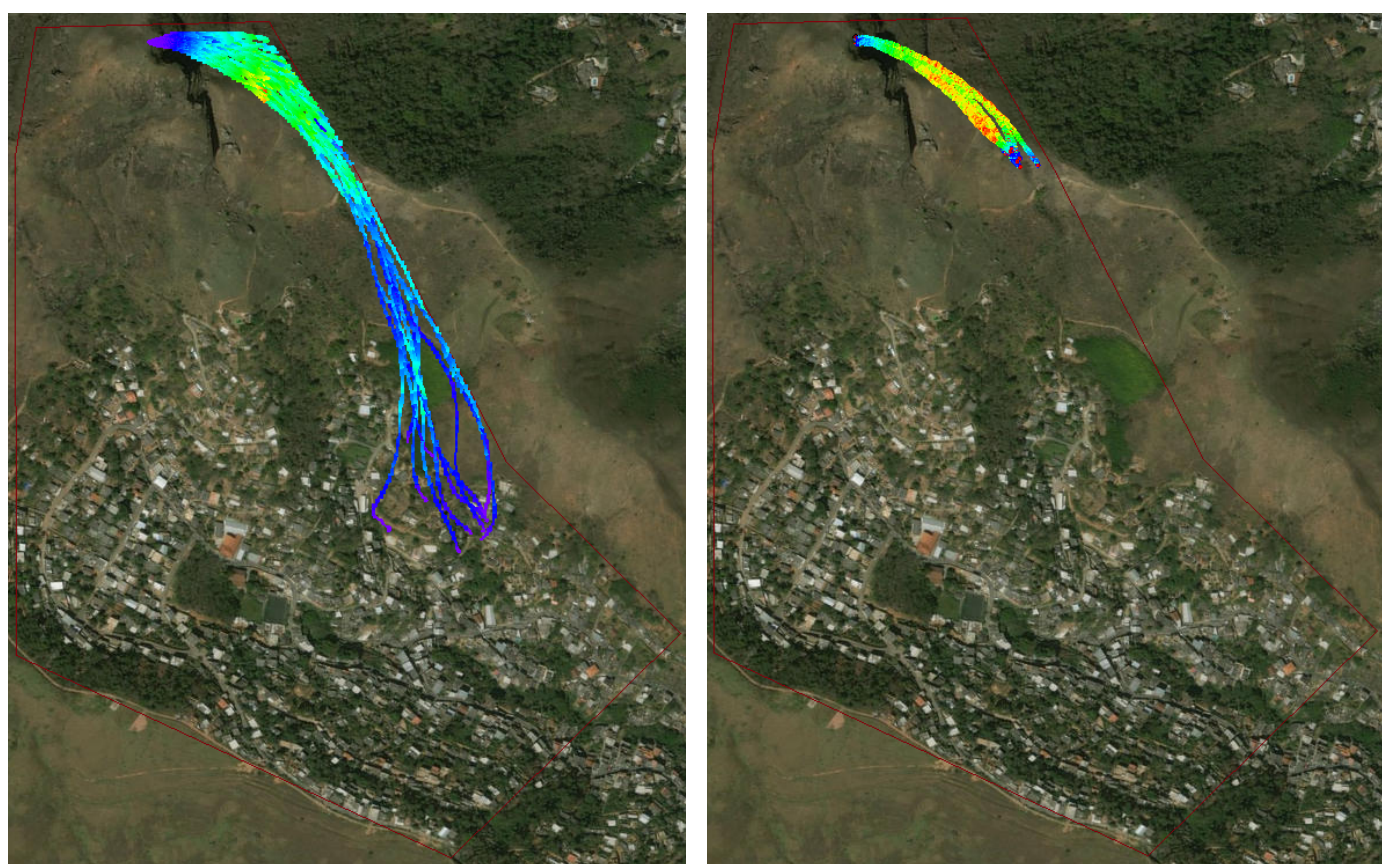

Figura 4.27 - Trajetória do bloco 3 no software RAMMS (a esquerda) e no programa PFC (a direita) com resistência ao rolamento.

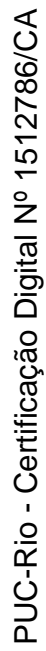

Em alguns casos a resistência ao rolamento foi tão alta os blocos não chegaram a sair da sua posição inicial no PFC3D, enquanto que no software RAMMS eles avançaram na topografia, é o caso do bloco 10 (figura 4.28). Alguns blocos acabaram se desviando da superfícíe definida, como observado nas figuras 4.27 e 4.28, o que acabou por limitar algumas simulações.
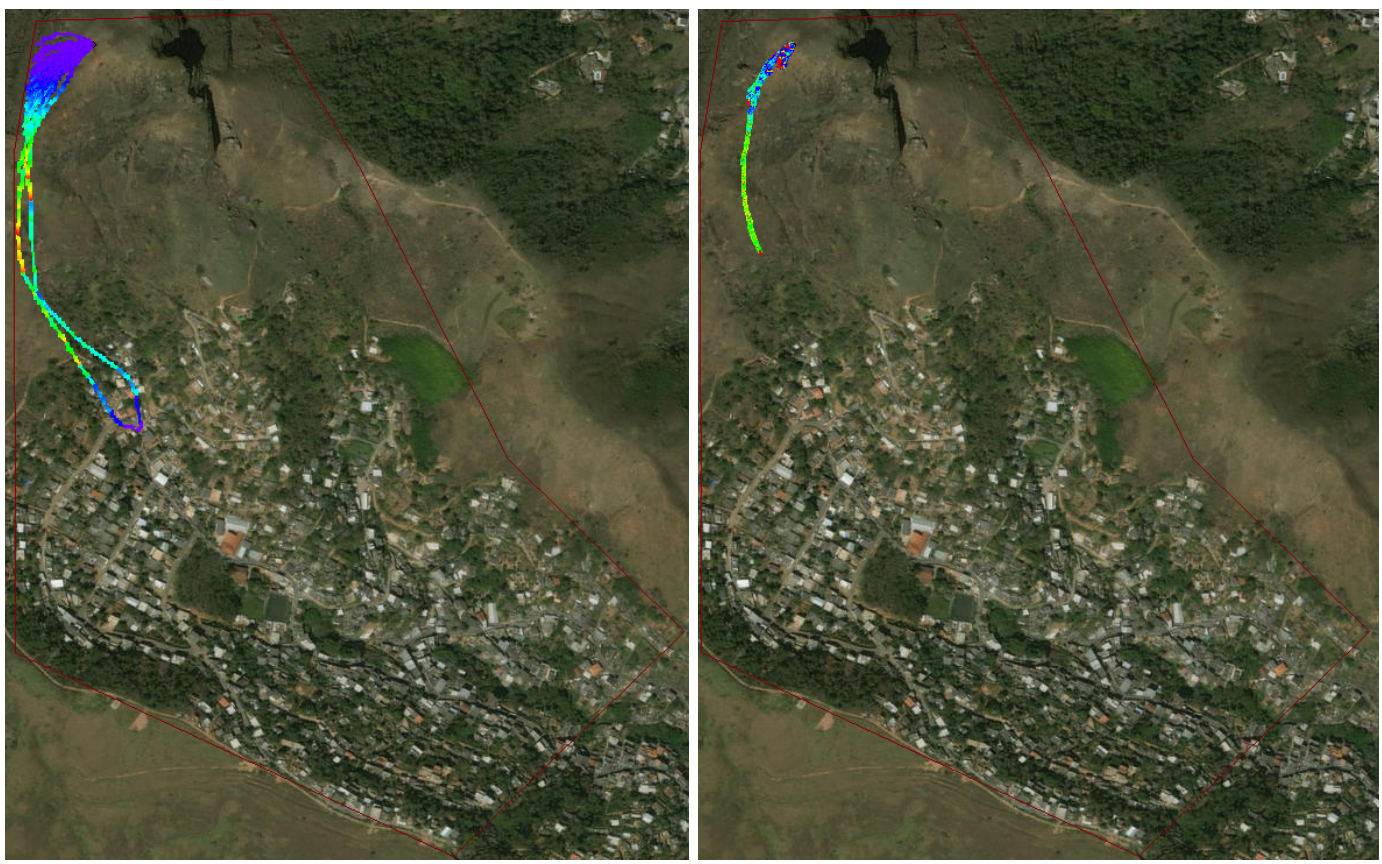

Figura 4.28 - Trajetória do bloco 10 no software RAMMS (à esquerda) e no programa PFC3D (à direita) com resistência ao rolamento. 
O bloco 11 foi um dos blocos que percorreu uma das maiores distâncias no PFC3D quando utilizada a resistência ao rolamento. Isto se deve à maior declividade da região inicial de onde o bloco se encontra, o que permite com que o bloco aumente sua velocidade inicial rapidamente. Para este bloco, as trajetórias nos dois programas foram similares (figura 4.29), mas assim como ocorreu nas outras simulações, no RAMMS as rochas percorreram uma maior distância.

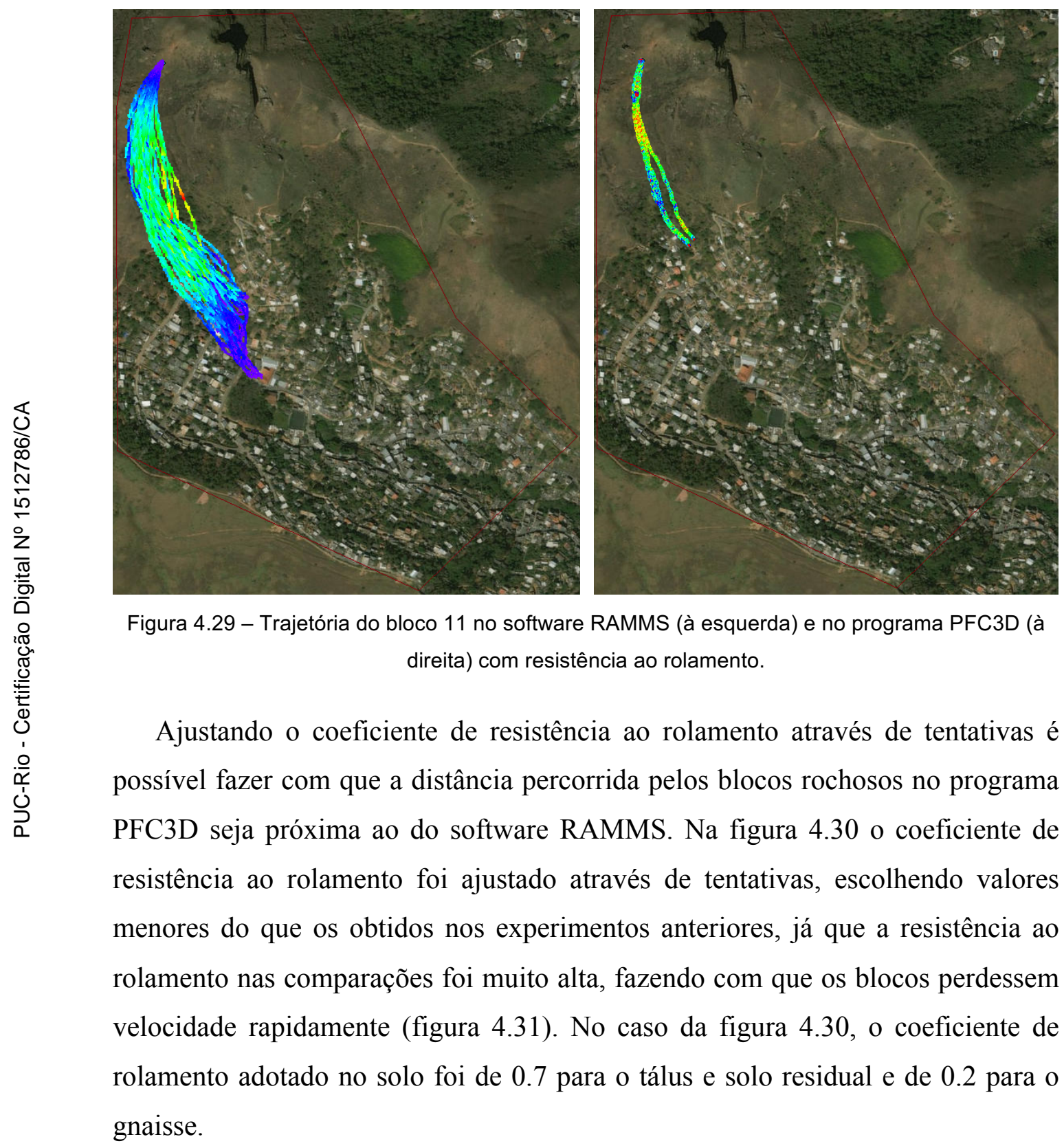



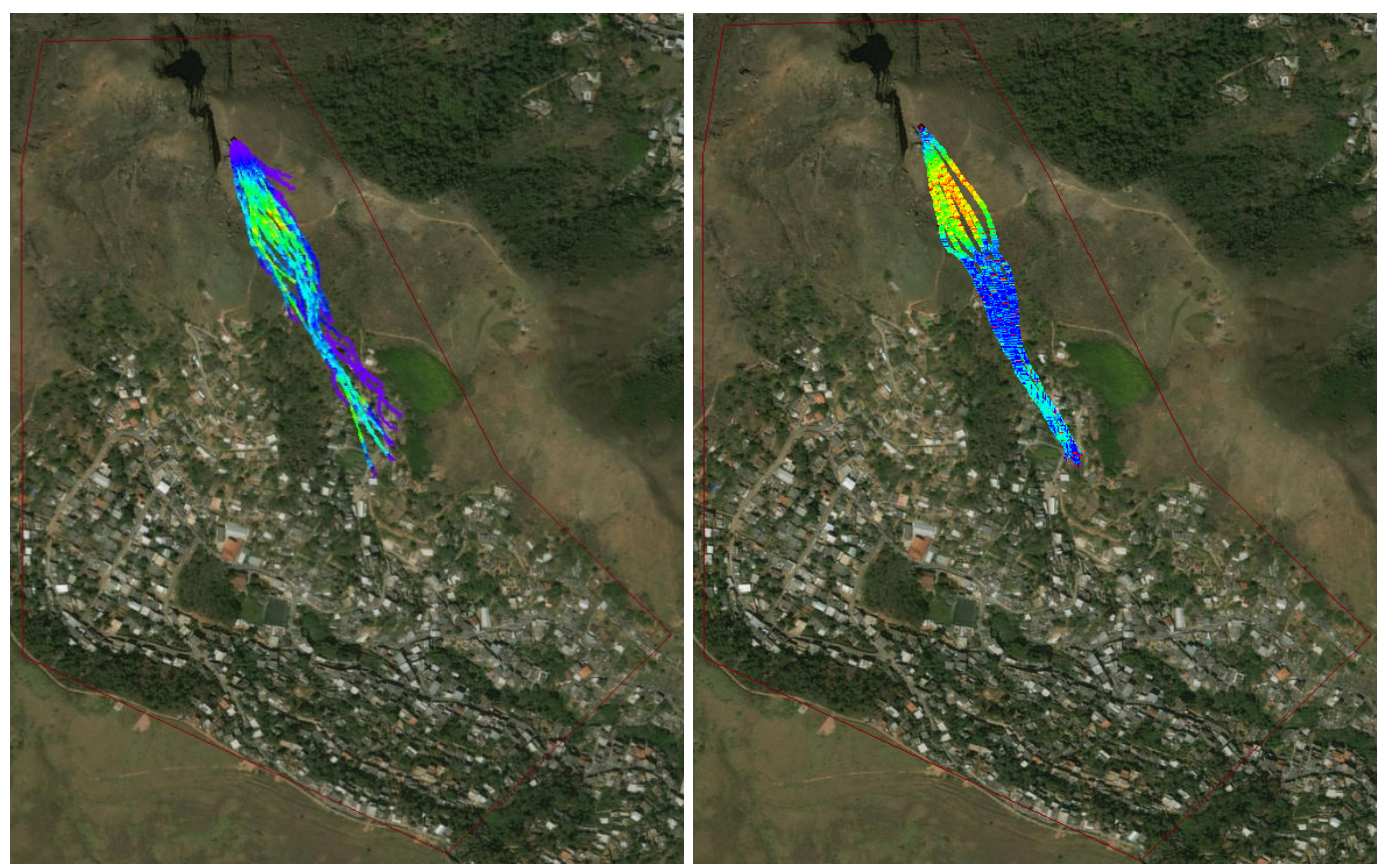

Figura 4.30 - Trajetória do bloco 1 no software RAMMS (à esquerda) e no programa PFC3D (à direita) com resistência ao rolamento ajustado por tentativas.

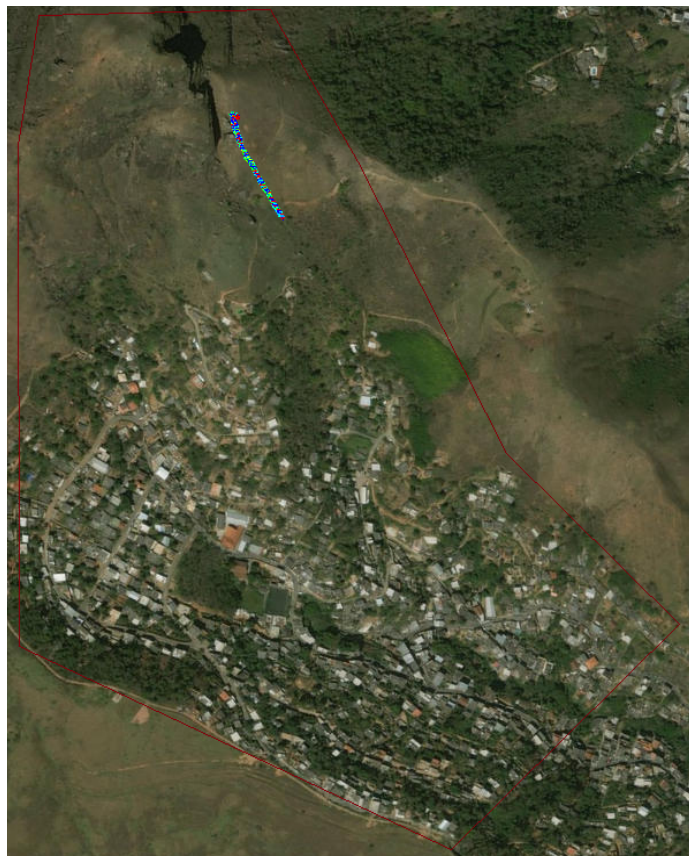

Figura 4.31 - Trajetória do bloco 1 no programa PFC3D com resistência ao rolamento.

Com os mesmos valores do coeficiente de resistência ao rolamento obtidos por tentativas para o bloco 1, simulações para o bloco 2 foram realizadas (figura 4.32), mesmo com os blocos possuindo geometrias diferentes. Percebe-se que os alcances dos blocos entre os dois programas apresentam uma similaridade, percorrendo trajetórias iguais e se depositando em regiões próximas. 

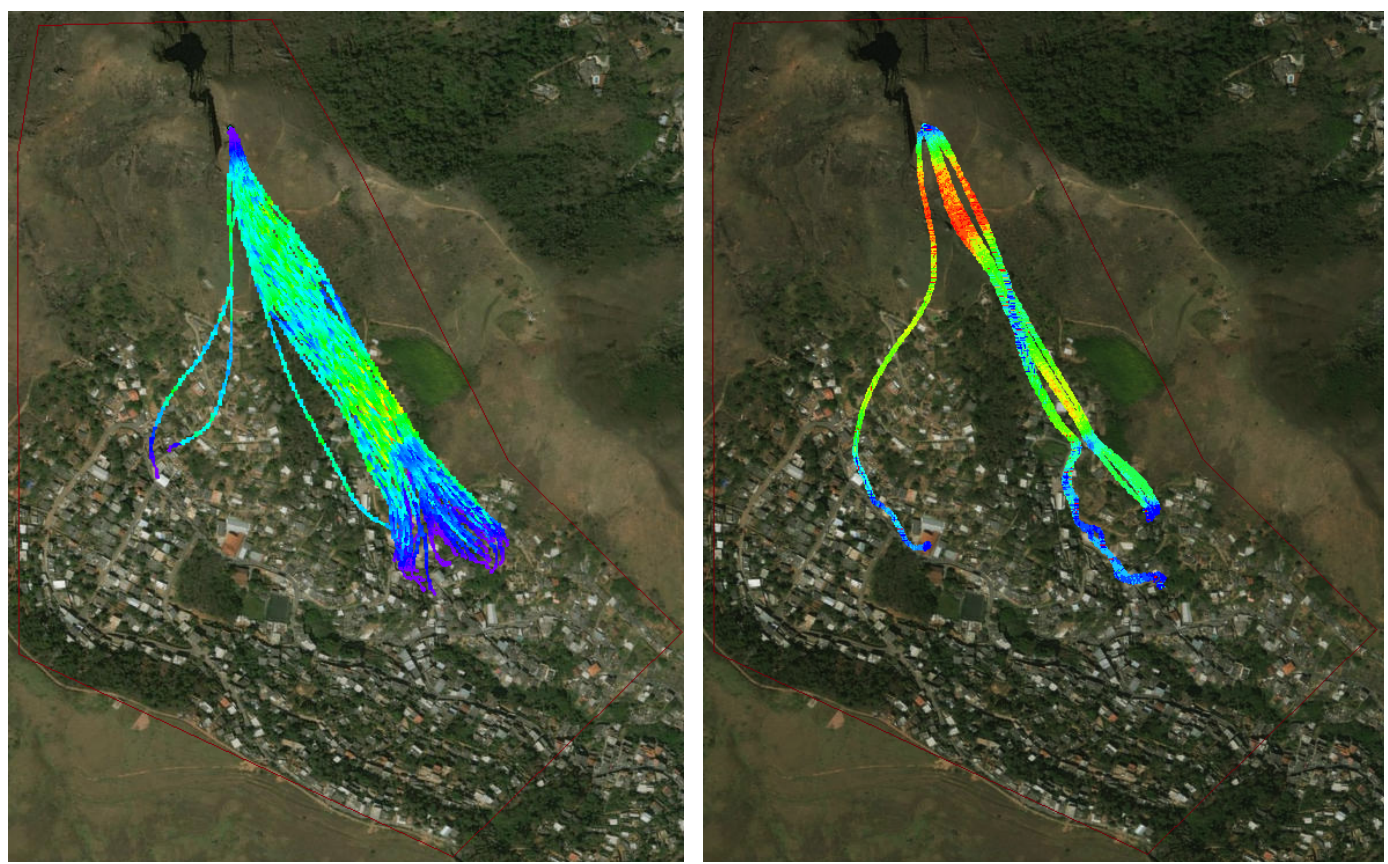

Figura 4.32 - Trajetória do bloco 2 no software RAMMS (à esquerda) e no programa PFC3D (à direita) com resistência ao rolamento ajustado por tentativas.

Uma terceira simulação utilizando os mesmos valores de coeficiente de resistência ao rolamento foi realizada para o bloco 4 (figura 4.33), já que a sua posição inicial difere consideravelmente dos blocos 1 e 2 , que possuem posições inicias parecidas, inclusive quanto a altitude e inclinação da superfície. Os valores adotados para o coeficiente no PFC3D resultaram em uma distância percorrida pelos blocos similar ao do software RAMMS, assim como para a simulação dos blocos 1 e 2 . 

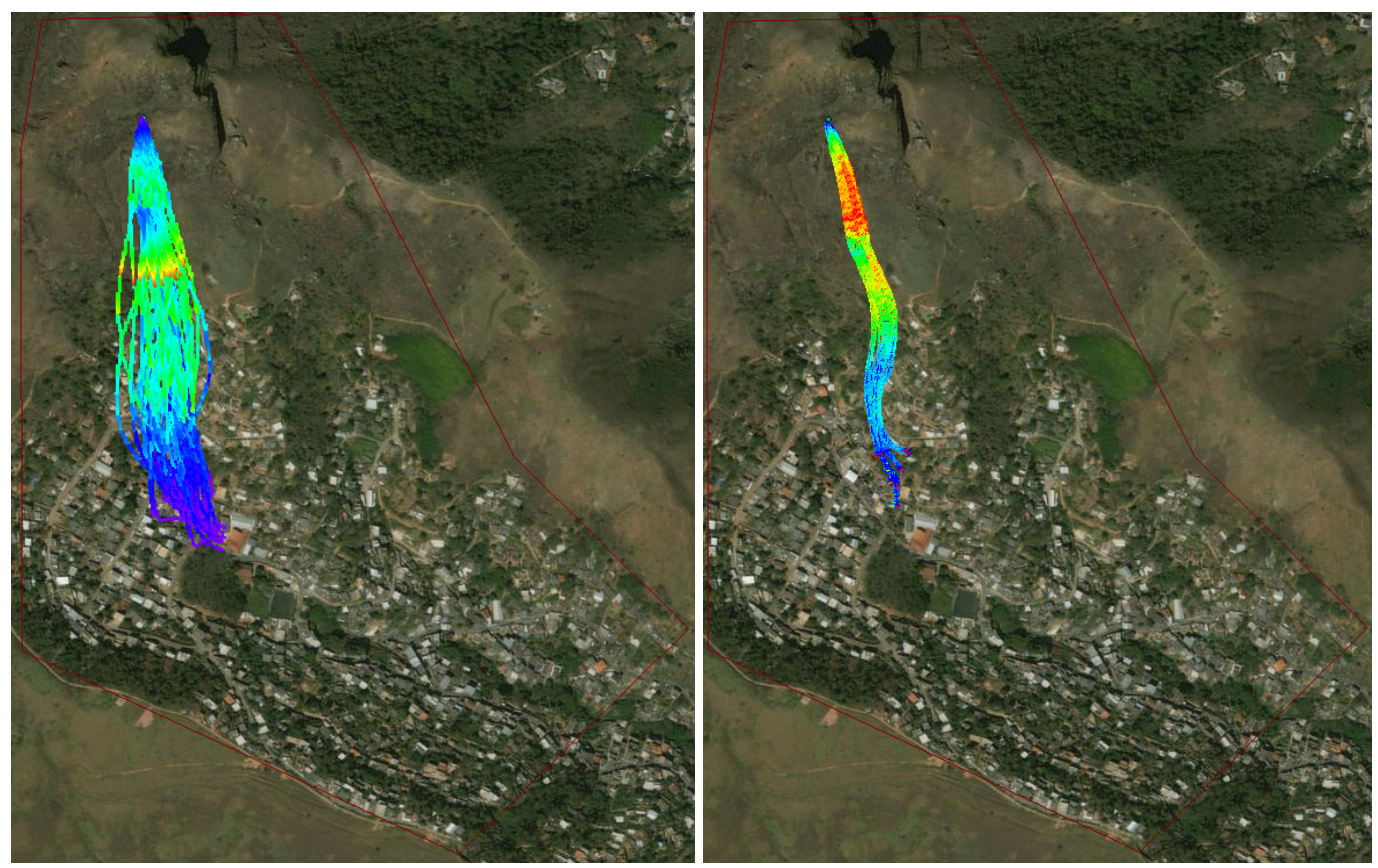

Figura 4.33 - Trajetória do bloco 4 no software RAMMS (à esquerda) e no programa PFC3D (à direita) com resistência ao rolamento ajustado por tentativas.

\section{5 \\ Efeitos da Vegetação na Queda de Blocos}

\subsection{1 \\ Simulação de Árvores como Blocos Rígidos no PFC3D}

No programa PFC3D foram simuladas árvores através de um conjunto de partículas inseridas dentro de um cilindro posicionadas em um plano com inclinação de $50^{\circ}$. O coeficiente de restituição adotado para o impacto árvore-bloco e bloco-superfície foi igual a 0 , havendo perda total de energia. O presente modelo visa observar a trajetória dos blocos quando entram em contato com algum obstáculo em seu caminho, por exemplo, árvores.

A figura 4.34 mostra a queda de bloco quando as árvores são inseridas no meio do percurso. As árvores acabam gerando grandes modificações na trajetória dos blocos, gerando uma maior dispersão na zona de deposição das rochas. A velocidade, neste caso, também é afetada, havendo grande perda de energia quando os blocos entram em contato com as árvores. 


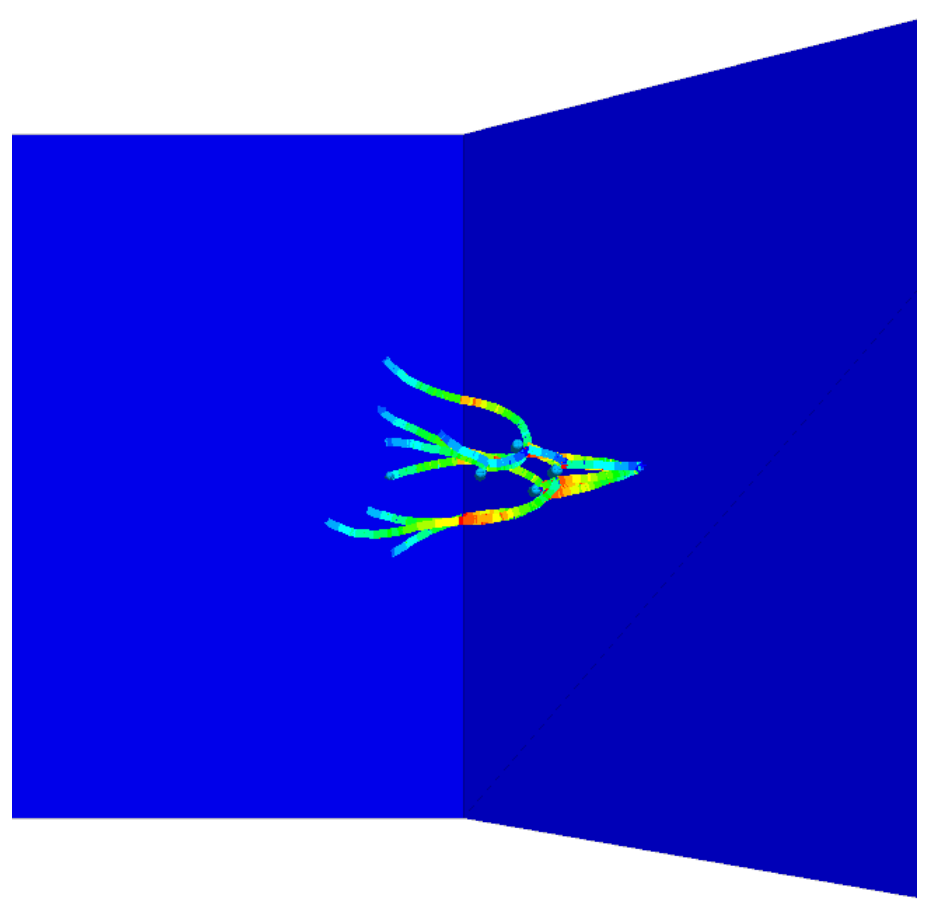

Figura 4.34 -Simulação de queda de blocos com árvores no percurso usando o PFC3D.

Na figura 4.35 é possível comparar o evento quanto a presença ou não de árvores no trajeto dos blocos em queda. Confirma-se através das figuras que as árvores retardam significativamente o percurso alcançado pelos blocos, servindo como um eficiente agente de proteção para este tipo de desastre.
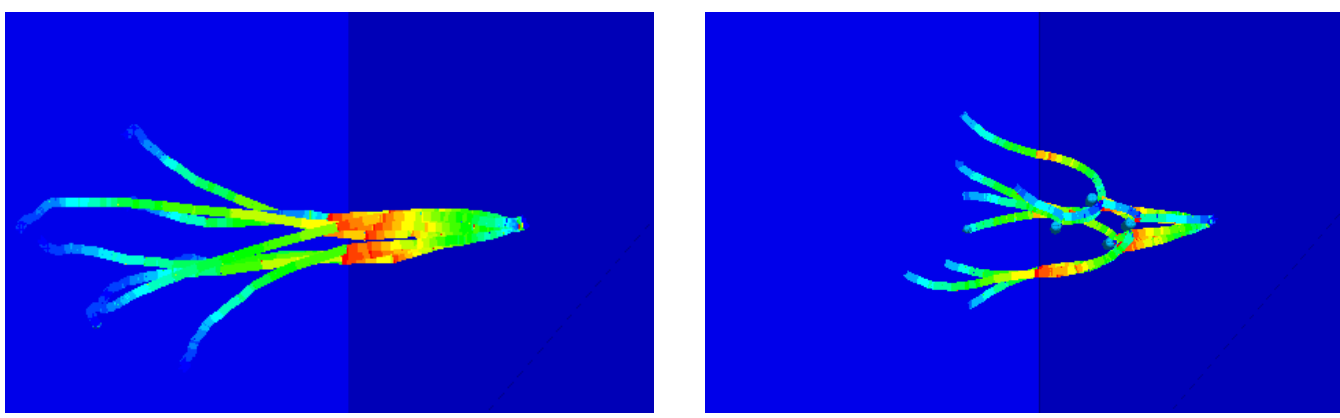

Figura 4.35 - Modelos de queda de blocos sem árvores e com árvores.

\subsection{2}

Efeitos da Vegetação para casos reais no estado do Rio de Janeiro através do software RAMMS

No primeiro caso, onde há somente uma cobertura vegetal no final da encosta, os experimentos foram realizados com os blocos long, geometria mais comum encontrada no local. A figura 4.36 mostra a trajetória e a zona de deposição dos 
blocos na região. Os blocos se concentram logo no final da superfície inclinada, não possuindo energia o suficiente para continuar a trajetória.

No segundo caso, foi realizado o mesmo experimento, mas sem cobertura vegetal. Este experimento representa casos onde a cobertura vegetal foi removida por movimentos de massa anteriores. Na figura 4.37 é notável a maior trajetória percorrida pelo bloco devido a remoção da cobertura vegetal, havendo também uma maior dispersão das rochas.

Observa-se que este modelo possui uma grande desvantagem quando comparado com o PFC3D, pois não é possível adicionar as árvores explicitamente para que elas modifiquem a trajetória dos blocos em queda. Elas atuam apenas como um sistema de perda de energia no sistema. 


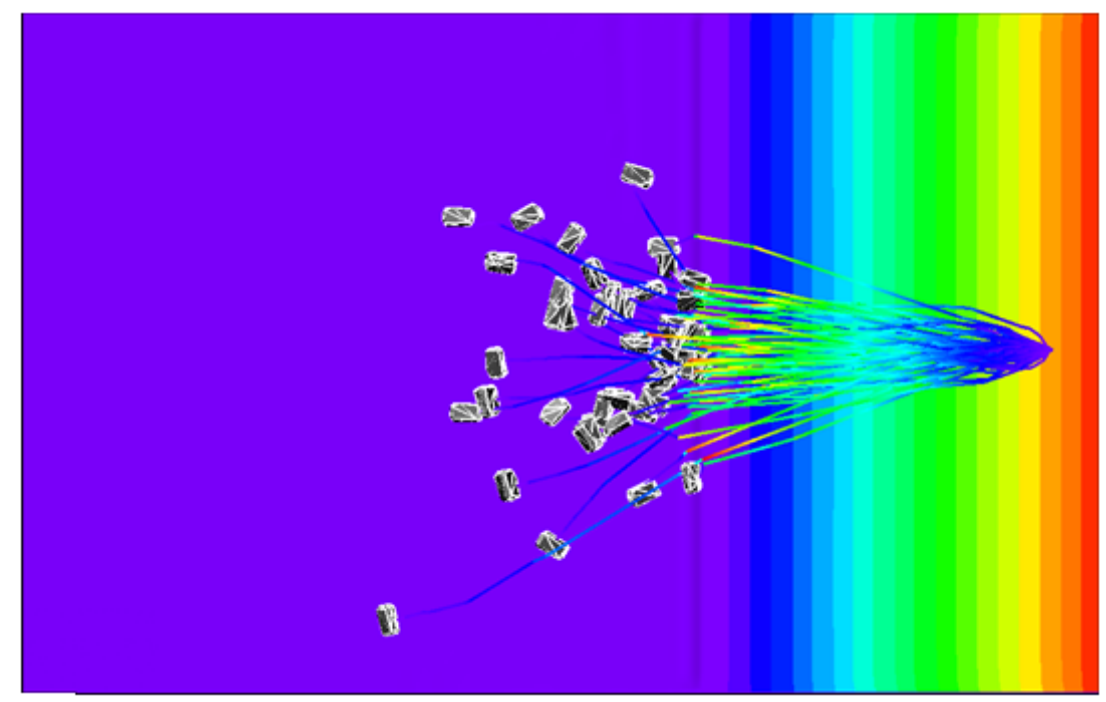

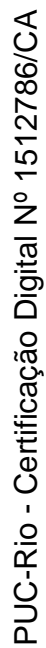

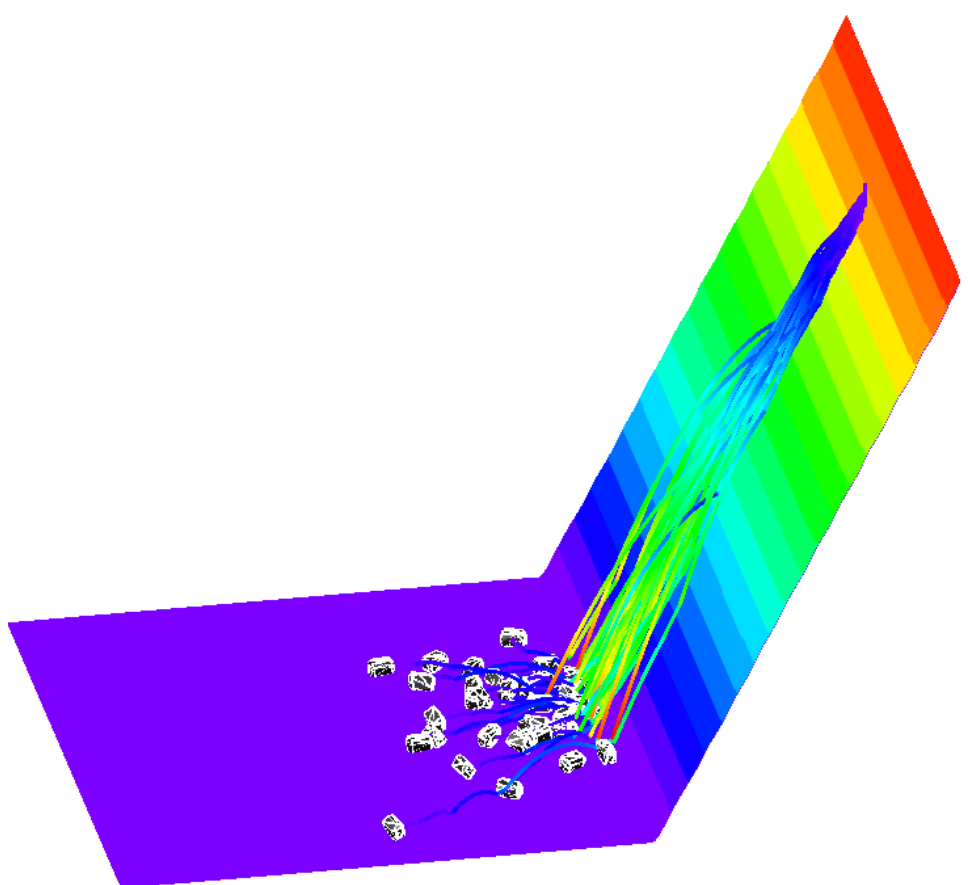

Figura 4.36 - Trajetória e Zona de Deposição dos Blocos para o caso 1 - com vegetação. 


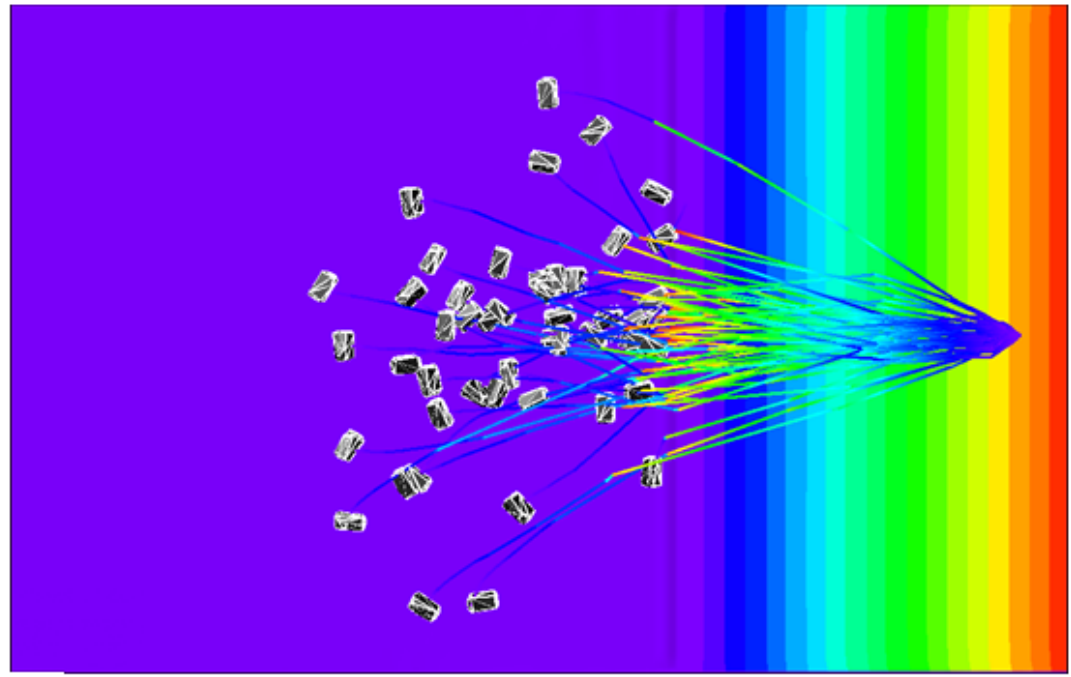

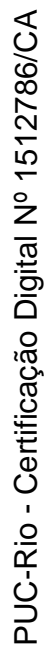

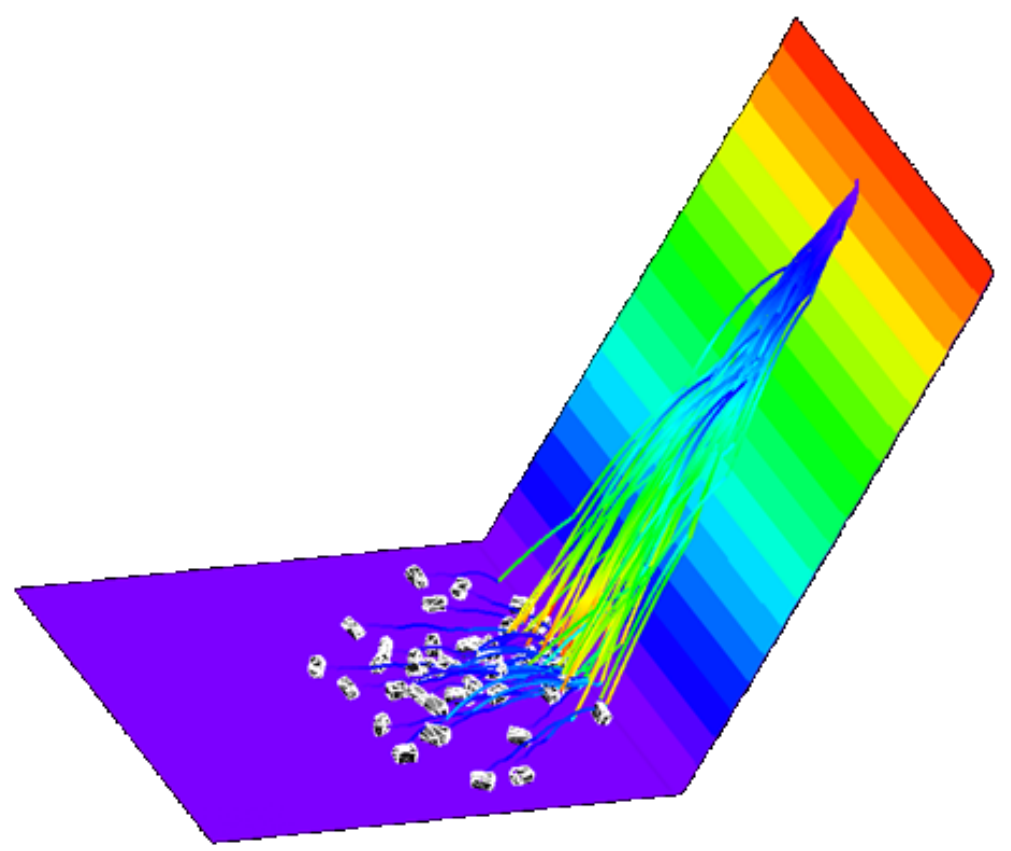

Figura 4.37 - Trajetória e Zona de Deposição dos Blocos para o caso 2 - sem vegetação. 


\section{5 \\ Conclusão}

\section{1}

\section{Conclusões Gerais}

Neste capítulo se encontram as conclusões finais dos resultados apresentados nos capítulos anteriores. São fornecidas as principais análises quanto à modelagem de queda de blocos usando o software RAMMS e o programa PFC3D, tanto com o modelo linear quanto com a adição da resistência ao rolamento. São também apresentadas algumas considerações quanto aos principais parâmetros que interferem no comportamento de queda de blocos, expondo críticas quanto a influência da declividade da topografia e da geometria do bloco no processo de queda.

- Comparando as simulações no software RAMMS e no programa PFC3D utilizando o modelo linear conclui-se que este modelo não consegue simular o processo de queda através de todos os modos de velocidade. O modelo linear não é eficiente para simular o processo quando este ocorre em solos mais macios, devido a viscoplasticidade deste tipo de solo, o que ocasiona uma maior perda de enegia cinética do sistema. E também quando a rocha é mais alongada, já que a perda de energia ocorre também por rolamento. Quando ocorre o contato de blocos mais alongados, mais pontos de contato com a superfície ficam ativos, fazendo com que o sistema perca mais energia, este efeito não ocorre no DEM com o modelo linear.

- No PFC3D, o modelo linear com resistência ao rolamento mostrou-se mais eficiente para simular o processo de queda de blocos. Com a adição da resistência ao rolamento foi possível fazer com que os blocos alcançassem todas as distâncias alcançadas no software RAMMS na primeira parte dos experimentos, mostrando que o método consegue cobrir uma extensão de trajetória mais ampla do que somente o modelo linear. 
- Para a simulação da queda de blocos na BR116 há uma tendência, em ambos os programas, da trajetória do bloco de seguir o caminho por onde ocorreu os deslizamentos, que foi identificado por uma cicatriz no local. Quando a energia cinética foi medida, a energia alcançada pelos blocos no software RAMMS é maior que no PFC3D, o que indica que no PFC3D possa estar ocorrendo uma perda de energia maior do que a que deveria ocorrer. E quando é comparada a trajetória da queda dos blocos em ambos os programas, ela possui uma alta similaridade em ambos os casos. Concluindo que uma melhora na calibração do modelo linear com resistência ao rolamento precisa ser realizada.

- A simulação do caso Petrópolis usando o software RAMMS mostrou uma similaridade na zona de deposição dos blocos simulados, a maioria alcançando uma grande distância, sendo possível determinar locais onde estes eventos teriam maior impacto, a fim de prover uma maior segurança para a infraestrutura e residentes da região. Quando o caso é analisado pelo PFC3D com modelo linear, é clara a grande dificuldade do bloco em perder energia cinética, apesar da trajetória parecida com os modelos simulados pelo software RAMMS. Todos os blocos perderam sua velocidade na região mais plana da topografia, mesmo com o coeficiente de restituição igual a 0 , o que acaba reafirmando que este método precisa de outros mecanismos de perda de energia. Já com a simulação realizada com o modelo linear adicionando uma resistência ao rolamento, as simulações mostraram que o método de escolha para o coeficiente de resistência ao rolamento não foi suficiente para que o alcance dos blocos fosse parecido com o do software RAMMS, mesmo com a trajetória permanecendo similar, houve uma perda de velocidade maior que a esperada. $\mathrm{O}$ modelo linear com resistência ao rolamento mostra-se mais eficiente que somente o método linear, como mostrou o experimento através de tentativas, devido a sua capacidade de fazer com que o sistema perca mais energia.

- A presença de vegetação mostrou-se eficiente em ambos os programas como um mecanismo de perda de energia do sistema. Entretanto, os 
dois programas apresentam grandes diferenças quanto à simulação da vegetação, no $\mathrm{PFC} 3 \mathrm{D}$ as árvores foram representadas como um material rígido, o que acaba afetando a trajetória dos blocos. Já no RAMMS, a vegetação é representada somente como um fator de perda de energia quando em contato com o bloco, não afetando a sua trajetória. Quando inserida a vegetação no software RAMMS, a perda de velocidade dos blocos foi significativa, e dependendo da área coberta com a vegetação, os blocos podem perder todo o seu movimento antes mesmo de chegar ao final da encosta. Já no DEM as árvores também contribuíram muito para a perda de energia do sistema, fazendo com que os blocos alcançassem uma distância menor, e nesta simulação também é possível notar a dispersão causada pelas árvores, o que acaba por determinar uma região de deposição das rochas mais dispersa e de menor alcance.

\section{2 \\ Sugestões para Futuros Trabalhos}

Durante o trabalho e com essas variadas simulações númericas, inúmeras questões passam a ser apontadas. Serão apresentadas algumas sugestões para futuros trabalhos para que o comportamento mecânico do processo de queda de blocos seja melhor compreendido e seu conhecimento ampliado.

- Uma investigação mais detalhada do coeficiente de resistência ao rolamento é necessária. Há poucos estudos envolvendo este modelo, e melhores resultado virão com mais experimentos numéricos e em campo. A realização de um campo experimental para que se possa analisar os diferentes tipos de movimentos dos blocos, a fim de compará-los com os experimentos numéricos e introduzi-los nas simulações.

- Mais estudos sobre a influência da vegetação na queda de blocos e estudos experimentais sobre os meios de perda de energia dos sistema rochaárvore. 
6

\section{Referências bibliográficas}

ACARY, V., BROGLIATO, B. Numerical Methods for Nonsmooth

Dynamical Systems; Applications in Mechanics and Electronics. Lecture Notes in Applied and Computational Mechanics, vol. 35. Springer, Berlin (2008).

AN, B.; TANNANT, D.D. Discrete element method contact model for dynamic simulation of inelastic rock impact. Computers \& Geosciences. v. 33, p. 513-52. 2007.

Al, J., J. F. CHEN, J. M. ROTTER, AND J. Y. OOI. Assessment of Rolling Resistance Models in Discrete Element Simulations, Powder Technology, 206, 269-282, 2011.

BLOTT, S. J. AND PYE, K. (2008). Particle shape: a review and new methods of characterization and classication. Sedimentology, 55(1):31-63.

BOURRIER F., DORREN L., NICOT F. Towards objective rockfall trajectory simulation using a stochastic impact model, Geomorphology, vol. 110, pp. 68-79, 2009.

BOURRIER F., ECKERT N., NICOT F. Bayesian stochastic modeling of a spherical rock bouncing on a coarse soil, Natural Hazards and Earth System Sciences, vol. 9, pp. 831-846, 2009.

BRAUNER M., WEINMEISTER W., AGNER P., VOSPERNIK S. AND HOESLE $B$. Forest management decision support for evaluating forest protection effects against rockfall. Forest Ecology and Management, 207(1-2):75-85. 2005.

CHRISTEN M., BARTELT P., GRUBER U. RAMMS - a modelling system for snow avalanches, debris flows and rockfalls based on IDL, PFG Photogrammetrie - Fernerkundung - Geoinformation, vol. 4, pp. 289-292, 2007.

CHRISTEN, M., BÜHLER, Y., BARTELT, P., LEINE, R., GLOVER, J., SCHWEIZER, A., GRAF, C., MCARDELL, B., GERBER, W., DEUBELBEISS, Y., FEISTL, T., VOLKWEIN, A. Integral hazard 
management using a unified software environment: numerical simulation tool "RAMMS" for gravitational natural hazards. In: Koboltschnig, G., Hübl, J., Braun, J. (eds.) Proceedings of 12th Congress INTERPRAEVENT, vol. 1, pp. 77-86 (2012).

CHRISTEN, M., KOWALSKI, J., BARTELT, P.: RAMMS: Numerical simulation of dense snow avalanches in three-dimensional terrain. Cold Reg. Sci. Technol. 63, 1-14 (2010).

CROSTA G.B., AGLIARDI F. Parametric evaluation of 3D dispersion of rockfall trajectories, Natural Hazards and Earth System Sciences, vol. 4, pp. 583-598, 2004.

CUNDALL P.A.; STRACK O.D.L. A discrete numerical model for granular assemblies, Geotechnique, 29(1), 47-65, 1979.

DESCOEUDRES F., ZIMMERMAN T. Three-dimensional dynamic calculation of rockfalls, International Society for Rock Mechanics, Rotterdam, pp. 337-342, 1987.

DONZÉ, F.V.; RICHEFEU, V.; MAGNIER S. A. Advances in Discrete Element Method Applied to Soil, Rock and Concrete Mechanics, Electronic Journal of Geotechnical Engineering, 2009: 44p.

DORREN L.K.A. AND BERGER F. Stem breakage of trees and energy dissipation during rockfall impacts. Tree Physiology, 26:63-71. 2006.

DORREN L., MAIER B., PUTTERS U.S. Combining field and modelling techniques to assess rockfall dynamics on a protection forest hillstop in the European Alps, Geomorphology, vol. 57, pp. 151-167, 2004.

FOETZKI A., JONSSON M.J., KALBERER M., SIMON H. AND LUNDSTRÄOM T. Interaction between trees and natural hazards in subalpine spruce forests. In 'TRACE, Tree Rings in Archaeology, Climatology and Ecology: Proceedings of the Dendrosym-posium 2004, 22 April - 24 April, 2004', pp. 54-57. Swiss Federal Institute of Forest, Snow and Landscape Research (WSL) Birmensdorf. 2004.

FRÉMOND, M. Rigid bodies collisions. Phys. Lett. A 204, 33-41 (1995).

GERBER, W. Directive on the type testing of protective nets against rockfall. Tech. rep., Bundesamt fur Umwelt,Wald und Landschaft (BUWAL), Eidgen ossische Forschungsanstalt WSL, Bern. 2001 
GLOCKER, C. Set-Valued Force Laws, Dynamics of Non-Smooth Systems. Lecture Notes in Applied Mechanics, vol. 1. Springer, Berlin (2001).

GLOCKER, C. Energetic consistency conditions for standard impacts. Part I. Newton-type inequality impact laws and Kane's example. Multibody Syst. Dyn. 29, 77-117 (2013).

GLOVER J. Rock-shape and its role in rockfall dynamics, Durhan, Thesis (PhD in geography) - Durham University. 2015.

HU, G.; HU, Z.; JIAN B.; LIU L.; WAN H. On the Determination of the Damping Coefficient of Non-linear Spring-dashpot System to Model Hertz Contact for Simulation by Discrete Element Method. Journal of Computers. V.6, nº 5, p. 984-988, 2011.

ITASCA. Manual do Programa PFC-3D (Particle Flow Code in 3 Dimensions), Versão 3.0. Minneapolis, Minnesota, Estados Unidos. 1999.

JEAN, M.: The non smooth contact dynamics method. Comput. Methods Appl. Mech. Eng. 177, 235-257 (1999).

JINGCAI J.; KAZUYOSHI Y.; TAKUO Y. Identification of dem parameters for rockfall simulation analysis. Chinese Journal of Rock Mechanics and Engineering. V 27. N12. (2008).

JING L. Fundamentals of Discrete Element Methods for Rock Engineering: Theory and Applications, Elsevier Science, 2007.

JONSSON, M, J. O. Energy absorption of trees in a rockfall protection forest. PhD thesis, Eidgenssische Technische Hochschule, Switzerland.(2007).

KRUMBEIN, W. Measurement and geological signi_cance of shape and roundness of sedimentary particles. Journal of Sedimentary Petrology, 11:64:72. 1941.

LEINE, R.I., SCHWEIZER A., CHRISTEN M., GLOVER J., BARTELT P., GERBER W. Simulation of rockfall trajectories with consideration of rock shape. Multibody System Dynamics, Volume 32, pp 241-271. 2014.

LEINE, R.I., VAN DE WOUW, N.: Stability and Convergence of Mechanical Systems with Unilateral Constraints. Lecture Notes in Applied and Computational Mechanics, vol. 36. Springer, Berlin (2008). 
LISJAK, A.; SPADARI, M.; GIACOMINI A.; GRASSELLI G. Rock fall numerical modelling using a combined finite-discrete element approach. SYMPOSIUM ROCK SLOPE STABILITY-RSS2010 - 24-25 November 2010 - Paris. 2013.

MOREAU, J.J.: Unilateral contact and dry friction in finite freedom dynamics. In: Moreau, J.J., Panagiotopoulos, P.D. (eds.) Non-smooth Mechanics and Applications. CISM Courses and Lectures, vol. 302, pp. 1-82. Springer, Wien (1988).

O'SULLIVAN C. Particulate Discrete Element Modeling: A Geomechanics Perspective, Spon Press, 2011.

RAMMS::ROCKFALL User Manual. A numerical model for rockfall in research and practice, 2016, $101 \mathrm{p}$.

RADTKE, A., TOE, D., BERGER, F., ZERBE, S., AND BOURRIER, F. (2014). Managing coppice forests for rockfall protection: lessons from modeling. Annals of Forest Science, 71:485-495. (2014).

RIBEIRO R. S. Simulação do processo de queda de blocos em encostas com aplicação da mecânica do contato e do método dos elementos discretos, Rio de Janeiro, Tese (Doutorado em Geologia) Programa de Pós-Graduação em Geologia da UFRJ, 2013.

RICHEFEU V.; CUERVO S.; DAUDON D.; VILLARD P.; LORENTZ J. Discrete Element Modeling of a Rockfall in the South of the "Massif Central", France, Engineering Geology for Society and Territory - Volume 2 p 1657-1661, 2005.

RICHEFEU V.; DAUDON D.; VILLARD P. Discrete modelling of rock avalanches: sensitivity to block and slope geometries, Granular matter. 2015.

SNEED, E. D. AND FOLK, R. L. Pebbles in the lower colorado river, texas, a study in particle morphogenesis. Journal of Geology, 66 (2):114-150. 1958.

STOFEL, M. AND PERRET, S. Reconstructing past rockfall activity with tree rings: Some methodological considerations.

Dendrochronologia, 24(1):1-15. 2006.

STO_EL, M., WEHRLI, A., KHNE, R., DORREN, L. K., PERRET, S., AND KIENHOLZ, H. (2006). Assessing the protective effect of mountain forests against rockfall using a 3D simulation model. Forest Ecology and Management, 225(1-3):113-122. (2006).

TAGHAVI R. Automatic clump generation based on mid-surface. Itasca Consulting Group, Inc., Minneapolis, MN, USA (2011). 
THOENI K.; GIACOMINI A.; LAMBERT C.; SLOAN S. W.; CARTER J. P. A 3D discrete element modelling approach for rockfall analysis with drapery systems, pp. 107-119. International Journal of Rock Mechanics \& Mining Sciences. (2013).

VILLELA R. J. Uso de barreiras flexíveis para o controle de queda de blocos de rocha, Rio de Janeiro, Projeto de Graduação submetido ao corpo docente do Curso de Engenharia Civil da UFRJ, (2011).

VOLKWEIN, A., SCHELLENBERG, K., LABIOUSE, V., AGLIARDI, F., BERGER, F., BOURRIER, F., DORREN, L.K.A., GERBER, W., JABOYEDOFF, M. Rockfall characterisation and structural protection-a review. Nat. Hazards Earth Syst. Sci. 11(9), 2617-2651 (2011).

WENSRICH C.M.; KATTERFELD A. Rolling friction as a technique for modelling particle shape in DEM, Powder Technology. $v 217, p$ 409417, 2010.

WENTWORTH, C. K. A scale of grade and class terms for clastic sediments. The Journal of Geology, 30(5):377-392. 1922 